University of Louisville

ThinkIR: The University of Louisville's Institutional Repository

$8-2012$

\title{
Blockade of CXCR4 inhibits Porphyromonas gingivalis colonization in vivo and subsequent periodontal bone loss.
}

Megan L. Mc Intosh

University of Louisville

Follow this and additional works at: https://ir.library.louisville.edu/etd

\section{Recommended Citation}

Mc Intosh, Megan L., "Blockade of CXCR4 inhibits Porphyromonas gingivalis colonization in vivo and subsequent periodontal bone loss." (2012). Electronic Theses and Dissertations. Paper 932.

https://doi.org/10.18297/etd/932

This Doctoral Dissertation is brought to you for free and open access by ThinkIR: The University of Louisville's Institutional Repository. It has been accepted for inclusion in Electronic Theses and Dissertations by an authorized administrator of ThinkIR: The University of Louisville's Institutional Repository. This title appears here courtesy of the author, who has retained all other copyrights. For more information, please contact thinkir@louisville.edu. 
BLOCKADE OF CXCR4 INHIBITS PORPHYROMONAS GINGIVALIS COLONIZATION IN VIVO AND SUBSEQUENT PERIODONTAL BONE LOSS

\author{
Megan L. Mc Intosh \\ Louisville in partial fulfillment of the Requirement for the degree of \\ Doctor of Philosophy \\ University of Louisville, School of Medicine \\ Department of Microbiology and Immunology
}

A dissertation submitted to the faculty of the School of Medicine of the University of

August 2012 
Copyright 2012 by Megan Lavonne Mc Intosh

All rights reserved 


\title{
BLOCKADE OF CXCR4 INHIBITS PORPHYROMONAS GINGIVALIS COLONIZATION IN VIVO AND SUBSEQUENT PERIODONTAL BONE LOSS
}

\author{
By
}

Megan L. Mc Intosh

A Dissertation approved on

18 May 2012

by the following Dissertation Committee:

George Hajishengallis, Ph.D. (Dissertation Director)

Uldis Streips, Ph.D. (Co-mentor)

Haribabu Bodduluri, Ph.D. (Co-mentor)

Thomas Mitchell, Ph.D.

James Graham, Ph.D.

Jan Potempa, Ph.D.

Gregg Rokosh, Ph.D. 


\section{ACKNOWLEDGMENTS}

I would like to extend appreciation to my mentor, Dr. George Hajishengallis as well as to my committee members: Dr. Haribabu Bodduluri, Dr. Uldis Streips, Dr. Thomas Mitchell, Dr. Greg Rokosh, Dr. Jim Graham and Dr. Jan Potempa. I'd also like to thank Dr. Richard Miller for helping make sure I was able to fulfill all departmental requirements in time to return to medical school.

A special thanks to Dr. Janice Ditslear, Dr. Karen Powell, Dana and the other animal care-givers at the $\mathrm{RRC}$ for the time and energy they spent to help me with my mouse studies. I would like to acknowledge the past and current members of the Hajishengallis lab: Jennifer Krauss, Ravi Jotwani, Toshiaru Abe, Shuang Liang, Fenge Li Min Wang, Kavita, Paul Ciero, Hisanori Domon, Rob Gleason, Akif Eskan, Sara Parnell and Deanne Pierce.

Thanks to Joan Scott and Gerard Buono and to the labs of Don Demuth, Jan Potempa, David Scott and the late Mike Martin. Thanks to Liz Novak: your dedication to keeping us both updated on all things OHSD and M\&I was phenomenal. Thank you to Adrianna Henson for food, commiseration and scientific comraderie.

Thank you to my family who supported my decision to pursue a Ph.D. 
To Microbiology \& Immunology students, past, present and future: Nevermind protocols that don't work, poorly worded methods or professors, generally. "Just go forward in all your beliefs and prove to me that I am not mistaken in mine."

Much like the "and" credit in film, I leave the most impressive name for last: Dr. Chris Price. I don't need to write a bunch of foppy thank yous and "oh, don't you remember that's". Just know that if you were no longer with me, I'd prolly stop dead like a fob watch one's pulled the ratchet wheel from. 


\begin{abstract}
BLOCKADE OF CXCR4 INHIBITS P. GINGIVALIS PERSISTENCE IN VIVO AND INDUCTION OF PERIODONTAL BONE LOSS

By

Megan L. Mc Intosh
\end{abstract}

18 May 2012

Chronic periodontitis is strongly associated with composition of the oral biofilm occupying the gingival crevicular aspect of the tooth and its associated root. Some gramnegative, "red complex" bacteria instigate periodontal bone loss in patients, principal among these Porphyromonas gingivalis. P. gingivalis is a "late colonizer", indicating not only its physical location within the oral biofilm, but also the pathogenic dynamic of the interaction between $P$. gingivalis and the host innate immunity. Among several other subversive tactics, $P$. gingivalis has been shown to compel receptors vital to the orchestration of an appropriate immune response to co-associate and consequently signal in a way that directly benefits the pathogen. Upon interaction with human monocytes and murine macrophages, $P$. gingivalis has been shown to induce TLR2 and CXCR4 to co- 
associate in lipid rafts via its surface fimbriae. The ensuing crosstalk results in a cAMP dependent, PKA mediated inhibition of NF- $\mathrm{KB}$ which in turn leads to a state of mixed signals. TLR2 attempts to upregulate NF- $\mathrm{kB}$ as $\mathrm{CXCR} 4$ simultaneously signals to inhibit TLR2 antimicrobial signaling. Functionally, this was shown in human monocytes and mouse macrophages to cause downregulation of TNF- $\alpha$ and upregulation of IL-10. Here we show the interaction between $P$. gingivalis fimbriae and CXCR4 to have physiological relevance to the initiation and maintenance of periodontal bone resorption in a mouse model of infection. Pharmacologic inhibition of the $P$. gingivalis fimbriaeCXCR4 interaction prevented bone loss as well as halted progression of periodontal disease instigated prior to treatment in the Baker Model of oral infection. We also found that systemic administration of the bicyclam CXCR4 inhibitor AMD3100 leads to enhanced killing of $P$. gingivalis in a subcutaneous chamber model of infection. The subcutaneous chamber is an in vivo model system of the microaerophilic environment of the gingival pocket as well as the influx of dominantly comprised of neutrophils into the gingival crevice characteristic of chronic periodontitis. It is interesting that we noted that CXCR4 deficient mice display a similar host inflammatory profile to wild-type mice treated with AMD3100. However, while most of these mice were protected from $P$. gingivalis-mediated bone loss, one of the CXCR4 deficient mice did not demonstrate protection from alveolar bone loss when chronically infected with $P$. gingivalis. These mice also showed a healthier inflammatory profile compared to their infected, untreated counterparts. Thus, the results below indicate that AMD3100 effectively inhibits periodontal bone loss due to the ability of the compound to counter $P$. gingivalis' 
recognition of CXCR4. This provides evidence supporting the importance of this coreceptor in developing therapeutic strategies for treating periodontal disease. 


\section{TABLE OF CONTENTS}

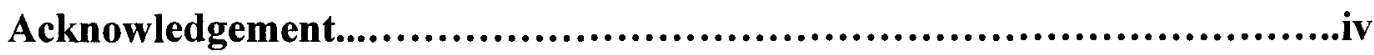

Abstract...........................................................................

Table of Contents.................................................................iii

List of Figures.................................................................

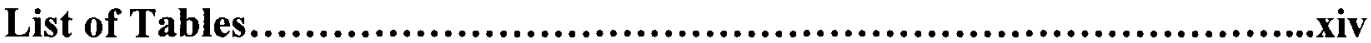

\section{Chapter 1: Introduction}

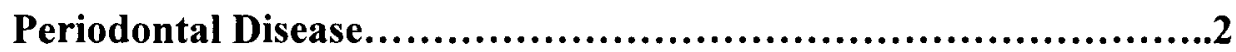

Periodontal Disease and Systemic Diseases...........................6

Innate Immunity at the Periodontium..................................9

Microbial Induction of Periodontal Disease ...........................17

CXCR4 in Periodontal Disease .....................................22

AMD3100: Bicyclam CXCR4 antagonist....................................................25

Considering CXCR7 and AMD3100................................29

Treatment of Periodontal Disease.....................................31

Chapter 2: Materials and Methods

Bacterial strains and culture conditions.................................34

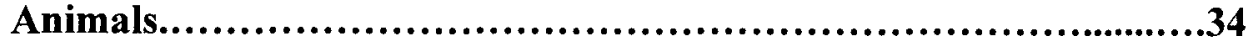

Subcutaneous osmotic pump implantation in mice......................34

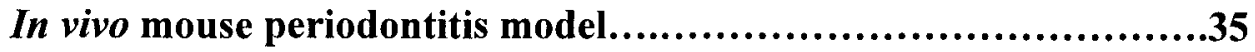


Analysis of alveolar bone resportion................................36

RNA Isolation, cDNA synthesis and RT-PCR of host genes...........37

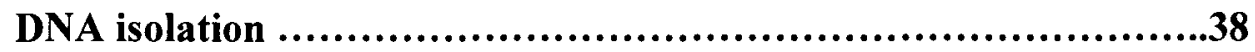

Titanium Coil Chamber Implantation..............................40

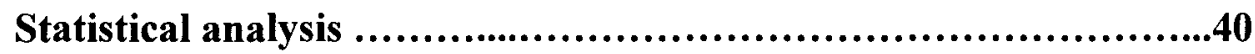

Chapter 3: Systemic AMD3100 administration prevents bone resorption in $P$. gingivalis infected mice

Introduction..........................................................43

Results...........................................................45

AMD3100 prevents development of perdiontal bone loss in mice infected with $P$. gingivalis.............................45

Systemic AMD3100 treatment effectively eliminates $P$. gingivalis from the oral cavity early in the oral infection model

AMD3100 infusion effectively halts progression of periodontal bone loss two weeks after induction of disease ..............52

Discussion..........................................................5

Chapter 4: CXCR4 blockade enhances clearance of $P$. gingivalis

Introduction.........................................................59

Results.............................................................63 
AMD3100 inhibits $P$. gingivalis-induced PMN recruitment but promotes killing of $P$. gingivalis............................ 63 AMD3100 does not affect $F$. nucleatum-induced PMN recruitment or $F$. nucleatum killing........................66 Host Response to treatment with AMD3100 in the subcutaneous chamber model.

Deficiency of CXCR4 or TLR2 differentially affects the inflammatory response to $P$. gingivalis infection in mice.......71

Discussion. .75

Chapter 5: Future Directions

Therapeutic benefit of Local AMD3100 administration?. .83

CXCR7 and AMD3100, relevance to our model? .84

Role of granulocyte mobilizations, priming and $\mathrm{C5}$ in response to AMD3100 treatment?.................................................85

AMD3100 treatment and osteoclastogenesis.......................86

CXCR4 blockade, SDF-1 and inflammation?.......................87

The polymicrobial nature of periodontal disease..................89

AMD3100 treatment and its (perhaps fortuitous) effect on other systemic diseases?

References..............................................................92

Curriculum vitae.........................................................114 


\section{LIST OF FIGURES}

\section{Chapter 1}

Figure 1: $\quad$ Anatomy of the periodontium...................................

Figure 2: Chemotactic recruitment of inflammatory cells in the gingival crevice .14

Figure 3: Toll-like receptors act as multifaceted guards stationed at the border between host and environment.

Figure 4: $\quad$ The formation of TLR-based receptor clusters generates a combinatorial repertoire to discriminate among diverse microbial signals..............................18

Figure 5: Development of the oral biofilom...........................21

Figure 6: $\quad$ CXCR4 associates with TLR2 in $P$. gingivalis-activated monocytes/macrophages...................................24

Figure 7: $\quad P$. gingivalis antagonizes TLR4 but not TLR2 at the receptor level..........................................33

\section{Chapter 2}

Figure 8: $\quad$ Baker model of oral infection............................... 37

Figure 9: Implantation of titanium steel coil for subcutaneous chamber model..................................................44

\section{Chapter 3}

Figure 10: Preventive treatment with AMD3100 abrogates $P$. gingivalismediated periodontal bone loss.

Figure 11: Effect of AMD3100 on the numbers of $P$. gingivalis or total bacteria in the murine periodontal tissue.......................51

Figure 12: $\quad$ Therapeutic treatment with AMD3100 halts $P$. gingivalismediated periodontal bone loss.

\section{Chapter 4}

Figure 13: $\quad$ AMD3100 inhibits $P$. gingivalis-induced $P M N$ recruitment but promotes killing of $P$. gingivalis ........................65

Figure 14: AMD3100 does not significantly affect $F$. nucleatum-induced PMN recruitment or $F$. nucleatum killing. 
Figure 15: $\quad$ AMD3100 treatment increases TNF- $\alpha$ and IL-10, indicating a more appropriate antimicrobial response to the presence of $P$. gingivalis .

Figure 16: AMD3100 treatment leads to an ultimate suppression of MIP-1 $\alpha$, indicating a resolution of inflammation, decreased superoxide release by neutrophils..........................70

Figure 17: Deficiency of TLR2, but not necessarily CXCR4, protects orally infected mice against alveolar bone loss........................73

Figure 18: Deficiency of CXCR4 or TLR2 has different effects upon inflammation in orally infected mice.

Figure 19: $\quad$ AMD3100 in the chronic $P$. gingivalis periodontitis model 


\section{LIST OF TABLES}

\section{Chapter 2}

Table 1: Bacterial Strains used in this Study ..............................41

Table 2: $\quad$ Primers used in this study ...................................42 


\section{CHAPTER ONE: INTRODUCTION}

Periodontitis is a chronic inflammatory disease with pathophysiological ties to systemic conditions such as rheumatoid arthritis, heart disease, and diabetes $(18,145)$ (273) (143). Periodontal disease is a widespread condition, with over $75 \%$ of adults in the United States demonstrating some stage of periodontal disease (18) and oral care is an expensive public health endeavor. According to the CDC, in $2010 \$ 108$ billion dollars was spent on dental care in the United States (209).

P. gingivalis has evolved several elegant mechanisms for survival in the oral biofilm and subversion of the host immunity, among these the release of gingipains which cleave complement components C3 and C5, degrading the C3 completely. Gingipain cleavage, however, leaves the C5a anaphylatoxic "a" fragment functionally intact. $P$. gingivalis affects the oral biofilm as extensively as the host immune system, altering both the total bacterial load and composition, even though the pathogen exists as an extremely small percentage of the total biofilm (97). Due to these behaviours, $P$. gingivalis has been termed a "keystone pathogen" meaning that, although it is typically a minute component of the oral biofilm, $P$. gingivalis is critical to the shift and consequent support of the more pathogenic biofilm now thought to be a majour etiological factor of chronic periodontal disease. The removal of $P$. gingivalis should cause the pathologic 
oral biofilm to return, albeit gradually, to a commensal state. $P$. gingivalis infection has been shown to be indicative of poor prognosis in chronic periodontitis, thus control or eradication of $P$. gingivalis is a target therapeutic strategy in periodontal disease (211) (197). For this reason, we focus on $P$. gingivalis as our primary target for periodontal therapy.

\section{Periodontal Disease}

Most adult humans demonstrate some degree of gingival or periodontal disease, with gingivitis being greatly increased in prevalence compared to its more severe cousin, periodontitis. According to the World Health Organization, periodontal disease is the major cause of tooth loss in adults over 40 years of age and affects human populations globally. Although it is less common, severe periodontal disease, defined clinically as 6 millimeters or greater of periodontal pocket attachment loss, affects about 14 percent of adults aged 45 to 54 (1). The most severe forms of periodontitis can reach rates of $10 \%$ to $20 \%$ prevalence in disadvantaged populations or those with high instances of predisposing behaviour (204). Periodontal disease is furthermore associated with an increase in premature death among adults (245) (244).

The gingivae, periodontal ligament and cementum to which the ligament attaches hold the tooth in place and this anatomical arrangement is collectively referred to as the periodontium. (See Figure 1) The pathologic mechanism of periodontal disease is comprised of chronic inflammation which leads to damage and eventually irreversible destruction of the supporting tissues of the tooth, including the underlying alveolar bone. Periodontal disease is instigated by the accumulation of subgingival plaque in the absence 
of appropriate oral hygiene $(36,156,250)$, particularly the presence of described "late colonizers" such as $P$. gingivalis, $P$. intermedia, Tannerella forsythia and the spirochete Treponema denticola $(89,241,246,253)$. While periodontal disease is instigated by infection, periodontal tissue destruction is actually caused by the host inflammatory response, principally via the constant influx of inflammatory cells and molecules such as TNF- $\alpha$, IL-1 $\beta$ and Il-17 $(136,232)(78,83,165,255)$.

Periodontal disease is a progressive condition demarcated by two primary stages: gingivitis and periodontitis. Gingivitis is the earlier and milder stage of periodontal disease. Gingivitis is characterized by bleeding of the gums, even upon gentle brushing, accompanied by tenderness, swelling and bright red or purple discoloration of the gums. Subgingival plaque accumulates at the junction between the gingival margin and the tooth. In response, inflammatory cells are mobilized to the area as the host attempts to reduce the bacterial burden. As the infection proceeds, the gums become more inflamed, damage accumulates and this results in gum tissue recession from the root surface of the tooth, exposing more sensitive areas and leading to painful temperature sensitivity. The inflammatory damage of gingivitis is generally reversible with restoration of adequate oral hygiene. However, if left uncorrected this chronic inflammation eventually leads to periodontitis. The hallmarks of advanced periodontal disease, periodontitis, include destruction further into the periodontium, alveolar bone resorption as well as eventual tooth loss (18) (225), and these pathological signs are not reversible (Figure. 1).

Part of the physiological mechanism leading to the irreversible damage of advanced periodontal disease has to do with a physiological turnover process referred to by Parfitt and coworkers as "coupling", in which a temporary bone resorption event 


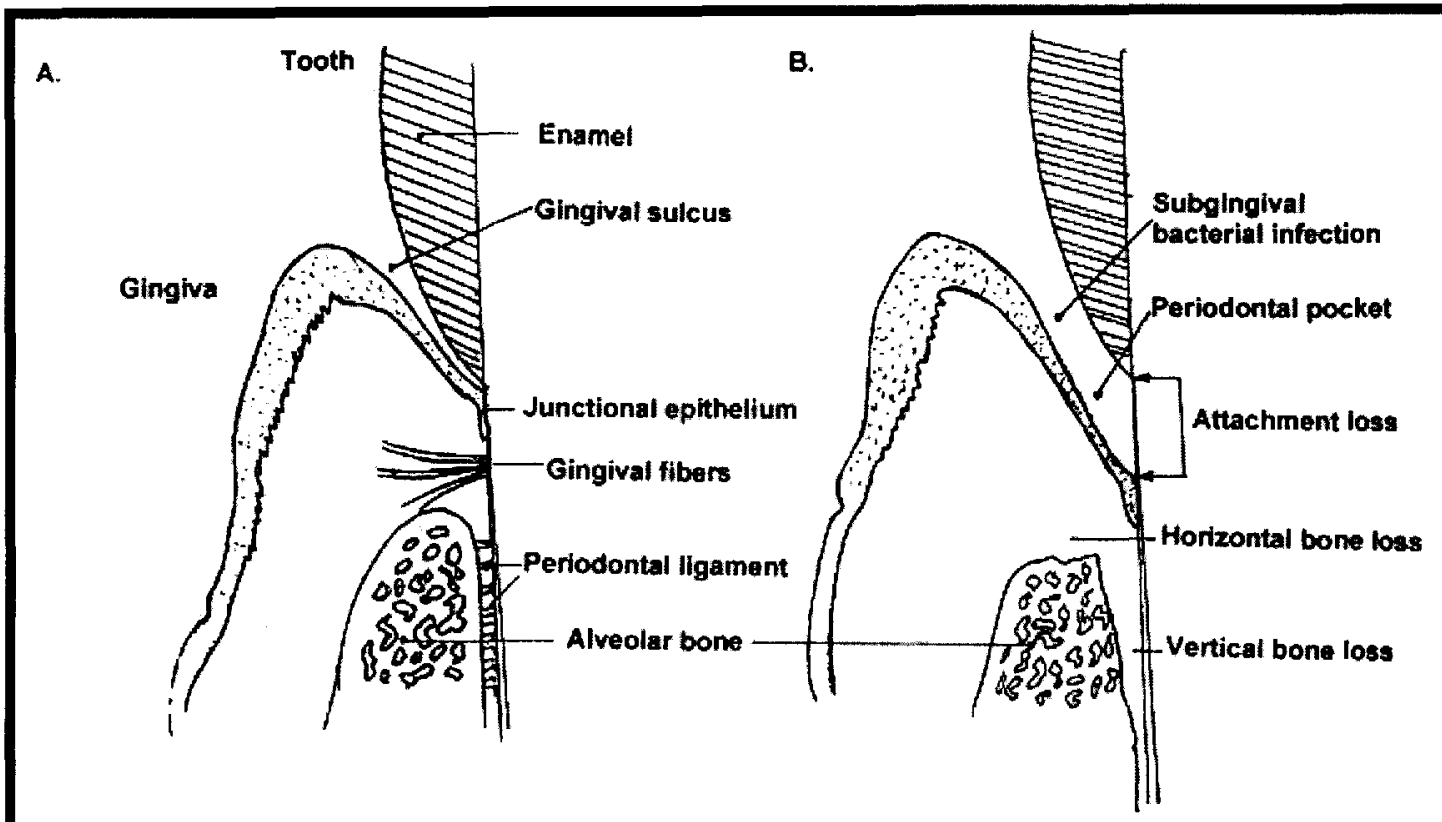

Figure 1. Anatomy of the periodontium (as reviewed by Baker, P.J. (12, 37, 42). A) In health, gingival fibers connect the gingival soft tissue to the root of the tooth, and the alveolar bone and cementum are connected by periodontal ligament fibers. B) In periodontal disease, subgingival infection by Gram-negative bacteria results in soft tissue damage, producing attachment loss and deepening the sulcus into the periodontal pocket. Alveolar bone resorption moves the bone surface away from the tooth root (vertical bone loss) and reduces the height of the alveolar bone crest (horizontal bone loss). Copyright permission to reproduce figure granted by Elsevier and (12).

followed by bone formation $(86,200)$. "Coupling" relies upon osteoblast precursor cells being available and able to differentiate as well as respond to appropriate signals for bone matrix re-formation. Normally all these components are adequately present and bone reformation can occur, however in chronic periodontal disease bone destructive processes 
outrun the bone formation processes, effectively "uncoupling" the two and making reformation increasingly difficult to instigate $(86,200)$. The result is, obviously, net alveolar bone loss.

Currently, clinical approaches to periodontal disease focus on prevention, largely consisting of public health education and prophylactic cleaning via mechanical debridement of the oral biofilm with tools including ultrasonic devices. Treatment for patients demonstrating periodontal disease include scaling and root planing, which is essentially a more extensive physical abrasion of plaque build-up than prophylactic cleaning (7). Patients for which scaling and root planing is not an adequate therapy may undergo various more extreme treatments including, but not limited to: pocket reduction, in which a periodontal surgeon "peels" back the soft gingival tissue in order to remove subgingival bacteria before replacing the tissue to reattach to the bone; attempts to regenerate underlying bone via graft or tissue-growth cocktails $(10,267)$ and, depending upon the quality of the underlying bone, dental implants to replace lost teeth (143).

Notably, antibiotic treatment beyond a basic chlorhexidine rinse (which does not adequately penetrate the oral biofilm) remains a complicated option due to the inaccessibility of the target pathogens as well as the tendency of biofilm species to development of antibiotic resistance, though studies focusing on combination therapy have made some progress (182) (7).

As we explore treatments for periodontal disease which have been developed in the "systemic" context, familiarity with the connections, both clinical and mechanistic, between periodontal disease and diseases of the whole body becomes essential. For example, systemic AMD3100 treatment has been shown to be beneficial in a mouse 
model for autoimmune collagen induced arthritis, which is used as a model for pathogenesis of rheumatoid arthritis in humans (168). As shown below, this systemic treatment also provides protection against periodontal disease. However, the possibility of discovering effects which would prove deleterious to patients in whom periodontitis is a secondary or perhaps tertiary disease cannot be under emphasized.

Periodontitis is not an isolated disease, affecting only a small portion of the mouth. It is logical to consider transmigration of both host inflammatory and bacterial products through the damaged epithelium lining the periodontium into the host circulation (127). While this has important negative inflammatory connotations to the pathological state of the entire bodily system, it also means periodontal disease can be likewise affected by systemic approaches to treatment.

\section{Periodontal Disease and Systemic Diseases}

Periodontal disease has been shown to be bidirectionally tied to the risk and extent of systemic diseases such as rheumatoid arthritis (18), aspiration pneumonia (100) (258), atherosclerosis $(264)$, heart disease $(183,273)$ as well as adverse pregnancy outcomes (34).

Prevalence and severity of periodontal disease are on average two-fold greater in patients with rheumatoid arthritis as compared to the healthy population and patients with rheumatoid arthritis are also twice as like to suffer edentulism (18). It is worthy to note that a common set of inflammatory players including TNF- $\alpha$ and IL-1 suggest a bidirectional relationship between the two diseases; the inflammatory dysregulation of one serving to worsen or, in some cases, induce the other $(18,174)(16)$. Porphyromonas 
gingivalis DNA has been detected via PCR in the synovial membrane from patients with RA and may promote citrullination of various self-antigens (164) (177) (220).

Recently, evidence has compounded which suggests $P$. gingivalis infection is a serious risk factor for development of RA. Like the periodontium, the synovial membrane of patients afflicted with RA becomes heavily infiltrated with leukocytes, primarily neutrophils, and subsequently contains numerous factors derived from those cells such as IL-1, IL-8 and TNF- $\alpha$ (26) (233). Activated neutrophils within the cartilage can release reactive oxygen species and degradative enzymes. The end result is a microenvironment skewed towards damage of cartilage and surrounding bone (43) (87) (2) (179, 180).

Periodontitis has also been shown as a risk factor for coronary heart disease (CHD) (128) $(20,234)$, the leading cause of death among humans (216). P. gingivalis has been specifically investigated as a possible contributor to coronary heart disease due to the chronic, inflammatory nature of periodontitis (189). Studies have shown elevated levels of C-reactive protein (CRP), an inflammatory biomarker of cardiovascular risk (214), in patients with periodontitis compared to patients with healthy oral cavities. The connection between periodontitis and CRP levels could be due to induction of IL-6, a major inducer of CRP, by $P$. gingivalis (142). Increases in concentrations of hs-CRP and, particularly relevant to our host inflammatory data regarding AMD3100 treatment, IL-6 have been reported in periodontitis patients and these increases are generally reversed upon induction of periodontal treatment. Contrastingly, and perhaps also relevant to our studies in mice, a decrease in TNF- $\alpha$ has been noted in the sera of periodontitis patients which was unaffected by periodontal therapy (189). 
P. gingivalis was detected in atherosclerotic plaque deposits as early as 1999 (40) and has continued to be regularly detected in peripheral atherosclerotic lesions, the descending aorta, as well as aortic aneurysm specimens (262) via PCR, DNA hybridization and conventional culture $(104,141,167,248)(135)$.

More recently, investigators have asked whether chronic periodontitis, an inflammatory condition with systemic ties, could furthermore contribute to deleterious effects behind the blood brain barrier (BBB). Generally, the BBB prevents entry of substances into the brain, however some inflammatory cytokines such as IL-6 have the ability to cross the barrier during acute phase inflammatory response via specific transport processes (199) (14) or more circuitous routes through fenestrated capillaries in circumventricular organs (example: the pineal gland) which technically lie outside the BBB (14) (203) (277). Sustained levels of inflammatory cytokines during chronic periodontitis (ex: IL-6, TNF and CRP) have been associated with development of cognitive decline and dementia (278) (286), (251) (58) (66). Periodontopathic bacteremia post tooth brushing has been documented by different research groups (215) (61) as well as the observation that $P$. gingivalis aggregates with and survives in platelets (152). Once the periodontopathogen enters the bloodstream, while the BBB blocks entry of the bacteria itself, bacterial or inflammatory products resulting from the pathogens presence may still cross. Chronic inflammation may cause heightened formation of amyloid $\beta$ fibrils (21) and eventual contribution to neurodegeneration $(203,217)$ as well as thrombus formation and damage to vascular integrity (277).

Periodontal disease has been associated with adverse pregnancy outcomes involving preterm birth or low- weight birth, miscarriage and spontaneous abortion (34, 
$62,120)$, though, there are conflicting reports regarding actual benefit of periodontal therapy during pregnancy (35).

The relationship between diabetes mellitus and periodontitis is perhaps the best example of the bidirectional association of periodontitis and systemic diseases. While diabetes mellitus is known to increase risk, prevalence, as well as severity and progression of periodontitis $(171,172,256)$, some recent studies have provided evidence that risk of diabetic complications is increased in patients with periodontitis as compared with patients with healthy oral status or mild disease. Among these complications are higher incidence of proteinuria and cardiovascular complications, including angina, intermittent claudication, transient ischemic attack, myocardial infarction and stroke (260) (143). These observations are important to keep in mind as we pursue potential therapeutic strategies in the pre-clinical context. AMD3100, the bicyclam CXCR4 antagonist used in our studies, has been shown to rapidly and strongly mobilize angiogenic cells, giving AMD3100 a potential role stimulating angiogenesis at sites of ischemia throughout the body $(48,121)$.

\section{Innate Immunity at the Periodontium}

Our innate immune system contributes significantly to defense against invading pathogens and the oral cavity is one of the most exquisite examples of this interface between the internal body and the surrounding external environment. At the oral epithelium-environmental interface there are several important physiological factors contributing to a healthy immune balance, the end result being a dynamic balance of environmental signals or stimuli eliciting just enough proinflammatory and antimicrobial 
actions while the innate immunity also employs regulatory, anti-inflammatory mechanisms to curb destructive inflammation (59), (136). When this homeostatic balance is disrupted, whether via genetic defects in host immunity or by the introduction of pathogens into the oral microbiota, periodontal disease will eventually manifest (131), (139).

The periodontium is a diverse immune environment containing multiple cell types to enable the host to deal with an abundant variety of environmental signals. In addition to the keratinized, stratified squamous epithelial barrier, the periodontium is home to tissue macrophages, neutrophils, dendritic cells within the gingival/periodontal lamina propria, or the tissue lining the gingival crevice, Langerhans cells within the oral mucosa, periodontal ligament fibroblasts and mesenchymal cells. All these cells types have a role to play in mediating the oral immune response through antigen presentation, regulating inflammation, directing pathogen clearance, as well as tissue remodeling and repair (257).

While the induction of periodontal disease relies upon the presence of microbes, the pathology of periodontal disease is manifested by collateral damage caused by a host immunity attempting so arduously, yet ineffectively, to clear a pathogen that it literally destroys everything in its path.

The innate immune cells present at the periodontal environment-host junction wield a number of tools to aid them in orchestrating appropriate responses to various environmental signals, among them microbial pathogens, as well as controlling internal processes such as inflammation and self-reactivity. Among these tools are germ-line encoded receptors which detect and discern pathogen-associated molecular patterns 
(PAMP) among the abundant and diverse microbial signals received at any given time at the host-environmental interface. Cells such as neutrophils, macrophages, dendritic cells and natural killer cells must orchestrate a response to invading pathogens that is both fine-tuned enough to ignore the constantly present "commensal" microbiota, but will rapidly act to eliminate insulting pathogens before they or the overall inflammation causes damage to the host (124) (See Figure 2).

Toll-like receptors (TLR) are transmembrane glycoproteins made of an $\mathrm{N}$ terminal leucine-rich repeat domain, a transmembrane region, and a C-terminal cytoplasmic signaling domain (129), (136). There are currently thirteen reported toll-like receptors and the extent of characterization regarding these receptors ranging from thorough to putative. These receptors are typically found at junctions between the host and environment where they can easily sense and respond to various microbial structures (136), (236, 237) (See Figure 3).

Ideally, in response to an invading pathogen, circulating leukocytes will respond to inflammatory signals (ex. TNF- $\alpha$ ) released by sentinel cells such as degranulated mast cells or local macrophages. Polymorphonuclear granulocytes (PMN) which migrate to the infection site can respond to the invader in a variety of ways. PMNs release inflammatory cytokines to amplify the antimicrobial reaction by recruiting various immune cells, phagocytose microbes upon opsonization, degranulate to douse the pathogen in soluble antimicrobial molecules such as myeloperoxidase or, as more recently discovered, generate structures called neutrophil extracellular traps (NETs) to catch and kill microbes (28). Currently, it is thought that NETs "catch" microbes in order to target high 
concentrations of antimicrobial components directly at them, prevent further spread of pathogens or both (28), (268).

Critical to this process are pattern recognition receptors (PRRs) such as toll-like receptors, NOD, and complement receptors, which are a component of the separately functional complement system. Part of the power of these PRRs is their propensity to form functional multi-receptor complexes in lipid rafts (19). These receptor clusters allow for generation of large combinatorial signaling repertoires and extremely enhance the scope of identifiable infections for mounting a context-relevant immune response (96). (See Figure 4). TLRs which recognize extracellular microbial structures, such as lipoteichoic acid and LPS, are located on the cell surface while TLRs which recognize intracellular signals, such as viral or bacterial nucleic acid, are positioned on endocytic vesicles or organelles where the odds of their interacting with their target ligands are maximized. (See Figure 3). For extracellular TLRs, cytoplasmic signaling is initiated upon binding of the ligand via recruitment of adaptor proteins to the TLR. The end result is expression of specific genes to tailor the immune response and modulate inflammation (136). In addition to physical compartmentalization, adaptor recruitment provides the TLR response a means to activate diverse intracellular pathways to further diversify the combinatorial immune response to microbial signals (193), (194).

While triggering of specific TLR signaling pathways by bacteria should initiate the innate immune response as well as coordinate the induction of adaptive immunity, the toll-like receptor interface is also a subversion opportunity for pathogens to specify certain immune pathways to be suppressed or enhanced for their own survival benefit $(91,136,257)$. 
The complement system is a critical branch of the innate immunity, especially so in the oral cavity where it serves in the activation and recruitment of inflammatory cells, microbial opsonization, phagocytosis, cell lysis, as well as orchestration of the adaptive response $(90,95,161)$. The complement system cross-talks extensively with other systems for the purpose of enhancing coordination of the host response to infection or injury, notably, complement receptors crosstalk with Toll-like receptors (95). A mutually beneficial cooperation has been characterized between TLRs and complement in which complement regulates TLR activation and can regulate the activity of complement receptors and TLRs can regulate the activity of complement receptors $(91)(102,105$, $108,290)$. When this exquisitely intertwined state is balanced, when the host is healthy, TLRs and complement receptors signal cooperatively to induce a targeted response to pathogens without producing an over-robust response. For example, complement signaling via $\mathrm{C} 3 \mathrm{aR}$ and $\mathrm{C} 5 \mathrm{aR}$ in response to DAF amplifies Toll-like receptor 4-mediated production of on IL-6, TNF- $\alpha$, and IL-1 while suppressing LPS-induced IL-12 production (290).

When the state is imbalanced, as occurs when pathogens hijack signaling pathways to interfere with elements of the immune response deleterious to its survival, inflammation can become excessive, and tissue damage occurs.

TLR2 willingly dimerizes with TLR1 and 6 in order to expand the structural repertoire of recognizable lipoprotein structures. TLR2 is also one example of communication between the TLR and complement systems to potentially result in synergistic or regulatory interactions via C5aR (19), (27), (69). 


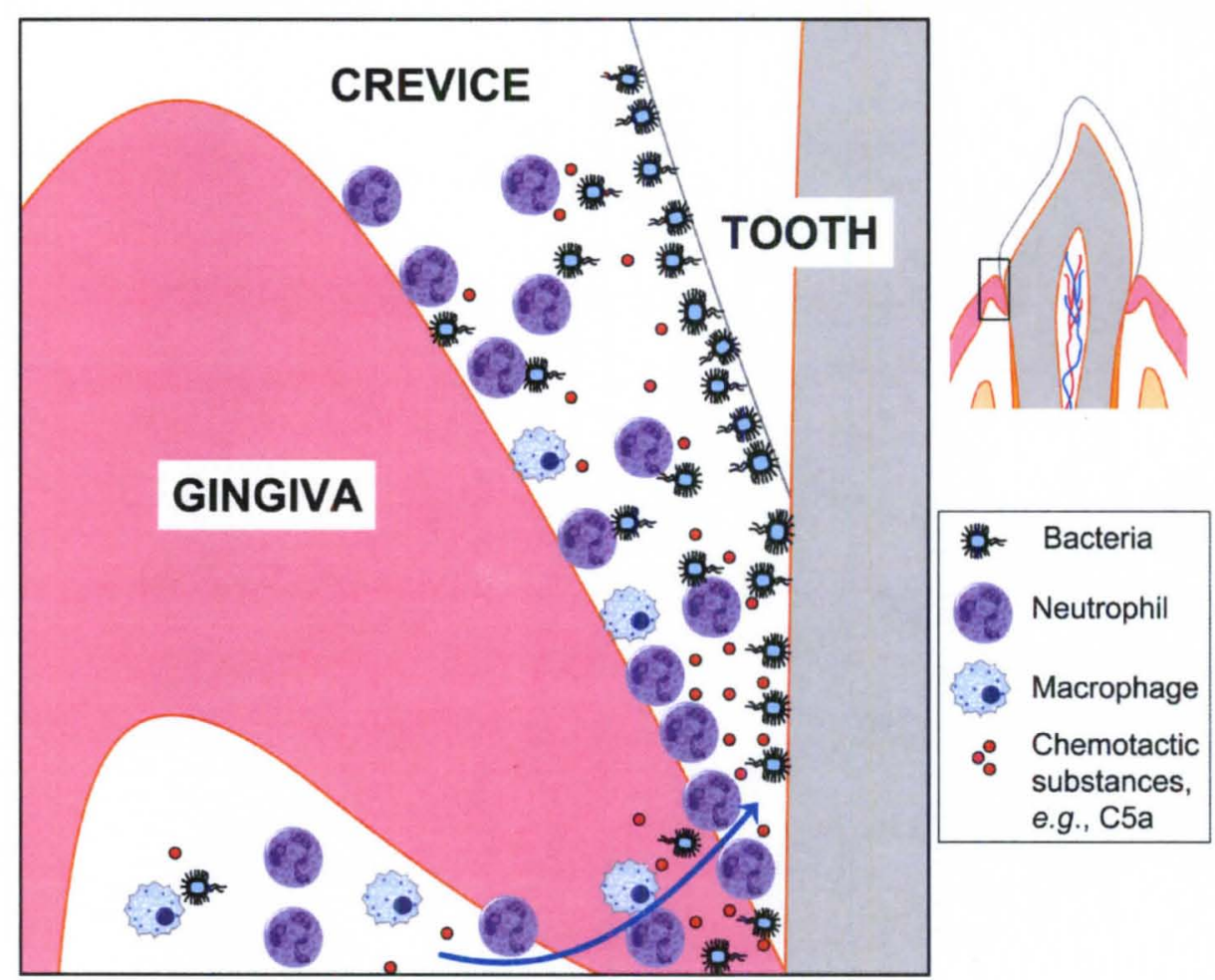

Figure 2. Chemotactic recruitment of inflammatory cells in the gingival crevice from the review Complement and Periodontitis (90). Inflammatory cells, the majority of which are neutrophils, are recruited to the gingival crevice in response to chemotactic signals such as the complement anaphylatoxin C5a (136), which can be generated either immunologically or through microbial action $(275,279)$. Although gingival crevicular neutrophils form what looks like a "defense wall" against the tooth-associated bacteria, they largely fail to control the infection and may cause collateral inflammatory tissue damage $(55,136)$ (191) (230) The cartoon (on the left) represents magnification of the demarcated tooth area on the right. Reprinted with permission. 
Dysregulated complement activation via other networks can also cause pathologic clotting. Crosstalk between the complement and coagulation systems can directly enhance blood clotting properties at several levels of the coagulation cascade. C3a anaphylatoxin activates platelets to enhance their aggregation and adhesion. The other anaphylatoxin which results from complement activation, $\mathrm{C} 5 \mathrm{a}$, can upregulate tissue fibrinogen and PA inhibitor (PAI-1) expression to enhance thrombogenicity while the complement membrane attack complex (MAC) increases potential clotting surface area. On the other side, coagulation players can amplify activation of complement. Thrombin cleaves $\mathrm{C} 3$ to $\mathrm{C} 3 \mathrm{a}$ and $\mathrm{C} 3 \mathrm{~b}$, and $\mathrm{C} 5$ to $\mathrm{C} 5 \mathrm{a}$ and $\mathrm{C} 5 \mathrm{~b}$. Additionally, platelets can both initiate the classical pathway of complement activation as well as elongate the lifespan of $\mathrm{C} 3 \mathrm{~b}$ via phosphorylation of the molecule $(67,280,281)$. One of the results of this closeknit relationship between the two systems is complement activated clotting which, while it can be deleterious, when done judiciously inhibits the spread of bacteria, and so benefits the host (162).

The immune system is also replenished via the cooperative action of complement with other receptors, for example CXCR4, to induce mobilization of hematopoietic stem/progenitor cells from the bone marrow $(119,149)$. The duties of the innate immunity do not end, however, with the influx of PMNs, macrophages and the activation of complement for the purpose of coating bacteria in the MAC and promoting 


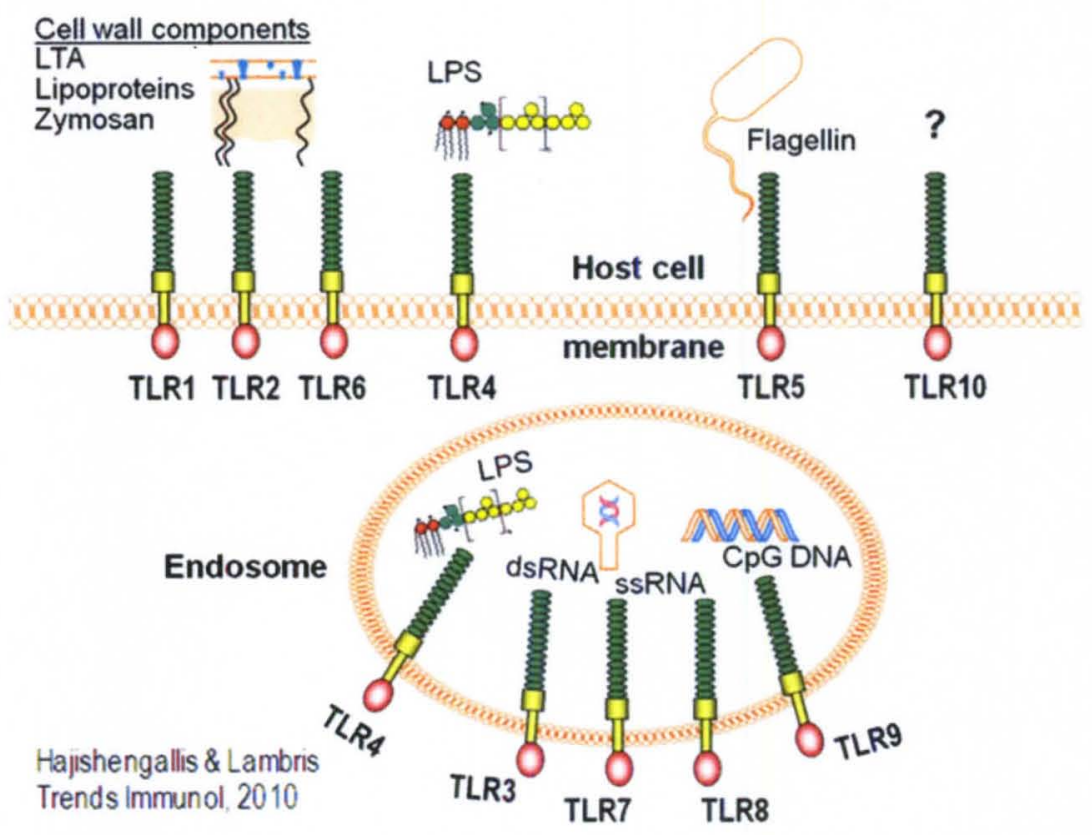

Figure 3. Toll-like receptors act as multifaceted guards stationed at the border between host and environment. A. Toll-like receptors stationed at the cell membrane recognize microbial cell wall components such as lipoprotein, lipoteichoic acid and bacterial fimbriae (TLR2/TLR1 or TLR2/TLR6 heterodimer) (5), lipopolysaccharide (TLR4) or bacterial flagellin (TLR5).The ligands of some TLRs, like TLR10, have not been discovered. Other TLRs reside within the cell embedded in endosomal membranes. These TLRs recognize signs of intracellular infections such as double-stranded viral RNA (TLR3), single-stranded viral RNA (TLR7 and TLR8) and microbial CpG DNA (TLR9).

inflammation. Relatively recently it has been discovered that the innate immunity must also instruct the adaptive immune response in its initiation and progress (118) (65) (136). Adaptive immune components such as $\mathrm{T}$ and $\mathrm{B}$ cell receptors as well as antibodies possess an incredible antigenic vocabulary both in scope and specificity, however, that 
vocabulary is comprised of only random words the immune cells happen to know. Adaptive immune specificity, the result of random gene recombination during development, ostensibly has the ability to recognize any peptide structure. Toll-like receptors and complement work to provide context to the adaptive response, ensuring that its specificity and memory are applied to appropriate pathogenic signals. When this direction goes awry, autoimmune and inflammatory disorders develop.

\section{Microbial Induction of Periodontal Disease}

The oral cavity is home to an abundant variety of microbes both bacterial and viral. The number of bacterial species has been estimated at approximately 700 , the variety encompassing Gram positive and negative, strict aerobic and facultative anaerobes of various morphologies (133) (202). Approximately $8 \times 10^{10}$ bacteria have been calculated just to shed from the surfaces of the mouth in a 24 hour period, and this quantification does not even include bacteria remaining adhered within the oral biofilm (44).

Colonization of the oral cavity is a multistep process the individual phases of which are demarcated by the presences of species defined as early, intermediate and late colonizers (133). Early colonizers tend to inhabit supragingivally and dominantly comprise the plaque there. Streptococcus species are a predominant component of the supragingival plaque, adhering to the thin layer of saliva and gingival crevicular fluid which coats the dentin called the pellicle (See Figure 1). Naturally, intermediate and late 


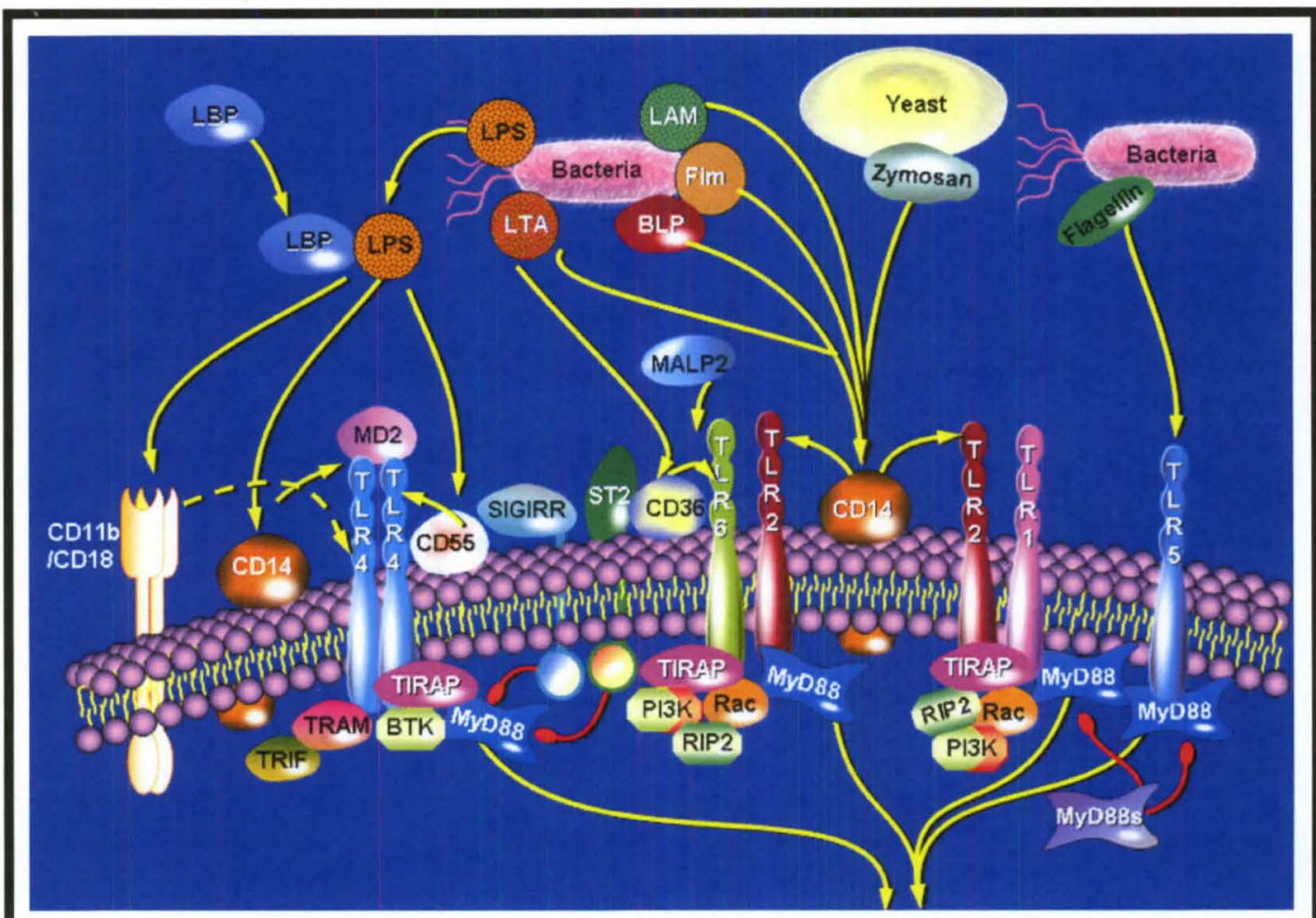

Figure 4. The formation of TLR-based receptor clusters generates a combinatorial repertoire to discriminate among the abundant and diverse microbial molecules and thereby to tailor the host response. However, pathogens may exploit the propensity of TLRs for cooperation with heterotypic receptors by instigating the recruitment of receptors which could deregulate effective innate immunity. The interaction between $P$. gingivalis, TLR2 and CXCR4 serves as a perfect example of pathogenic subversion targeting toll-like receptor cooperation.

colonizers use both the tooth surface and interactions with earlier colonizers to gain a stronger foothold into the oral cavity (243) (284) (44). The later colonizers are generally Gram negative, more anaerobic bacteria associated with disease, such as $P$. gingivalis, Treponema denticola, and Tanerella forsythia, and prefer to colonize subgingivally (243) 
(88) (157). These pathogenic colonizers induce a local inflammatory response consisting predominantly of influx by PMNs which, if left untreated, can give rise to periodontal disease (114) (243). Members of the "orange complex", while being generally thought of as less pathogenic than the red complex, are also associated with forms of periodontal disease $(243)(45,285)$ (See Figure 5).

P. gingivalis itself expresses an array of virulence factors to establish itself within the biofilm, albeit as a low-abundance member, and subsequently uncouple the inflammatory response within the gingival crevice (144). Included within this arsenal are various structures and enzymes. $P$. gingivalis uses its fimbriae to interact with and subvert Toll-like signaling on both receptor-ligand and downstream signaling levels. $P$. gingivalis also possesses a set of Arg- and Lys- specific cysteine proteinases, termed "gingipains" which it uses to target specific levels of the complement cascade, namely the conversion of C3 and C5 for opsonization and formation of the MAC (207) (240). P. gingivalis also uses at least one specific gingipain, HRgpA, to capture and coat its own cell surface with $\mathrm{C} 4 \mathrm{~b}$-binding protein, effectively masking itself from the complement cascade (208).

$P$. gingivalis does not only target the complement system, as mentioned above, $P$. gingivalis also possesses the ability to target the toll-like receptors. As gram-negative bacteria, the LPS of $P$. gingivalis should be recognized by TLR4. However, $P$. gingivalis modifies its LPS to become a tetra-acylated, dephosphorylated lipid A structure (41). This means that the LPS of $P$. gingivalis is biologically inert, or invisible to TLR4. Furthermore, once periodontal inflammation is induces, correlating with increased levels of hemin in the periodontium, $P$. gingivalis LPS undergoes a further modification to its 
lipid A, monophosphorylation, which converts the pathogens LPS to a TLR4 antagonist $(41,42)$.

The Hajishengallis group also previously found that $P$. gingivalis fimbriae interact with TLR2 and CR3 to induce an intracellular signaling crosstalk between the receptors, the ultimate result being inhibition of IL-12p70 production via ERK1/2 signaling in macrophages and in vivo $(98,266,276)$. Furthermore, the use of a CR3 antagonist reversed the ability of $P$. gingivalis to suppress induction of IL-12p70 which leads to enhanced clearance of the pathogen from systemically infected mice and protection against $P$.gingivalis-induced periodontitis in orally infected mice, as evidenced by reduced induction of periodontal bone loss (98).

P. gingivalis also induces a subversive crosstalk between the complement C5a receptor $(\mathrm{C} 5 \mathrm{aR})$ and TLR2 that impairs NO-dependent intracellular killing in macrophages (275). P. gingivalis does this by first producing C5a (via gingipains) to bind C5aR. C5aR then engages in crosstalk with TLR2 via ERK1/2 to inhibit that receptors induction of IL-12p70. While this crosstalk downregulates IL-12p70, induction of proinflammatory and bone-resorptive cytokines (IL-1 $\beta$, IL-6, and TNF- $\alpha$ ) is actually enhanced, further proof that $P$. gingivalis does not globally down or upregulate the inflammatory response, but rather fine tunes the immune response to its own liking. Moreover, $\mathrm{C} 5 \mathrm{aR}$ signaling is required for $P$. gingivalis to induce periodontal bone loss in a mouse model of experimental periodontitis, showing that despite $P$. gingivalis ability to hijack and subvert a variety of receptors, it is left vulnerable when these subversive mechanisms are prevented (154). 


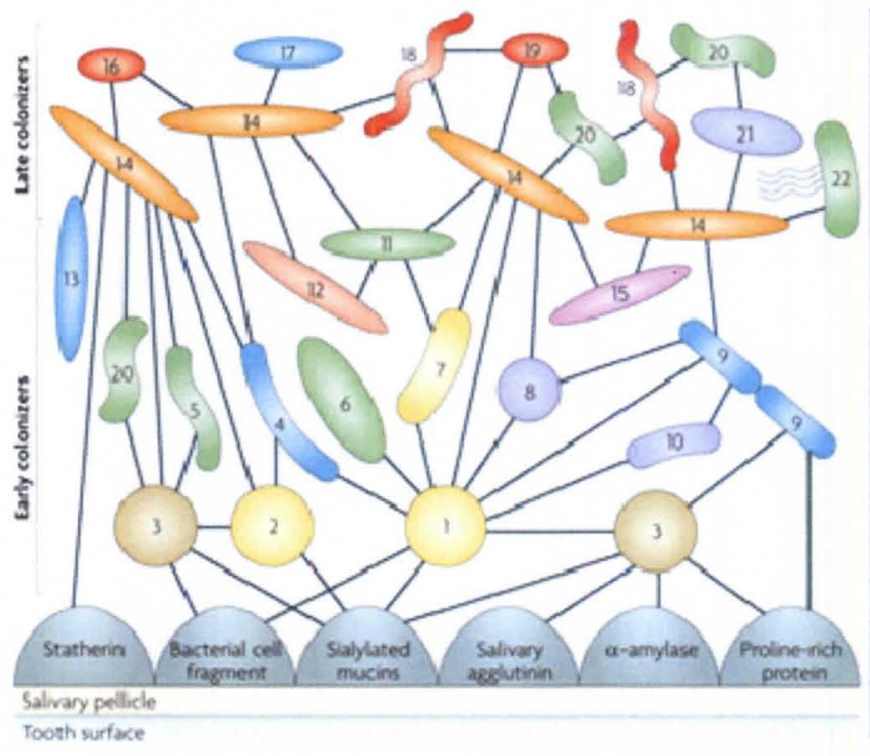

P. Kolenbrander, 2010
Strepeococeus orols and

streptococeus songurm

2 streptococcus mitis

3. Streptocoscin fordon:

4. Capnocytophaga oxhreced

s Propicnabocterium ocnes

6 Hoemophilus parantuenzoe

7 prevotella loesches

8 Wellonetla spp

Actinamytes cons and

Actenomyces noptandi

10. Etsenella corroderis

1. Actinamyces woeli

1) Capnocytophasa genevais

i3 Copnocytophoga spuetigena

14. fusobacterimem nixlectum

s. Prevotella denricola

Asgregatibacter

actinompcetencomitam

17 fisocterum upp

8. Ireponema dentercla

9 Ternerella foryythe

20 Porphynomonas ginguvals.

1 Prevotella intermedia

2. Selenomonas flunger

Nature Reviems | Macrobiologo

Figure 5. Development of the oral biofilom. The oral biofilm is colonized in a particular order. Typically, more commensal species such as $S$. oralis colonize early, and thus are more closely associated with the tooth surface. Therefore placement within the biofilm can be used as an indicator of a microbe's pathogenicity. For example, "orange complex" bacteria precede "red complex" pathogens. Species in the orange complex show significant association with increasing pocket depth as exemplified by $P$. intermedia and $F$. nucleatum. Species in the red complex show a very strong relationship with pocket depth, adding another parameter to determining the pathogenic qualities of microbes within the oral biofilm: distance from tooth surface and pocket depth.

Other factors important to successful invasion of the gingival crevice by $P$. gingivalis and subsequent induction of alveolar bone loss include IFN- $\gamma$ and IL-6. Mice deficient in 
these cytokines suffer less periodontal bone loss due to $P$. gingivalis infection than their wildtype counterparts. IFN- $\gamma$ is an interesting cytokine often assayed for in the examination of the host response to $P$.gingivalis and AMD3100 because of its potential role in osteoclastogenesis. IFN- $\gamma$ may contribute indirectly to $P$. gingivalis-induced osteoclastogenesis by stimulating monocytes and lymphocytes, although in contrast to the IFN- $\gamma$ 's established role inhibiting osteoclastogenesis (287) (75). IFN- $\gamma$ is known to also be important to increased levels of inflammatory cytokines and leukocyte recruitment into the periodontium, elements critical to the periodontal bone loss process $(77,86)$.

\section{CXCR4 in Periodontal Disease.}

It is critical that innate immune cells successfully discriminate pathogenassociated molecular patterns from the abundant and diverse microbial signals present at such host-environmental interfaces as the oral cavity. Toll-like receptors(TLRs) and the complement system are instrumental in the process of coordinating the immune response to microbial infection via rapid activation, extensive functional cooperation and formation of multi-receptor complexes which can include other TLRs, complement receptors and co-receptors such as CD14 $(99,173)$. However, the tendency of TLRs to cooperate with heterotypic receptors poses an opportunity for exploitation by pathogens capable of inducing inappropriate recruitment of receptors to deregulate host immunity. This can be especially true of pathogens which have evolved closely with the host organism (70). P. gingivalis, a keystone pathogen in human periodontal disease, has been shown extensively to interact in various and elegant ways with several host immune 
receptors, among them $\mathrm{C} 5 \mathrm{aR}, \mathrm{CR} 3$, and CXCR4, to enhance its own adaptive fitness (94, $98,102,103,154)$.

Since TLR2 is critical in identifying the mixture of atypical LPS molecules which decorate $P$. gingivalis (99) (30), it stands to reason that this receptor be strongly targeted by the pathogen for subversion. We have previously established that P. gingivalis signals via CXCR4 to divert antimicrobial signaling pathways initiated by TLR2 (100). TLR2 recognizes lipid A species associated with $P$. gingivalis LPS, however $P$. gingivalis also interacts with TLR2 via its fimbriae (105). P. gingivalis induces co-association of TLR2 with other co-receptors such as CD14 and CXCR4 into lipid rafts (99) to manipulate TLR2 signaling (See Figure 6).

It has been documented that TLR2 specifically is a target for $P$. gingivalis pathogenesis. As opposed to TLR4- deficient or wild type control mice, TLR2 deficient mice demonstrate protection against $P$. gingivalis-induced bone loss $(30,81)$. Whereas CD14 is summoned to facilitate activation of TLR2 by the pathogen (99), P. gingivalis itself physically interacts with CXCR4 via its fimbriae to abrogate TLR2 activation in human monocytes/mouse macrophages over a wide concentration range $(0.2-10 \mu \mathrm{g} / \mathrm{ml}$, corresponding to $2 \times 10^{7}$ to $10^{9}$ bacteria) $(103,291)$. The CXCR4 receptor is a transmembrane G-protein-coupled receptor that, once activated by $P$. gingivalis fimbriae, induces cAMP dependent protein kinase A (PKA) signaling which inhibits NF- $\mathrm{kB}$ activation. At first glance this appears to be a stopgap against excessive inflammatory upregulation, which should be beneficial to the host as chronic periodontitis is a disease of inflammation. However, it has been shown that this interaction actually serves to 
benefit the survival of the pathogen both in vitro and in vivo (103) (See Figure 3). In terms of the inflammatory response, this subversive signaling

A.

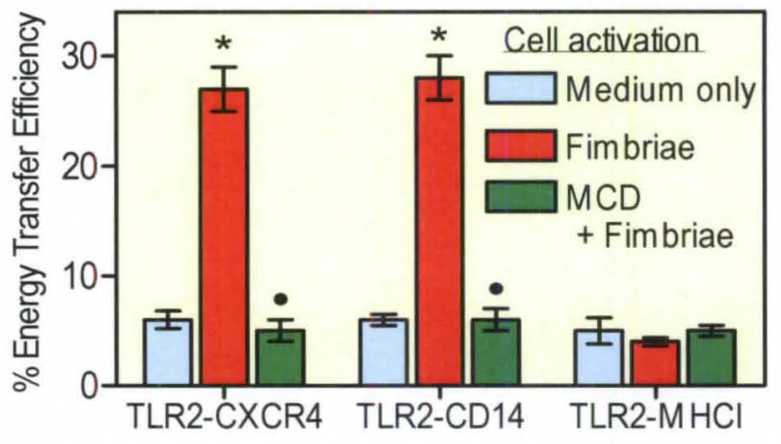

B.

$P$. gingivalis

CXCR4

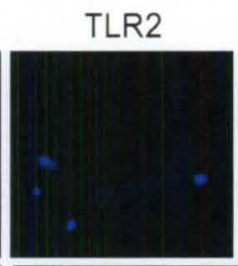

Merge
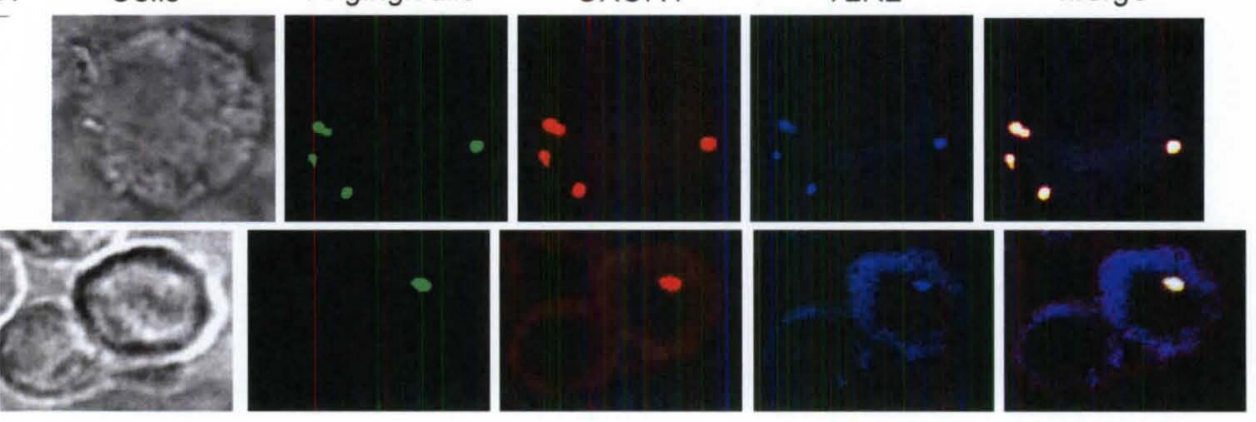

Figure 6. CXCR4 associates with TLR2 in $P$. gingivalis-activated monocytes/macrophages. $(A)$ Human monocytes were pretreated or not with MCD $(10 \mathrm{mM})$ and stimulated with Pg-fimbriae $(1 \mu \mathrm{g} / \mathrm{ml}, 10 \mathrm{~min})$. FRET between TLR2 (Cy3-labeled) and CXCR4, CD14, or MHC class I (Cy5-labeled) was measured from the increase in donor ( $\mathrm{Cy} 3)$ fluorescence after acceptor (Cy5) photobleaching. B. Confocal colocalization of FITC-P. gingivalis with both CXCR4 and TLR2 in human monocytes (Upper) or mouse macrophages (Lower) (103). 
ultimately results in inhibition of TNF- $\alpha$ as well as NO, the synthesis of which is also $\mathrm{NF}-\kappa \mathrm{B}$ dependent (283) and up-regulation of IL-10, consistent with the observation that its transcription is positively regulated by cAMP (25). CXCR4 has also been identified as a member of TLR4-based receptors complexes, showing that CXCR4 is bound directly by $P$. gingivalis LPS $(132,263)$ leading to upregulation of IL-6, possibly via a cAMPresponsive element in the transcription regulation of IL-6 (265) (56) (See Figure 7).

\section{AMD3100: Bycyclam CXCR4 antagonist}

Once the role of CXCR4 in TLR2 subversion mediated by $P$. gingivalis was determined, the next logical step was to define methods by which to interrupt $P$. gingivalis

influence upon the chemokine receptor. AMD3100, a bicyclam drug that inhibits SDF-1 binding to $\mathrm{CXCR} 4$ was found to interrupt the $P$. gingivalis fimbriae-CXCR4 interaction without causing collateral signaling or receptor internalization $(60,103)$. Ultimately, in mouse macrophages and human monocytes, this led to enhanced killing of the pathogen (103).

AMD3100 was discovered accidentally as an impurity contained within one of several commercial cyclam inhibitors while investigators were searching for potential anti-HIV compounds (50). Upon characterization, the bicyclam impurity was synthesized itself, modified and subsequent studies determined this bicyclam class of molecular target as CXCR4 (48) (51) (54) (228). The compound designation, JM3100, was changed to AMD3100 in order to indicate the developer. AMD3100 was subsequently found to inhibit T-tropic HIV strains via selectively inhibiting the interaction between HIV gp120 
to CXCR4 after it has bound to the CD4 receptor, but prior to initiation of cell membrane fusion by HIV gp41 (68) (48). The antiviral activity of AMD3100 was further characterized in a study which demonstrated the compound reduced viral load in SCIDhu Thy/Liv mice infected with a CXCR4- using clinical HIV isolate (47). AMD3100 can only suppress CXCR4 using viruses, such as the $\mathrm{X} 4$ and $\mathrm{R} 5$ tropic HIV variants, as opposed to variants which use CCR5 to facilitate entry (72). AMD3100 is now known to be both a CXCR4 antagonist as well as a CXCR7 agonist, though the effects of the later interaction are still being discovered (123) (190) (64). AMD3100 allosterically inhibits SDF-1 binding to CXCR4 and thus the subsequent Ca2+ influx resultant of SDF-1CXCR4 interaction $(125)(48,71,106)$. Specifically, AMD3100 binds to three acidic residues in the main SDF-1 binding pocket of CXCR4 (Asp171 in transmembrane domain [TM]-IV, Asp262 in TM-VI and Glu288 in TM-VII) (74) (106) (219) (282).

It has also been discovered that AMD3100 is a rapid and efficient stem-cell mobiliser (33), and this discovery has implications for stem cell transplantation and treatments for cancers such as multiple myeloma and non-Hodgkins lymphoma (57). Bone marrow stromal cells constitutively display SDF-1 which keeps CXCR4 expressing CD34+ stem cells anchored into the marrow. AMD3100 interferes with this anchoring, loosing the cells from SDF-1 (32) (71) and allowing them to mobilise into the peripheral circulation (272) (32). Under healthy conditions, very few haematopoietic stem/progenitor cells can be found circulating in the peripheral blood, peripheral levels typically increasing only in response to such emergency situations as infection or trauma (149) (166) (147). Under the name Plerixafor, the CXCR4 antagonist has been approved as a subcutaneous treatment, in combination with G-CSF, in the U.S. to mobilize 
haematopoietic stem cells for collection and treatment in adults with non-Hodgkins lymphoma or multiple myeloma (125).

Upon a single subcutaneous dose of $0.4-0.24 \mathrm{mg} / \mathrm{kg}(116,155)$ AMD3100, healthy volunteers demonstrated a dose dependent, transient increase in circulating $\mathrm{CD} 34+$ cells as well as other leukocytes, with mobilization into the periphery peaking about nine hours post administration in the highest concentration. The pharmacokinetics for subcutaneously administered AMD3100 are mostly linear over tested dose ranges (57). It is necessary to note that certain elements of the innate immunity which are also targets of $P$. gingivalis-mediated subversion regulate HSPC mobilization. Examples of these include the complement cascade, neutrophils and Toll-like receptors (181) (149, 210, 212, 213) (186). C5, specifically the C5a cleavage fragments spared by $P$. gingivalis gingipain degradation, was shown to be a critical component to HSPC mobilization via G-CSF and or zyomasan (149) (148) by showing that C5 deficient mice are uniformly poor mobilizers. It is important to note that, in relation to HSPC mobilization, there seems to be a passing back and forth of activation between granulocytes, particularly neutrophils, and the complement cascade, with granulocytes being activated the BM by complement cleavage fragments, aiding in HSPC retention signal perturbation, and further $\mathrm{C} 5$ activation. Once the granulocytes have paved the way for HSPC escape into the peripheral circulation, they are stimulated again by $\mathrm{C} 5 \mathrm{a}$ to release cationic peptides like cathelicidin and $\beta 2$-defensin as well as other metalloproteinases $(148,149)$.

Like the other methods of mobilization, AMD3100-directed HSPC mobilization likewise relies upon complement activation for success, however at different levels of the 
complement cascade. AMD3100 directly activates the complement cascade at the C5 level by inducing granulocytes to release proteases (149).

As mentioned above, AMD3100 has been shown to aid in controlling inflammation in a mouse model of collagen-induced arthritis (168). AMD3100 treatment reduced the severity of autoimmune collagen-induced arthritis (CIA) in IFN- $\gamma$ R-deficient DBA/1 mice. The delayed-type hypersensitivity response to the autoantigen, in this model collage type II, was reduced upon systemic AMD3100 treatment. The authors of the study concluded that AMD3100 must act upon chemokine-mediated attraction of leukocytes into joint tissues, a pathogenic process comparable to the chemoattraction of leukocytes into the periodontium during periodontal disease. The authors hypothesized involvement of SDF-1 and injected SDF-1 into periarthritic tissue and noted a subsequent inflammatory response. This reaction was inhibited by AMD3100. In these studies, treatment was initiated between the time of immunization, or, the experimental induction of the inflammatory disease, and the appearance of symptoms. While not exactly a model for "therapeutic" treatment, these studies indicated that CXCR4 antagonism post induction of disease could provide a clinical benefit.

CXCR4 expression can be observed in the sites of several flavors of pathology, and, depending upon the mechanistic role of CXCR4 in pathogenesis, CXCR4 blockade could be an effective "theme" for therapy across many diseases of separate etiologies. CXCR4 has been associated with a variety of infectious diseases. Not only is CXCR4 a critical point of entry for HIV tropic virus cells (17) and as shown here a critical target of signal transduction in $P$. gingivalis mediated periodontitis. CXCR4 blockade has been reported to reduce viral load within the CNS of West Nile Virus infected mice and 
significantly improved infection (170). Due to the broad connections of CXCR4 to disease processes, molecules targeting the co-receptors have understandably demonstrated side effects involving heart function and thrombocytopenia ostensibly due to inhibition of other essential functions of CXCR4 (109).

CXCR4 expression has been noted in some breast cancer cell lines (185) and CXCR4 has also been connected to progression of diverse malignancies of the brain, including intracranial glioblastoma and medulloblastoma (222). Waldenstrom macroglobinemia (WM) is a lymphoma of B cells and the trans-endothelial migration of these cells relies upon CXCR4 signaling, ostensibly through SDF-1 (192) and CXCR4 blockade may be a beneficial adjunct to existing therapy. In a mouse model of anaplastic thyroid carcinoma, AMD3100 was shown to reduce tumour growth (52). CXCR4 activation may enhance pituitary adenoma development, as CXCR 4 and SDF-1 are both overexpressed in human pituitary adenomas (15). AMD3100 treatment decreases human colorectal cell migration in Boyden chamber experiments as well as in vitro assays designed to measure invasion across an $8-\mu \mathrm{m}$ pore size polycarbonate membrane precoated with a layer of basement membrane matrix (151). Very recently, one group published a study indicating the SDF-1-CXCR4 signaling axis in pancreatic cell invasion, at least in vitro, showing that SDF-1 activation of CXCR4-positive pancreatic cells induces invasion, demonstrating yet another pathogenic process to which abnormal chemotaxis signals, specifically through CXCR4, may play a critical role (153).

\section{Considering CXCR7 and AMD3100.}


It was originally thought that AMD3100 was a specific allosteric antagonist of the monogamous CXCR4-SDF-1 binding pair (106), however, in 2005 CXCR7 was described as a second receptor for the SDF-1 molecule which, in humans, finds expression in embryonic neuronal and heart tissue, hematopoietic cells and activated endothelium $(31,117)$ (13). CXCR7 is a heptahelical G-protein coupled receptor (13) (73) which recognizes CXCL12 but upon activation does not induce typical GPCR mobilization of $\mathrm{Ca}++$ (288), G-protein-mediated signal transduction and cell migration (31). Instead, activation of the $\beta$-arrestin pathway and subsequent scavenging of the ligand has been shown $(190,259)$. CXCR7 can also heterodimerize with CXCR4 to abrogate the G protein complex signaling (150).

Like CXCR4, pathogenic roles, especially in malignancy and metastasis, are being elucidated for $\mathrm{CXCR} 7$, an example being the ability of CXCR7 to signal through PLC/MAPK pathway increasing cell survival within gliomas $(64,107)$. In metastatic cell lines CXCR7 overexpression correlated with enhanced proliferation and in clinical correlative studies upregulated CXCR7 expression was connected to increased aggressiveness of prostate cancer (274) as well as in vivo growth of breast and lung tumours (176). Also like CXCR4, CXCR7 expression is necessary for successful development, as CXCR7 deficient mice die perinatally due to heart valve malformations (238). While different theories as to the specific mechanism have been proposed, the cause for this perinatal fatality has been linked to the role of CXCR7 in embryogenesis. Specifically, the chemokine receptor has a role in directing the migration of primordial germ cells (269) (23). 
The discovery that CXCR7 binds SDF-1 logically led to the hypothesis that AMD3100 must also interact with the chemokine receptor. Ligand recognition by GPCRs is followed by a conformational change in the receptor to activate the associated heterotrimeric G-protein. When a receptor, such as CXCR4, is bound by a molecule other than its intended ligand, at a separate site on the receptor, allosteric modulation can occur (123). This is the case with AMD3100 and CXCR4, because AMD3100 allosterically inhibits SDF-1/CXCR4 interaction. In the case of CXCR7, however, binding of AMD3100 to the receptor actually increases the receptors affinity for SDF-1, making AMD3100 a positive allosteric ligand for this receptor, including at in vitro study concentrations $(123,169)(190)$. AMD3100 administered alone selectively recruits $\beta$ arrestin to CXCR7 in mammalian cells instead of CXCR4. These recent developments make CXCR7 a worthwhile receptor to study in periodontal disease, especially as studies involving the action of AMD3100 proceed.

\section{Treatment of Periodontal Disease}

$P$. gingivalis is a low-abundance anaerobic bacterium which plays a critical role in the pathogenesis of periodontal disease, a polymicrobial as well as inflammatory condition. $P$. gingivalis manipulates its environment, the deep gingival crevice, in a variety of ways to enhance its own survival, not least among them triggering quantitative as well as qualitative changes in the composition of the oral microbiota which in turn promotes dysbiosis and consequent periodontal inflammation (97). At this time, it seems as though periodontal bone loss requires a triumvirate of players, including the host complement, $P$. gingivalis itself and the commensal microbiota, because germ-free mice 
or conventionally raised C3a and C5aR-deficient mice did not develop bone loss post $P$. gingivalis inoculation $(97,154)$. While $P$. gingivalis is thus identified as a "keystone" pathogen and does employ various tactics to out-maneuver the host response, as well as all but the most invasive clinical interventions, targeting this low-abundance pathogen may reverse its community-wide impact and thus prove important to treatment to periodontal treatment and prevention.

This study focused on the crosstalk events induced by $P$. gingivalis fimbriae between TLR2 and an associated co-receptor chemokine receptor 4 (CXCR4). $P$. gingivalis exploits CXCR4 to undermine host signaling and promote its own adaptive fitness. In this way $P$. gingivalis acts like a conductor which has hijacked the orchestra of host immune receptors, directing them not to maintain a homeostatic balance, but rather to drive a chronic inflammatory state. This selectively nonproductive response benefits $P$. gingivalis while causing extensive collateral damage in the periodontal tissues as well as potentially increasing the risk and extent of systemic diseases such as rheumatoid arthritis (18), aspiration pneumonia (100), atherosclerosis (264) and heart disease $(183,273)$. 


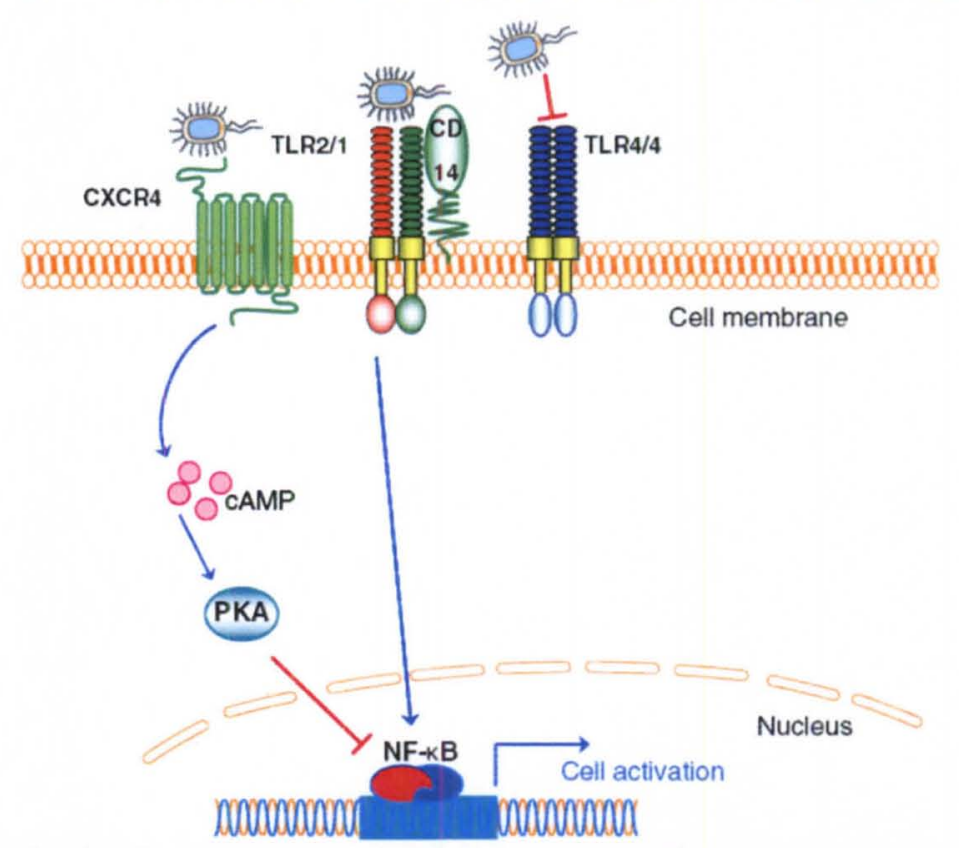

Figure 7. $P$. gingivalis antagonizes TLR4 but not TLR2 at the receptor level. $P$. gingivalis targets TLR2 at the downstream signaling level via CXCR4 exploitation. P. gingivalis uses an elaborate system of lipid A phosphatase and deacylase activities that modify the lipid A structure of its lipopolysaccharide (41). These modifications result in lipopolysaccharide molecules that can either evade or actively antagonize TLR4 activation (depicted as a homodimer; TLR4/4) (41). Although the activation of the TLR2/TLR1 heterodimer (TLR2/1) is not antagonized at the TLR receptor level, $P$. gingivalis instigates a molecular crosstalk between the CXC-chemokine receptor 4 and TLR2/1. Unlike CD14 which facilitates TLR2/1 activation by the pathogen $(55,99)$, CXCR4 suppresses TLR2 signaling (103). Mechanistically, $P$. gingivalis uses its fimbriae to bind CXCR4 and induce cAMP-dependent PKA signaling, which in turn inhibits the activation of nuclear factor- $\kappa \mathrm{B}(\mathrm{NF}-\kappa \mathrm{B})$ activation(103). Reprinted with permission. 


\section{CHAPTER TWO: MATERIALS AND METHODS}

Bacterial strains and culture conditions. P.gingivalis ATCC 33277 was grown anaerobically from frozen stocks on modified Gifu anaerobic medium-based blood agar plates (Nissui Seiyaku Co., Tokyo, Japan) for $5-6$ days at $37^{\circ} \mathrm{C}$ under microaerophilic conditions. $P$. gingivalis was also grown in reduced Trypticase Soy Broth (TSB; BD) supplemented with yeast extract (1 gram per liter; BD), menadione $(1 \mu \mathrm{g}$ per ml; SigmaAldrich), and hemin (5 $\mu \mathrm{g}$ per ml; Sigma-Aldrich). The medium was reduced for 24 hours under anaerobic conditions by equilibration in an atmosphere consisting of $10 \%$ $\mathrm{CO}_{2}, 10 \% \mathrm{H}_{2}$, and $80 \% \mathrm{~N}_{2}$.

Animals. Female BALB/c mice were obtained from The Jackson Laboratory. C57BL/6 conditional CXCR4-deficient mice (with their respective wildtype control mice) were provided by Dr. Gregg Rokosh (University of Louisville) and were housed in conventional vivarium conditions. Inducible conditional knockout mice were generated using a cre recombinase modified with an estrogen receptor ligand-binding domain. This modified cre recombinase was non-functional until induction with tamoxifen at four weeks of age (6). 
Subcutaneous osmotic pump implantation in mice. ALZET osmotic pumps were loaded prior to insertion following manufacturer instructions. Mice were weighed prior to implantation to assure adherence to the pump implantation weight guidelines. Anaesthesia was induced over 2 minutes by isoflurane (Butler Schein Animal Health) inhalation through a vaporizer $\left(3 \%\right.$ isoflurane and $\left.100 \% \mathrm{O}_{2}\right)$. Surgical anaesthesia was confirmed by pinching the foot pad and observing reaction. Artificial tears (Butler Schein Animal Health) were applied to avoid eye injury during surgical implantation/ discomfort upon waking. The target area for subcutaneous implantation was sanitized using $70 \%$ ethanol and then Nolvasan $4 \%$ antibicrobial solution (Butler Schein). The area was shaved using surgical preparatory blades and the area was sanitized again with Nolvasan rinse. A subcutaneous incision was made dorsolaterally, posterior to the scapulae. The incision was made anteriorly so that the pump, once inserted, would slide posteriorly. This was done so the mouse could not access and chew the sutures or staples before the wound was adequately healed. Alzet osmotic minipumps (model \#2004; Alza, Palo Alto, CA) were subcutaneously implanted "delivery portal first" within a pocket large enough to allow a relatively free movement of the pump without allowing the pump to turn or slip down the flank of the animal. The incisions were closed with a wound closing stapler system (BD). Mice were monitored and on Day 10 staples were removed.

In vivo mouse periodontitis model. The $P$. gingivalis-induced periodontal bone loss model used was essentially as originally developed by Baker and colleagues (12) as follows. 10-12 week old wild-type or CXCR4 conditional deficient mice were fed water 
with antibiotics $(800 \mu \mathrm{g}$ sulfamethoxazole $/ \mathrm{ml}$ and $400 \mu \mathrm{g}$ trimethoprim $/ \mathrm{ml}$ ) ad libitum for ten days to suppress the normal flora and create a more favourable niche for $P$. gingivalis colonization as the mouse is not a natural host to $P$. gingivalis. This was followed by 3 days of regular water ad libitum to allow the antibiotics to clear the system. $P$. gingivalis 33277 was grown on TSB or GAM blood agar plates for 3-6 days in anaerobic buckets and suspended into $5 \mathrm{ml}$ PBS. An OD 600 reading was taken to measure CFU and the bacteria were spun down at 4000 RPM for 10 minutes. Bacteria were resuspended at $2 \mathrm{x}$ $10^{10} / \mathrm{ml}$. The bacteria were added to $2 \% \mathrm{CMC}$ (the oral gavage vehicle) at a $1: 1$ ratio so that the final concentration of bacteria should be $1 \times 10^{10} / \mathrm{ml}$.

Mice were orally infected five times at 2-day intervals with $10^{9} \mathrm{CFU} P$. gingivalis suspended in $100 \mu 12 \%$ carboxymethylcellulose/PBS. Sham-infected control animals received 2\% carboxymethylcellulose in PBS alone. Mice were fed using a $1 \mathrm{ml}$ syringe and a $22 \times 1 " \mathrm{~W} / 1-1 / 4$ animal feeding needle. A separate needle for the $P$. gingivalis and sham infected mice was used and the needles were kept separate at all at times including when they were cleaned. Needles were treated with a D/Rnase solution to eliminate $P$. gingivalis DNA cross contamination. See Figure 8.

Analysis of alveolar bone resportion. Six weeks after the final infection, mice were euthanized via $\mathrm{CO}_{2}$ inhalation. After euthanization, the mice were decapitated. The mouse heads were boiled for 15 minutes under $15 \mathrm{lb} / \mathrm{in}^{2}$ of pressure and subsequently defleshed. The skulls were then immersed in 3\% hydrogen peroxide overnight at room temperature to remove any remaining musculature and washed with deioinized water. To ensure that any residual bacteria and/or tissues were removed from the teeth, skulls were 
sonicated at 4 volts in $1 \%$ bleach for 30 seconds, rinsed with water, and then gently brushed with toothpaste for 30 seconds. They were rinsed clean, swirled in distilled water for 30 seconds, and then once again sonicated at 4 volts in $1 \%$ bleach and rinsed clean

A.

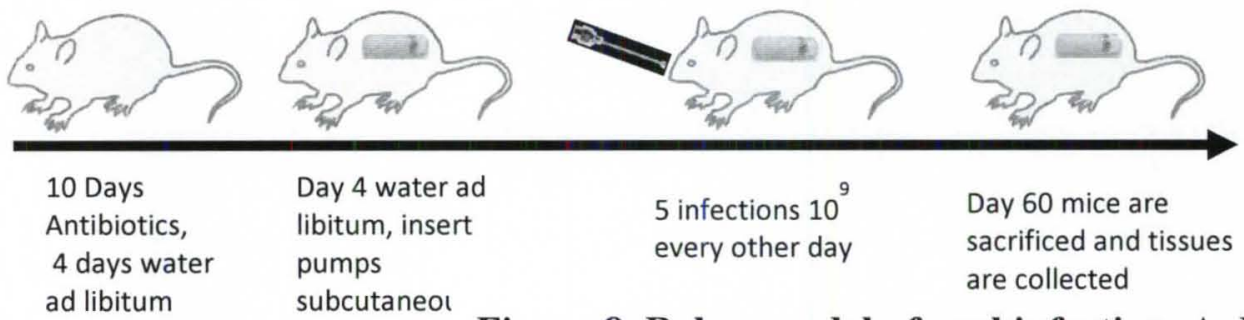

Figure 8. Baker model of oral infection. A. Mice

B.

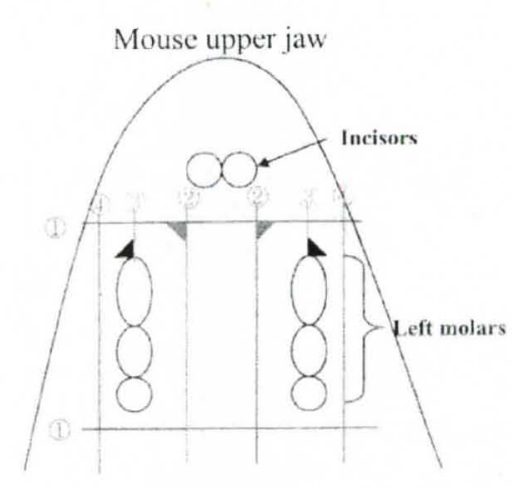

are given broad spectrum antibiotics to clear normal flora and create a niche for $P$. gingivalis.

After a rest period to clear antibiotics from the mouse system, mice are infected every other day. On day 60 mice are euthanized. B. Schematic of gingivae dissection following euthanasia of mice.

with deionized water. The cleaned teeth were stained for 5 minutes with $0.5 \%$ Eosin $\mathrm{Y}$ TS, 30 seconds with 1\% Methylene Blue (Ricca Chemical Company, Arlington, TX) and rinsed with deionized water to remove excess dye. Skulls were allowed to air-dry prior to measurement of the alveolar bone.

Assessment of periodontal bone loss in defleshed maxillae was performed under a dissecting microscope (x40) fitted with a video image marker measurement system (model VIA-170K; Fryer, Huntley, IL) standardized for measurements in millimeters 
(mm). Specifically, the distance from the cementoenamel junction (CEJ) to the alveolar bone crest $(\mathrm{ABC})$ was measured on 14 predetermined points on the buccal surfaces of the maxillary molars (12). The 14-site total CEJ-ABC distance for each mouse was subtracted from the mean $\mathrm{CEJ}-\mathrm{ABC}$ distance from the group of sham-infected mice; results were expressed as millimeter change in bone, and negative values indicated bone loss compared with sham-infected controls (12). All animal procedures received Institutional Animal Care and Use Committee approval and were in accordance with federal guidelines for the care and use of laboratory animals.

RNA Isolation, cDNA synthesis and RT-PCR of host genes. Palatal and buccal gingival tissue immediately adjacent to maxillary molars was dissected and stored at $70^{\circ} \mathrm{C}$ in RNALATER. RNA was extracted using the Qiagen RNeasy Mini Kit and quantified at 260 and $280 \mathrm{~nm}$ using a NanoDrop spectrophotometer. The RNA was reverse transcribed using the $\mathrm{qScript}{ }^{\mathrm{TM}}$ cDNA SuperMix (Quanta Biosciences) and quantitative real-time PCR was performed using the ABI 7500 Fast System, according to the manufacturer's protocol (Applied Biosystems) in $20 \mu$ l. All TaqMan probes, sense primers and antisense primers for expression of genes were purchased from Applied Biosystems (154). The amplification conditions for all qPCR reactions were as follows: 20 seconds at $95^{\circ} \mathrm{C}$, then 40 cycles of two steps, 3 seconds at $95^{\circ} \mathrm{C}$ to denature, and 30 seconds at $60^{\circ} \mathrm{C}$ for annealing and elongation. All changes in gene expression were expressed as the difference in threshold value between GAPDH and the gene of interest in experimental groups versus the negative control group. See Table 2. 
DNA isolation. 24 hours after the last infection mice were euthanized, maxillary palatal, and buccal gingival tissues as well as the tooth and immediate bone were harvested (sham mice first to avoid contamination), placed in the lysis buffer (ATL) provided with the Qiagen Dneasy kit and lysed overnight at $56^{\circ} \mathrm{C}$ with occasional agitation. DNA was then harvested using the Qiagen DNeasy and stored at $4{ }^{\circ} \mathrm{C}$ short term or $-20^{\circ} \mathrm{C}$ long term. The concentration and purity of each DNA sample were measured via spectrophotometry at $260 \mathrm{~nm}$ (ND-1000 Spectrophotometer, NanoDrop Technologies, Inc, Wilmington, DE). Using the concentration estimate gained from the spectrophotometric readings the DNA preparations were diluted to give roughly equivalent amounts of DNA per PCR reaction. Quantitative real-time PCR for total bacteria was done using Taqman primers to $16 \mathrm{~S}$ (137) and for $P$. gingivalis using Taqman primers designed for ISPG1 in a final reaction volume of $20 \mu 1$ (Applied Biosystems). See Table 2. Total bacteria and $P$. gingivalis genomic copy number were quantified using a standard serial dilution of DNA extracted from $P$. gingivalis broth culture. The broth culture was quantified by CFU in order to construct a standard curve.

Titanium Coil Chamber Implantation. Isofluorane anesthetized Balb/c mice were dorsolaterally implanted with a surgical-grade titanium coil chamber. Following a 7 day healing period, $P$. gingivalis $\left(10^{\circ} \mathrm{CFU}\right.$ in $100 \mu \mathrm{l}$ of PBS) was injected into the chambers of each mouse. Various doses of AMD3100 were co-injected in the same $100 \mu 1$ volume. Chamber exudates were harvested from mice at indicated time points and centrifuged at 1000 rpm for 5 minutes. Subsequently, recruited cells were phenotypically characterized by flow cytometry, supernatants were used to determine viable counts of $P$. gingivalis, and cytokines were analyzed using EIA (EB Biosciences) or Luminex-100/multiplex cytokine analysis system (Upstate). See Figure 9. 

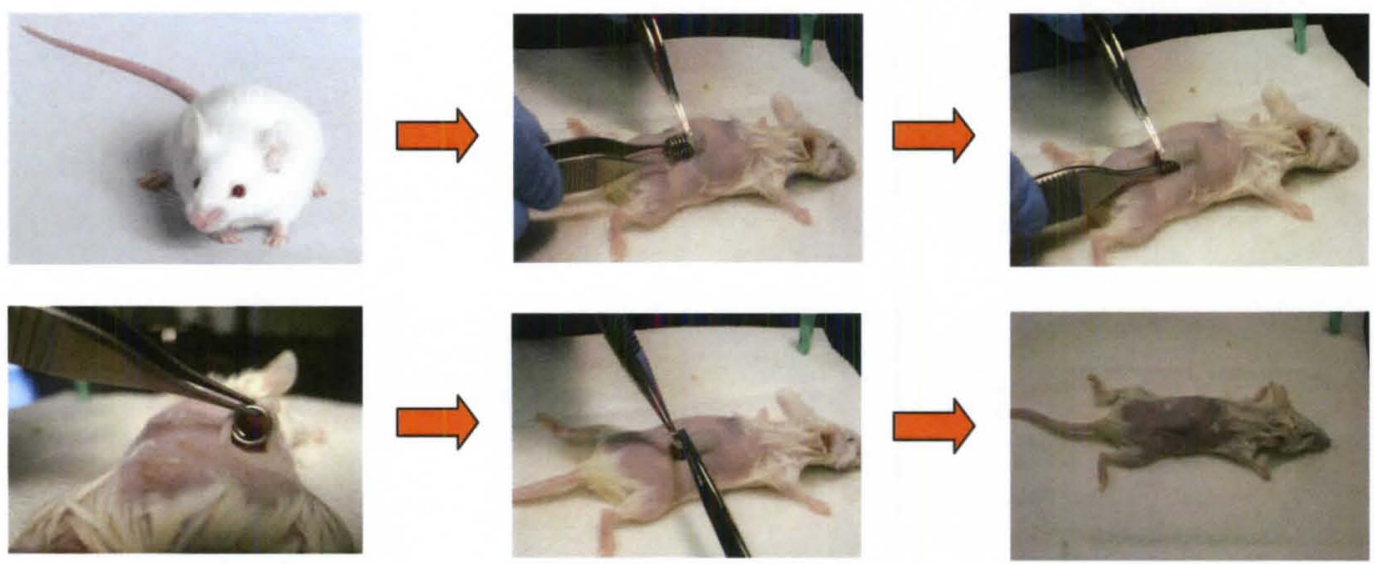

Fig. 9. Implantation of titanium steel coil for subcutaneous chamber model. Mice were typically anesthetized using Isoflurane/Oxygen mix and measures for pain alleviation were followed as per the veterinarian recommendations, allowing for non-interference with host response analysis.

Statistical analysis. Data were evaluated by analysis of variance and the TukeyKramer multiple comparisons test using the InStat program (GRAPHPAD Software, San Diego, CA, USA). Where appropriate (comparison of two groups only), Student's twotailed unpaired t-tests were performed. The level of significance was taken as $p<0.05$. All experiments were performed at least twice for verification. 
Table 1. Bacterial Strains used in this Study.

Bacterial Strain Description

Source

P. gingivalis ATCC 33277

Gram-negative, rod-shaped, anaerobic pathogenic bacterium.

ATCC

F. nucleatum ATCC 25586

Anaerobic rod; oral bacteria, orange complex 
Table 2. Primers used in this study.

Primers $\quad$ Primer Sequence $\left(5^{\prime}-3^{\prime}\right)$

Source

Bacterial Squences

5' Universal $16 \mathrm{~s}$

5'TCCTACGGGA GGCAGCAGT-3'

3' Universal $16 \mathrm{~s}$

5'-GGACTACCAGGGTATCTAATCCTGTT-3'

Universal 16s Reporter

5' $P$. gingivalis ISPG1

3' $P$. gingivalis ISPG1

5'-FAM-CGTATTACCGCGGCTGCTGGCAC-TAMRA-3'

5'-CGCAGACGACAGAGAAGACA-3'

This Study

5'-ACGGACAACCTGTTTTTGATAATCCT-3'

This Study

$P$. gingivalis ISPG1 Reporter

5'-FAM-TCCGCCTCGCTCCGAT-TAMRA-3'

This Study 


\section{CHAPTER THREE: SYSTEMIC AMD3100 ADMINISTRATION PREVENTS ALVEOLAR BONE RESORPTION IN P. GINGIVALIS INFECTED MICE}

\section{Introduction}

The inflammatory immune response is critical to protection against oral pathogens but is ultimately also the driving factor in chronic periodontitis. Some investigators have attributed this pathogenesis at least partly to a spatial shift in the constant inflammatory infiltrate closer to the bone surface (86). Graves and coworkers reported in a non-human primate model of experimental periodontitis that the inflammatory front shifts closer to the crest of the alveolar bone in association with increased osteoclast formation. This process was significantly alleviated by blockade of IL-1 and TNF- $\alpha(84,86)$. Other investigators have noted that the closer the inflammation comes to the bone, the more aggravated the bone loss becomes (229) (221) (198). These observations were taken to mean that, by inhibiting inflammatory migration from the sub-epithelial connect tissue closer to the one, that progression from gingivitis to periodontitis could be prevented.

Toll-like receptors (TLRs) detect and respond to microbial infection via rapid activation of inflammatory and antimicrobial responses in cooperation with other innate 
immune receptors with which they form multi-receptor complexes in membrane lipid rafts of front-line defense cells (e.g., neutrophils and macrophages) (263).

However, the tendency of TLRs to functionally associate with heterotypic receptors poses an opportunity for exploitation by microbial pathogens capable of inducing inappropriate lipid raft recruitment of receptors that could subvert host immunity (96).

We have previously shown that Porphyromonas gingivalis, a keystone pathogen in periodontal disease (97), interacts with several innate immune receptors, including complement receptors and the $\mathrm{CXC}$ chemokine receptor 4 (CXCR4), in ways that enhance its own adaptive fitness (101) (103) (154) $(275,276)$. With regard to CXCR4, we have shown that $P$. gingivalis uses its surface fimbriae to directly bind and activate CXCR4 to subvert antimicrobial signaling initiated by TLR2 (103) (205).

Specifically, $P$. gingivalis induces co-association between CXCR4 and TLR2 in lipid rafts, leading to a subversive crosstalk pathway in which cAMP-dependent protein kinase A signaling inhibits intracellular nitric oxide production. This activity, in turn, impairs the killing function of leukocytes (103) suggesting that $P$. gingivalis exploits CXCR4 to evade host immunity and, perhaps, to persist in the periodontal tissue and cause disease (231).

However, in our previous studies we did not examine whether the exploitation of CXCR4 by $P$. gingivalis enhances its ability to cause periodontitis. To address this hypothesis, we now determined whether a specific and potent antagonist of CXCR4, the bicyclam drug AMD3100 (60), can inhibit $P$. gingivalis-induced periodontitis in the mouse model. Our current results show that AMD3100 impairs the ability of $P$. gingivalis 
to cause bone loss by interfering with its colonization in the murine periodontal tissue. These findings provide proof of concept that CXCR4 antagonists may be promising therapeutics for the treatment of human periodontitis.

Prior to these studies, AMD3100 was used in combination with preexisting therapeutic molecules (G-CSF and GM-CSF) in a clinical setting to increase circulating peripheral blood stem cells and it has been proposed that CXCR4 blockade may have a role to play in treating leukemia due to shared surface expression of adhesion molecules and CXCR4 on leukemic precursor cells and HSPCs $(231)(24)(218,247)$

Generally no single animal model completely recapitulates the pathophysiology of human disease. However, animal models possess utility in testing specific mechanistic hypotheses involving the pathology periodontal disease (85). In the Baker model of periodontitis, induction of several inflammatory cytokines can be reliably observed in conjunction with alveolar bone loss. Therefore, modulation of cytokine expression in the gingival tissues is analyzed along with the more clinical parameter of bone loss.

It is critical to demonstrate cause-and-effect relationships when studying potential therapeutic compounds and these studies cannot be addressed in humans (85) as clinical trials can be initiated only after safety and efficacy have been demonstrated in animal models. In this study we show that treatment both prior to and post $P$. gingivalis mediated induction of disease arrests the progress of inflammatory bone loss.

\section{Results}

AMD3100 prevents development of periodontal bone loss in mice infected with $P$. gingivalis 
CXCR4 antagonism leads to enhanced clearance of $P$. gingivalis in mouse macrophages/human monocytes (103), therefore we hypothesized that treatment with AMD3100 would protect mice from periodontal bone loss in the Baker model of chronic periodontitis. Physiological protection could be due to either: 1) enhanced clearance of the bacteria, or 2) inhibition of $P$. gingivalis-mediated inflammatory tissue destruction by the immune system. To account for both possibilities, systemic treatment with AMD3100 was initiated 24 hours prior to initial $P$. gingivalis inoculation. In order to ensure the antagonist was delivered for an adequate amount of time to produce a measurably protective effect, Alzet mini-osmotic pumps administering $0.25 \mu \mathrm{l} / \mathrm{hr}$ at a steady rate for four weeks were subcutaneously implanted dorsolaterally in BALB/c mice. $600 \mu \mathrm{g}$ AMD3100 was delivered a day, corresponding to a steady serum level of about $1 \mu \mathrm{g} / \mathrm{ml}$ (168). This concentration has previously been found to effectively block CXCR4 in cell culture experiments $(103,205)$. Systemic treatment is advantageous because of AMD3100's low oral bioavailability $(110,271)$ as well as the extensively documented successful administration of AMD3100 (in terms of its efficacy in CXCR4-mediated diseases), ranging from 1 to $5 \mathrm{mg} / \mathrm{kg}$ mouse body-weight $(113,121,224,242)$. Systemically administered AMD3100 has been shown to be safe both in mice and in human phase I clinical trials (110). Moreover, our laboratory has shown that a single intraperitoneal injection of AMD3100 results in enhanced clearance of $P$. gingivalis from the peritoneal cavity.

Continual systemic administration of AMD3100 completely abrogated periodontal bone loss caused by $P$. gingivalis in Balb/c mice $(\mathrm{p}<0.01$; See Figure 10), in stark contrast to mice receiving only PBS which developed significant bone loss relative 
to sham-infected controls. AMD3100 treatment in the absence of bacterial infection did not affect bone loss in the mice.

Since $P$. gingivalis interacts with several immune receptors involved in inflammation (TLR2, TLR4, CXCR4) and since one of the downstream targets of these interactions was $\mathrm{NF}-\mathrm{\kappa B}$, we elected to survey two mice from each experimental group using a 96 well gene array designed to identify trends in the NF- $\kappa \mathrm{B}$-mediated inflammatory profile. While differences in gene expression assayed in this experiment were not significant, there was an observable trend in differences between infected treated and untreated mice. Later, we used this information to do RT-PCR in CXCR4 KO mice, experiments in which starting amounts of gingival tissue were limited, and assay a targeted group of inflammatory/osteoclastogenic genes. In the CXCR4 KO experiments, the trends we observed using the arrays in AMD3100 treatment experiments were confirmed. One of the most striking correlations was the observation of high amounts of mRNA for several inflammatory genes without the presence of bone loss in sham infected, CXCR4 KO mice, just as in the AMD3100 treated, sham infected mice (See Chapter Four).

We noted a difference in relative expression of proinflammatory mediators important to the progression of periodontal disease. By day 60 , AMD3100 treatment had caused down-regulation of IL-6 and upregulation of TGF- $\beta$ in $P$. gingivalis-infected mice relative to untreated mice. We noted upregulation of RANK-L in one AMD3100 treated mouse, but osteoprotegerin was also upregulated in the same mouse so it's reasonable to attribute the lack of bone loss to the decoy receptor competing with RANK-L resulting in inhibition of osteoclastogenesis. Long term AMD3100 treatment alone caused 
downregulation of IL-6, and RANK-L and upregulation in IL-1 $\beta$, TNF- $\alpha$, TGF- $\beta$ and OPG relative to no treatment. These mice did not display alveolar bone loss, despite an apparent upregulation of inflammatory cytokine production.

These data indicated that AMD3100 treatment protects mice from P. gingivalismediated bone loss when the drug is administered prior to exposure to the pathogen and for an extended duration. This protection appeared to be due at least in part to a shift in the inflammatory response to $P$. gingivalis as a result of CXCR4 blockade. We concluded, upon surveying the inflammatory response at day 60 , that the downregulation of IL-6 in P. gingivalis-infected AMD3100 must be due to a combination of CXCR4 blockade and resolution of $P$. gingivalis-mediated inflammation prior to day 60 . However, the elevated IL-1 $\beta$ and RANK-L levels in infected, treated mice conflict with the later conclusion, so we decided to ask whether the infection was actually being resolved early during the oral chronic periodontitis model. 
A.
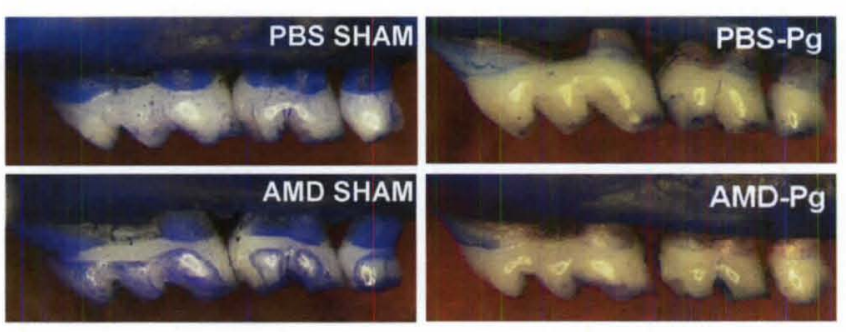

C.

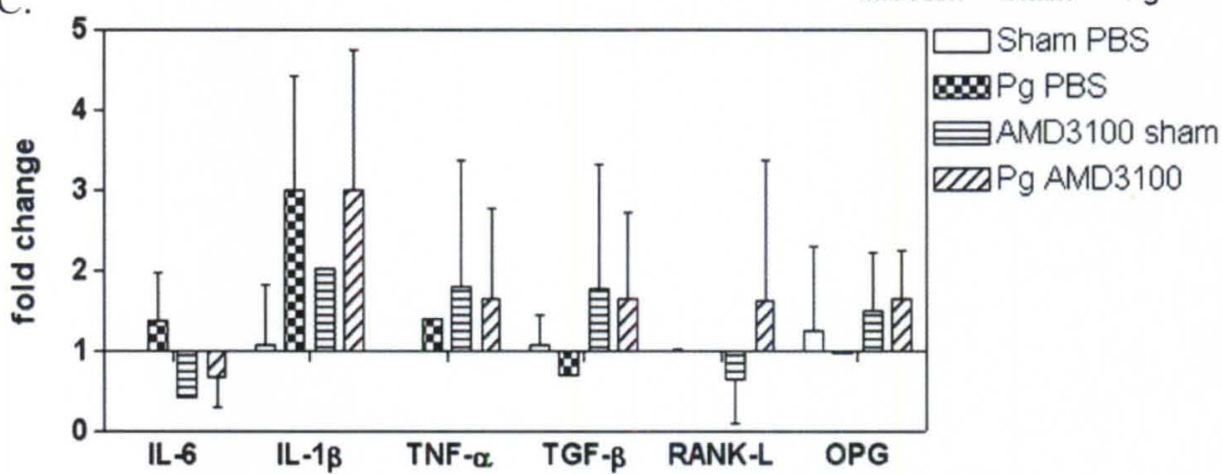

B.

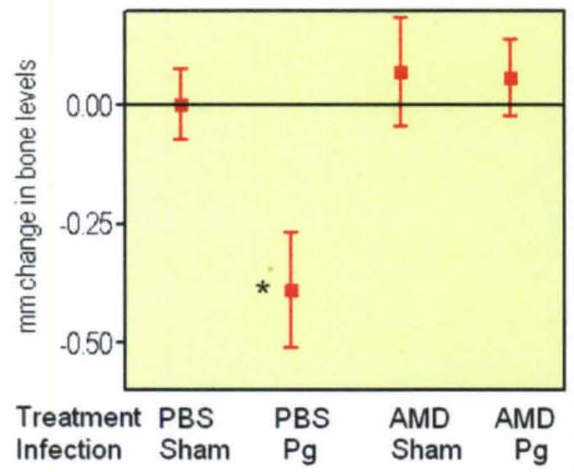

$\square$ Sham PBS

Figure 10. Preventive treatment with AMD3100 abrogates $P$. gingivalis-induced periodontal bone loss. BALB/c mice (10-12 weeks of age) were administered AMD3100 (or PBS control) through osmotic minipumps which were implanted subcutaneously 24 hours prior to oral infection with $P$. gingivalis (or vehicle only; sham) as described in the Methods. The mice were euthanized six weeks after the last inoculation with $P$. gingivalis, gingivae were dissected for RT-PCR and bone loss measurements were performed in defleshed maxillae. Data are means $\pm \mathrm{SD}(n=$ 5 mice per group); negative values indicate bone loss in P. gingivalis-infected mice relative to sham-infected controls. ${ }^{* *} P<0.01$ compared to control and all other experimental groups. AMD, AMD3100; Pg, P. gingivalis. 


\section{Systemic AMD3100 treatment effectively eliminates $P$. gingivalis from the oral cavity early in the oral infection model.}

We next investigated whether AMD3100 treatment actually enables the host to clear the pathogen from the oral cavity, or if $P$. gingivalis persists in the oral cavity during AMD3100 treatment but is not able to incite pathologic bone loss. This is important because, if the $P$. gingivalis manages to persist despite the AMD3100 treatment, once treatment is removed $P$. gingivalis would be free to instigate disease. CXCR4 blockade inhibits survival of $P$. gingivalis in mouse macrophages, therefore we hypothesized that the protective effect of AMD3100 treatment in the context of chronic periodontitis is due to enhanced clearance of the bacteria.

To this purpose, an abbreviated version of the Baker oral model of disease was used. Mice were given ten days of broad spectrum antibiotics and three days regular water ad libitum as in the regular model. 24 hours prior to the initial $P$. gingivalis inoculation, 14 day osmotic pumps were implanted subcutaneously in mice. Seven days after the final (fifth) infection, mice were euthanized and periodontal tissues were collected. qRT-PCR targeting ISPG1, a high-copy number gene, was used to detect $P$. gingivalis in the soft and hard tissues of the periodontium. There was a statistically significant increase in copy number of $P$. gingivalis in untreated mice $(p<0.01$, See Figure 11).

However, ISPG1 copy number in $P$. gingivalis-infected, AMD3100 treated mice was indistinguishable from sham infected mice. There was also a statistically significant trend in the total bacterial load (both aerobic and anaerobic) as measured by 
A.

P. gingivalis $\square$ Total oral bacteria

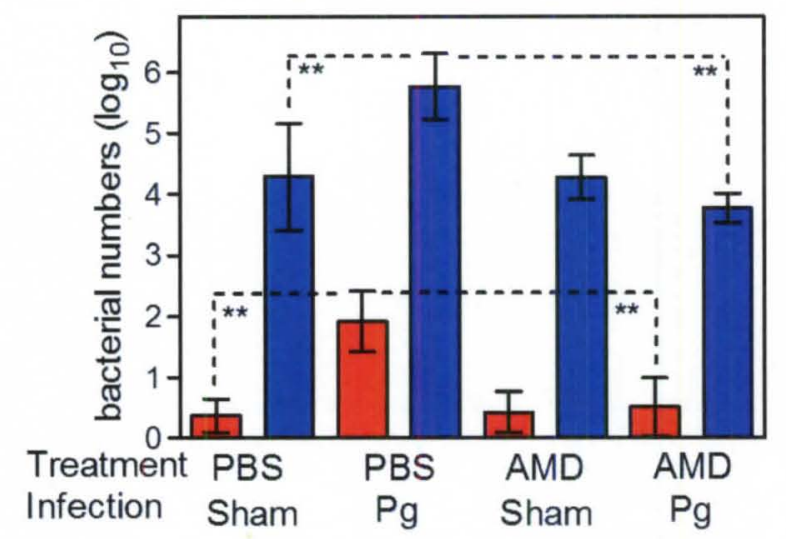

B.

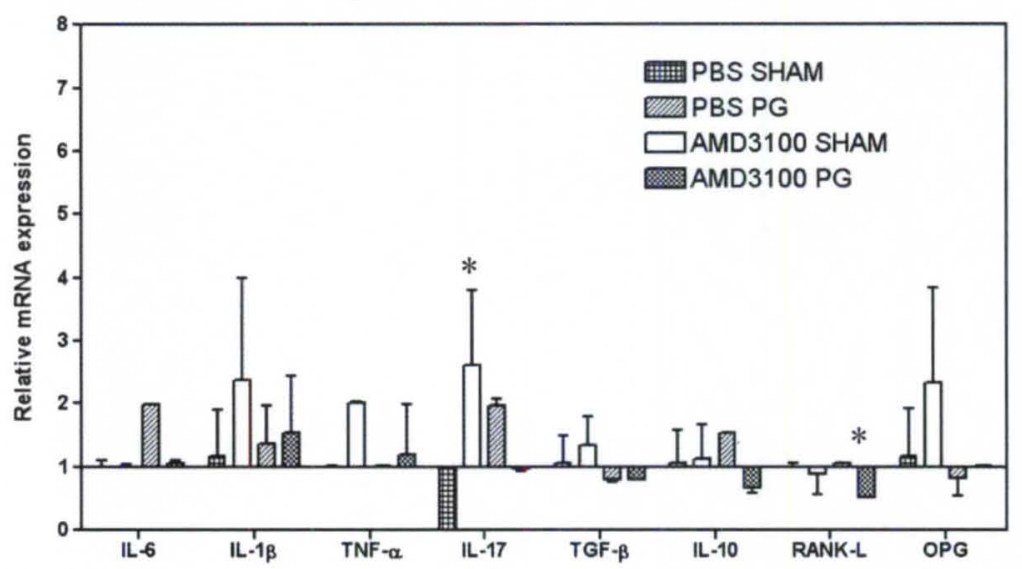

Figure 11. Effect of AMD3100 on the numbers of $P$. gingivalis or total bacteria in the murine periodontal tissue. BALB/c mice (10-12 weeks of age) were treated with AMD3100 (or PBS control) and infected with P. gingivalis (or vehicle only; sham) as described in the legend to Figure 1. The mice were sacrificed 7 days after the last inoculation with $P$. gingivalis. The numbers of $P$. gingivalis and of total periodontal bacteria in the periodontal tissue were determined using quantitative real-time PCR of the ISPgI gene ( $P$. gingivalis) or the $16 \mathrm{~S}$ rRNA gene (total bacteria). Host gene expression was determined via qRT-PCR. Data are means $\pm \mathrm{SD}\left(n=5\right.$ mice per group). ${ }^{*} P<0.05 ; * * P<0.01$ between the indicated groups. AMD, AMD3100; Pg, P. gingivalis. 
16S copy number. There was a significant increase in total bacterial load in untreated mice infected with $P$. gingivalis, while the total bacterial load remained at sham infected levels in mice also treated with AMD3100, $(p<0.01$, See Figure 11). We previously showed that $P$. gingivalis colonizes the oral cavity in specific-pathogen free mice at low levels and causes an elevation of the total cultivatable commensal bacterial load, and this shift in the commensal bacteria is essential to induction of bone loss (97). The finding that $P$. gingivalis causes a pathologic, quantitative increase in commensal bacteria and that AMD3100 treatment reverses that shift supports our previous conclusion that $P$. gingivalis plays the role of a keystone pathogen within the oral biofilm. Taken together, these data indicate that systemic AMD3100 treatment leads to elimination of $P$. gingivalis from the oral cavity and prevents the quantitative increase in the oral commensal microbiota attributable to the successful colonization of $P$. gingivalis (97).

Again, we used 96 well assays to look for changes in inflammatory genes downstream of NF- $\mathrm{kB}$. While we only used two mice per group, as above, we noted IL17 expression was nearly undetectable in PBS Sham (negative control) mice versus infected mice and lower RANK-L expression in AMD3100-treated, infected mice versus the other groups. Relatively lower gingival expression of inflammatory mediators, including molecules implicated in bone resorption (IL-6, IL-17 and RANK-L), was demonstrated in AMD3100 treated, $P$. gingivalis- infected mice in contrast to infected mice who received no treatment. AMD3100 treatment provided a protective effect against development of destructive periodontal inflammation by preventing establishment of $P$. gingivalis infection and the resultant increase in commensal flora. 
AMD3100 infusion effectively halts progression of periodontal bone loss two weeks after induction of disease.

AMD3100 treatment resulted in eradication of $P$. gingivalis from the oral tissues and protection from $P$. gingivalis-mediated bone loss in the context of prophylaxis (See Figure 10), suggesting the drug could be an excellent candidate as a therapeutic agent in periodontal disease. To test this hypothesis, mice were inoculated with $10^{9} P$. gingivalis or sterile PBS as in previous oral infection model experiments. Two weeks after the final inoculation mice were implanted with mini osmotic pumps designed to release drug for two weeks containing $10 \mathrm{mg}$ AMD3100 in $0.1 \mathrm{ml}$ PBS or PBS only. On Day 60 mice were euthanized to evaluate periodontal disease and host inflammatory status in the gingival tissues. We elected to begin therapy two weeks after the final inoculation because our group previously demonstrated that bone loss in $P$. gingivalis- infected mice is statistically significant versus sham infected mice at that time. Two weeks into the oral infection model corresponds theoretically to early stages of periodontal disease when bone loss is not yet extensive. This stage of the oral infection model is a window in which it would be maximally efficacious for patients already demonstrating disease to initiate treatment. Indeed, systemic AMD3100 therapy post induction of periodontal disease halted progression of bone loss (See Figure 12). Some isolated pockets of bone loss were noted in AMD3100 treated, $P$. gingivalis infected, mice, particularly around the third molar (Figure 12) as bone resorption experienced in periodontitis is non-reversible (8) (143). Overall, however, treated mice demonstrated significantly less alveolar bone loss than untreated ice when challenged with $P$. gingivalis, indicating an effective halt in disease progression upon initiation of AMD3100 therapy $(\mathrm{p}<0.01)$. Taken together the 
above studies indicate the $P$. gingivalis- CXCR4 interaction as a promising therapeutic target and treatment with antagonists such as AMD3100 as a possible strategy for halting progression of periodontal disease.

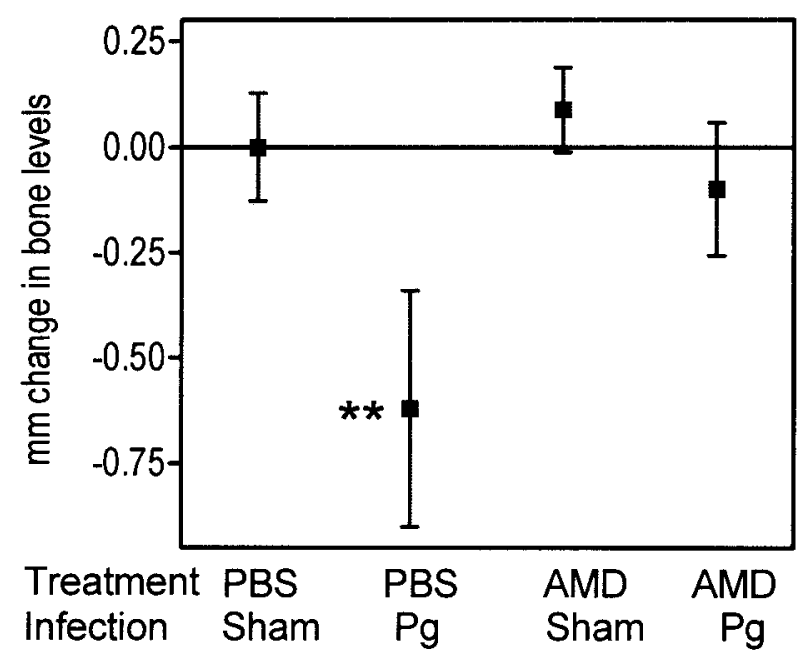

Figure 12. Therapeutic treatment with AMD3100 halts $P$. gingivalismediated periodontal bone loss. BALB/c mice (10-12 weeks of age) were orally infected with $P$. gingivalis as described in Methods. Two weeks after the last inoculation with $P$. gingivalis, the mice were administered AMD3100 (or PBS control) via osmotic minipumps. Data are means \pm SD $(n=5$ mice per group); negative values indicate bone loss in $P$. gingivalis-infected mice relative to sham-infected controls. ${ }^{* * P}<0.01$ compared to control and all other experimental or groups. AMD, AMD3100; Pg, P. gingivalis.

\section{Discussion}

It has recently been proposed that periodontitis fundamentally represents a disruption of host microbe homeostasis in the periodontal tissue (46). This notion is 
supported by mechanistic studies in the mouse model of periodontitis: Alterations either in the composition of the periodontal microbiota or in local regulatory mechanisms that control leukocyte recruitment can cause disruption of periodontal homeostasis which, in turn, may lead to uncontrolled inflammation and periodontal bone loss (97).

P. gingivalis benefits from modulating the inflammatory response. Through interactions with several receptors and elements of the innate immunity $P$. gingivalis selectively allows inflammation beneficial to its survival to carry on while other key aspects of immunity are shut down. Induction of subversive crosstalk between innate immune receptors seems to be a favorite mechanism of $P$. gingivalis. We have previously shown that $P$. gingivalis induces inflammation via C5aR-TLR2 crosstalk which is likely to cause collateral tissue damage (inflammatory periodontal bone destruction) (154). We now demonstrate in a preclinical model that $P$. gingivalis participates in CXCR4 modulation of TLR2 antimicrobial signaling. $P$. gingivalis manipulates both sets of receptors by inducing their collection into close physical proximity $(103,276)$, and as a result TLR2-mediated antimicrobial signaling is inhibited. Perhaps $P$. gingivalis' multifactorial attack upon TLR2 antimicrobial signaling betrays the important role of this Toll-Like receptor to success of the pathogen.

Currently, there is an urgent need to develop innovative adjunctive therapeutic strategies in chronic periodontitis (92). Indeed, conventional periodontal treatment is often not sufficient by itself to treat destructive inflammation and, moreover, this oral disease appears to increase the patients risk for atherosclerosis, diabetes, chronic obstructive pulmonary disease, adverse pregnancy outcomes, and possibly rheumatoid arthritis (80) (143) (159) (206) (261). 
One approach to treating periodontitis is to counteract immune evasion or subversion by major periodontal pathogens. Periodontal and other microbial pathogens preferentially target and corrupt innate immunity (70) (96). Subversion of innate immunity may additionally undermine the overall host defense, given the instructive role of the innate response in the development of adaptive immunity (201). Therefore, understanding the molecular mechanisms whereby microbial pathogens interact with and exploit innate immune receptors may facilitate the development of intervention approaches to inhibit immune evasion and disease pathogenesis.

In this study, I took advantage of our group's earlier findings that implicated CXCR4 in $P$. gingivalis immune subversion (103) and showed that a CXCR4 antagonist can protect against $P$. gingivalis-induced periodontal bone loss in both preventive and therapeutic models. The expression of CXCR4 has been shown to be elevated in chronic periodontitis compared to healthy gingiva (122) (126). However, it is uncertain whether CXCR4 plays a role in periodontal pathogenesis. In this regard, the above study is the first to causally link CXCR4 to periodontitis in a preclinical model. The protective effect of AMD3100 against $P$. gingivalis-induced periodontitis may be attributed, at least in part, to the blockade of the host receptor, CXCR4, which is apparently important to survival of $P$. gingivalis in the periodontium. This conclusion is based on the ability of AMD3100 to enhance the killing of $P$. gingivalis by leukocytes (103) and, moreover, to mediate its elimination from the periodontal tissue in vivo (this study).

The natural ligand for CXCR4 is the chemokine stromal cell-derived factor-1 (SDF-1), although CXCR4 also functions as a co-receptor with CD4 for the HIV-1 envelope gp120/gp41 complex (195). In this context, AMD3100, which can also potently 
antagonize human CXCR4 (106), was shown to block CXCR4-dependent HIV-1 entry and replication (49) (60). Moreover, AMD3100 can protect against several CXCR4mediated pathophysiological conditions, such as rheumatoid, infectious, allergic, and malignant diseases, both in humans and in experimental mouse models (49) (113) (158, 168). This study adds periodontitis to the list of potential therapeutic applications of AMD3100.

The ability of AMD3100 to inhibit periodontitis by apparently targeting $P$. gingivalis (as this antagonist did not directly influence the periodontal microbiota) has a theoretical basis on the keystone pathogen concept. According to this concept, $P$. gingivalis- at low colonization levels- impairs innate immunity in ways that alter the growth and development of the entire biofilm resulting in dysbiosis that triggers periodontal disease, at least in the mouse model (97). On the other hand, neither the indigenous murine microbiota alone, nor $P$. gingivalis by itself (i.e., in germ-free mice) can initiate pathologic bone loss in young healthy mice (97). In the presence of AMD3100, $P$. gingivalis failed in this study to support the overgrowth of the total periodontal microbiota which is required for induction of periodontitis. AMD3100 was effective against periodontitis even when the disease was already in progress, suggesting that the continuous presence of $P$. gingivalis, albeit at very low levels compared to the total bacterial counts, is strictly required to sustain dysbiosis and disease progression.

In humans, $P$. gingivalis is also a quantitatively minor component of subgingival pathogenic biofilms, despite its high prevalence, and is associated with progressive bone loss in periodontitis patients (38) (63) (138) (184) (184). It should be noted that adult chronic periodontitis is associated with multiple etiologies and disease 
modifiers (93) (134) (143) (206) and, therefore, the presence of $P$. gingivalis may be just one of several etiologic factors. Nevertheless, under favorable environmental conditions, this bacterium has the potential to act as a keystone pathogen to transform an otherwise symbiotic microbiota into a dysbiotic microbial community that can cause periodontitis (97).

In summary, my results establish a role for CXCR4 in $P$. gingivalis-induced periodontitis and show that CXCR4 antagonism by AMD3100 confers protection against the disease through an antimicrobial effect. Given that AMD3100 has been shown to be safe in humans (227), this and other CXCR4 antagonists could find application as adjunctive therapeutics for the treatment of human periodontitis. 


\section{CHAPTER FOUR: CXCR4 BLOCKADE ENHANCES CLEARANCE OF $P$. GINGIVALIS}

\section{Introduction}

The oral cavity is an impressive and elegant example of the ability of innate immune cells to interact with a staggering number of constant commensal microbial signals and still parse out the pathogenic signals among them. However, it is also a critical example of the clinical repercussions of innate immunity gone wrong. In periodontal disease, host immune signaling is hijacked by pathogens such as $P$. gingivalis, causing specific repression of host immunity that would clear the bacteria, while unproductive aspects of the response are allowed to proceed, such as the induction of inflammatory and bone resorptive cytokines.

Gram-negative, anaerobic bacteria are typically the instigators of periodontal disease, given opportunity to step beyond the boundaries of the commensal lifestyle by poor oral hygiene, and the resulting tissue destruction can further provide a route of invasion for oral pathogens beyond the gingival epithelium into the systemic circulation and beyond. In this situation, bacterial products such as endotoxin can induce inflammatory cytokine production in distal areas of the body to incite pathogenic 
processes, for example, atherosclerotic plaque formation and thrombogenesis (270) (249) (277). Upon repeated challenge, local cytokine receptors within the periodontium can become saturated, allowing cytokines to evade clearance and spill into the systemic circulation $(196,277)$.

CXCR4 is a G-protein-coupled chemokine receptor possessing seven transmembrane regions which specifically recognizes CXCL12 (SDF-1), although it is recently shown that SDF-1 does not specifically interact with CXCR4 but also demonstrates interaction with CXCR7. CXCR4 is found predominantly on leukocytes and in response to SDF-1 activates MAPK1/MAPK3 signaling by increasing intracellular calcium ion levels. It has been recently shown that CXCR4 recognizes extracellular ubiquitin as a natural agonist and in response to extracellular ubiquitin CXCR4 promotes intracellular $\mathrm{Ca}(2+)$ flux and reduces cAMP levels in THP1 cells (223).

CXCR4 is a co-receptor for CD4 to facilitate HIV entry into host cells and is highly expressed on breast cancer cells. Mutations in CXCR4 have been associated with WHIM (warts, hypogammaglobulinemia, infections, and myelokathexis) syndrome.

In addition to mediating chemotaxis of immune cells such as monocytes and $\mathrm{T}$ cells, SDF-1 can be found on stromal cells of the bone marrow, which constitutively express the CXC chemokine(187) $(22,29)$. Here SDF-1 plays a critical role in cell survival, proliferation, directed migration, and engraftment $(3,4,146,155,178)$. CXCR4, consequently, is expressed upon hematopoietic progenitor cells and these cells are anchored into the stroma via the CXCR4-SDF-1 interaction $(3,178)$. Since this anchoring is reliant upon the SDF-CXCR4 interaction, AMD3100 was discovered to interrupt and mobilize these progenitors, notably CD34+ hematopoietic progenitor cells (116). 
Gene deletion of CXCR4 or SDF-1 leads to perinatal death in mice, the animals succumbing to hematopoietic, cardiac, gastrointestinal and cerebellar abnormalities (188) (160). However, mice in which the genes are conditionally knocked out after the critical development window survive and can be used for studies involving the role of CXCR4SDF-1. We hypothesized that, although AMD3100 acts as an agonist upon CXCR7, CXCR4 was more likely to be the functional target causing protection from periodontitis as $P$. gingivalis is known to interact with CXCR4. The CXCR4 conditional knock out mice used in our study were developed on a B6 background using beta-actin-cre to select and knockout all or most of CXCR4.

Previously it was shown in come cancer lines, among them squamous cell carcinoma, that osteoblasts can produce SDF-1 and that this expression can induce IL-6 production. AMD3100 inhibited this SDF-1 induced IL-6 expression (252). While these results were found in an abnormal cell line we wondered whether SDF-1 signaling could play any, albeit a secondary, role in $P$. gingivalis infection. It could be that $P$. gingivalis acts as a surrogate SDF-1-like signal, inducing IL-6 expression through activation of NF$\kappa B$. We therefore assayed several inflammatory cytokines such as IL- 6 and TNF- $\alpha$ to track the effect of CXCR4 deficiency in mice which were sham and $P$. gingivalis infected.

While RT-PCR has increasingly become a reliable and, in $P$.gingivalis' case in the Baker oral model, necessary method of detecting and quantifying bacteria, we wanted to know more about the kinetics of the AMD3100 effect on P. gingivalis, as well as to show definitively that AMD3100 is quickly lethal to the pathogen. Therefore we decided to use the subcutaneous chamber model to determine in vivo bacterial viability in the 
presence of the compound and to look at how AMD3100 treatment changes to host dynamic in a microaerophilic space representative of the deep gingival pocket (79). The chamber itself is a titanium coil which is implanted subcutaneously dorsolateral of the mid-spine. The coil becomes encapsulated by connective tissue, creating a hypoxic interior lumen (85). This experimental scenario allows for studying the interactions between bacteria, compounds, and the host response in a close, temporal way. Since cytokines, host cell influx and viable bacterial counts can all be taken from the chamber, one can tell exactly what the host immune response less than an hour after introduction of the bacteria $(30,85,175)$. Therefore this model was ideal to confirm our hypothesis that CXCR4 blockade with AMD3100 leads to a quick elimination of $P$. gingivalis by the host.

Deficiency in other receptors involved in $P$. gingivalis-mediated subversive crosstalk (C5aR, TLR2, CR3), protects against periodontal bone loss. Use of C5aRdeficient mice elucidated the role of C5aR signaling in $P$.gingivalis immune evasion, including the induction of hallmark inflammatory cytokines in periodontal destruction (82) (154). CR3 was likewise shown to be an exploited receptor by $P$. gingivalis using CR3-deficient mice (94). CR3 was necessary for survival of $P$. gingivalis in a peritoneal lavage model, along with reduction in Il-12p70 and IFN- $\gamma$ levels.

With these studies we sought to confirm the specific role of CXCR4 in periodontal disease induction by $P$. gingivalis. We show that CXCR4 deficiency indeed changes the dynamic of the host response to $P$. gingivalis, though attempts to discern whether this effect is necessarily protective were initially mixed. We show that the overall cytokine profile of CXCR4 deficient mice infected with $P$. gingivalis is largely 
comparable to that of $P$. gingivalis-infected mice treated with AMD3100. We also show using the subcutaneous chamber model that AMD3100 treatment induces a stronger, targeted immune response to $P$. gingivalis, necessitating accelerated clearance of the pathogen by two hours post inoculation. No effect was observed when AMD3100 was co-injected with a fellow gram negative oral anaerobe of $P$. gingivalis, $F$. nucleatum. Viable bacterial counts of $F$. nucleatum were unaffected, showing that the effect of AMD3100 on viability is at least to some extent specific to $P$. gingivalis, for $F$. nucleatum is a bacterium which, given its location and relationship to $P$. gingivalis, is highly likely to be affected by non-specific treatments targeting $P$. gingivalis.

\section{Results}

AMD3100 inhibits $P$. gingivalis-induced PMN recruitment but promotes killing of $\boldsymbol{P}$. gingivalis. Systemic treatment with AMD3100 prevents periodontal disease in a prophylactic context and halts disease progression in mice when administered therapeutically and according to the PCR data likely leads to eradication of the pathogen. However, direct culture of $P$. gingivalis is generally impractical from the Baker Model so we decided to use the subcutaneous chamber model to gain a more mechanistic insight as to the effect of AMD3100 administration specifically on $P$. gingivalis survival and leukocyte migration to the site of infection. To this end we employed the subcutaneous chamber model to test $P$. gingivalis viability with AMD3100 treatment. As a baseline control for cytokine analysis and to assure sterility of the chambers prior to $P$. gingivalis inoculation we drew chamber exudates immediately prior to infection. We diluted and plated these exudates for $\mathrm{CFU}$ and analyzed them for key cytokines using EIA and 
Luminex. The actual destruction associated with periodontal disease is caused by uncoupled osteoclastogenesis in response to constantly infiltrating leukocytes (86), therefore we additionally quantified leukocyte infiltration into the chamber to determine if AMD3100's efficacy could be attributable to its effect on leukocyte trafficking.

We found that concurrent AMD3100 treatment with inoculation of $P$. gingivalis leads to a ten-fold enhancement of $P$. gingivalis killing at 2 hours post injection and over a hundred fold increase in killing by 24 hours (See figure 13). We also found that, although AMD3100 promotes $P$. gingivalis killing, it inhibits leukocyte recruitment into the subcutaneous chamber. However, when AMD3100 is injected alone into chambers it induces a moderate amount of leukocyte recruitment, ostensibly due to its effects on granulocyte precursor and CD34+ HSPC emigration from the bone marrow.

Inhibition of intracellular crosstalk pathways instigated by $P$. gingivalis enhances the ability of the host immune system to eradicate the pathogen. We, therefore, reasoned that CXCR4 blockade must reduce $P$. gingivalis' ability to subvert TLR2 mediated inflammation, leading to increased efficiency of neutrophil uptake/killing of the bacteria in the chamber at the earlier time-point and therefore less recruitment signal at the later time-point corresponding with the significantly lower number of viable bacteria.

Taken together, these data suggest that AMD3100 treatment leads to enhanced killing of $P$. gingivalis early in infection by enhancing the ability of recruited leukocytes to rapidly clear the infection through TLR2 mediated antimicrobial inflammation. A product of this efficiency is lowered PMN recruitment probably due to chemotactic signals indicating successful reduction of infection. 
A.

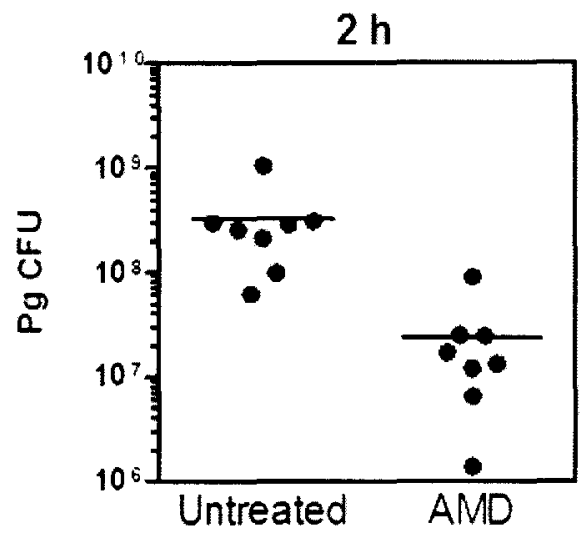

B.

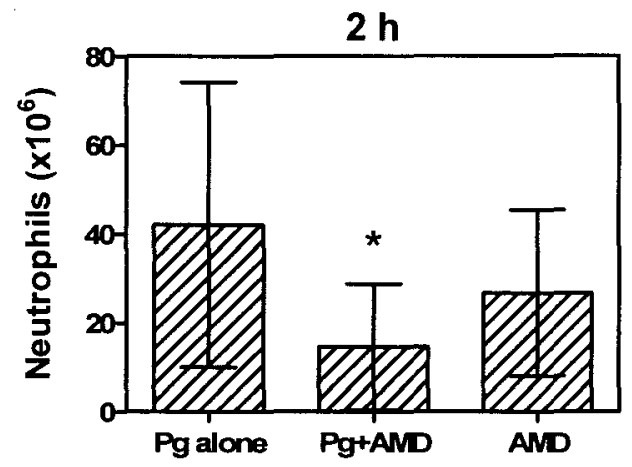

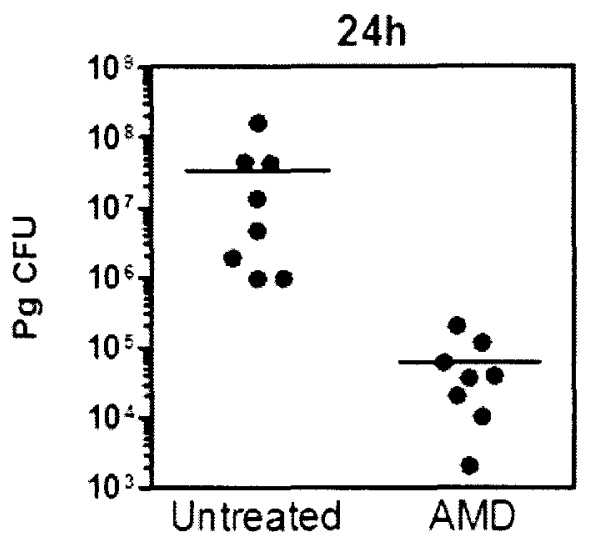

$24 \mathrm{~h}$

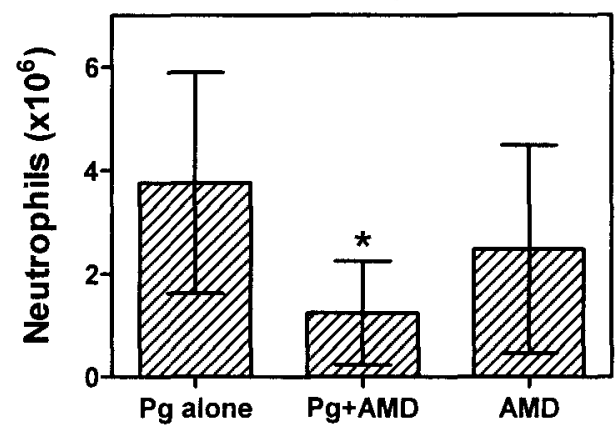

Figure 13. AMD3100 inhibits $P$. gingivalis-induced PMN recruitment but promotes killing of $\boldsymbol{P}$. gingivalis. BALB/c mice (10-12 weeks of age) were implanted with titanium coil chambers subcutaneously. After a ten day healing period, exudates were drawn from the titanium chambers to verify sterility prior to experimental infection as well as analyze baseline amounts of leukocytes and inflammatory markers. Mice were infected or treated as described in Methods. The mice were euthanised 24 hours after injection. Exudates were plated for $P$. gingivalis CFUs and leukocytes were counted using a hemocytometer. Data are means $\pm \mathrm{SD}$ ( $n=5$ mice per group). ${ }^{* *} P<0.01$ compared to control and all other experimental groups. AMD, AMD3100; Pg, P. gingivalis. 


\section{AMD3100 does not affect $F$. nucleatum-induced PMN recruitment or $F$. nucleatum}

killing. Systemic administration of AMD3100 causes a transient leukocytosis. General as it is, the leukocytosis is comprised predominantly of circulating neutrophils (155). This, coupled with our data indicating the enhanced killing resultant of co-AMD3100 administration in the chamber model, made us wonder if we were observing a trend generally true for all bacteria. Specifically, greater numbers of roaming granulocytes throughout the body may pose a greater threat to any bacteria placed within the chamber. To test this hypothesis we inoculated subcutaneous chambers with $F$. nucleatum either co-injected with sterile PBS or AMD3100.

We found that, while $F$. mucleatum generally does not survive the subcutaneous chamber as well as $P$. gingivalis, AMD3100 co-treatment had no significant effect on viable $F$. nucleatum recovery from chambers (See Figure 14). We also noted that leukocyte recruitment in $F$. nucleatum AMD3100 treated chambers was similar to recruitment in AMD3100 treatment alone or P. gingivalis and AMD3100 injected mice compared to their corresponding baseline leukocyte counts.

Taken together, these data indicate that AMD3100 does not affect other gram negative oral anaerobes and that the observed clearance of $P$. gingivalis is probably due to uncoupling of the subversive CXCR4-TLR2 crosstalk. With TLR2 more able to initiate the appropriate downstream inflammatory pathways, infiltrating neutrophils can clear the pathogen more efficiently, leading to a decreased recruitment of neutrophils into the infected area. 
A.

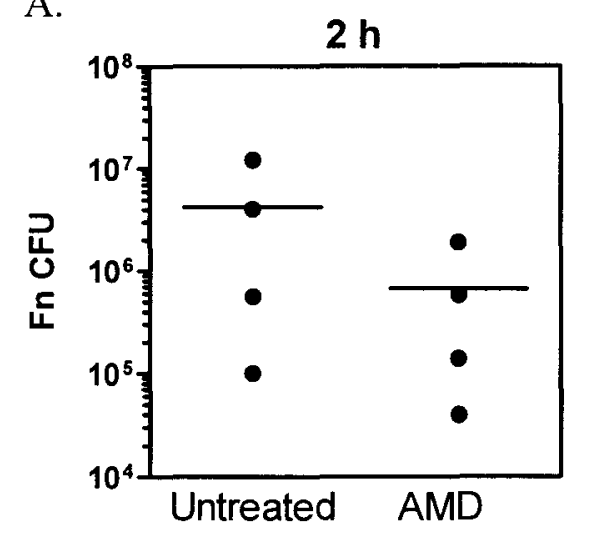

B.

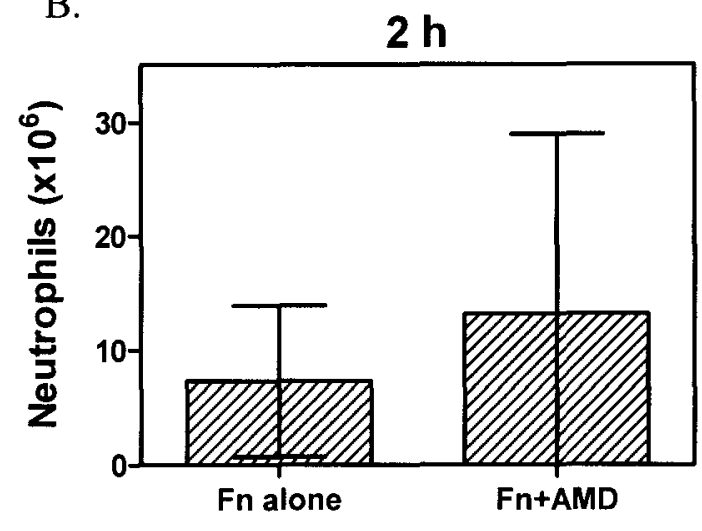

Figure 14. AMD3100 does not significantly affect $F$. nucleatum-induced PMN recruitment or $\boldsymbol{F}$. nucleatum killing. BALB/c mice (10-12 weeks of age) were implanted with titanium coil chambers subcutaneously. Exudates were drawn from the titanium chambers to verify sterility prior to experimental infection as well as analyze baseline amounts of leukocytes and inflammatory markers. Mice were infected or treated as described in Methods. The mice were euthanised 24 hours after the inoculation/treatment. Exudates were plated for $F$. nucleatum CFUs and leukocytes were counted using a hemocytometer. Data are means $\pm \mathrm{SD}$ ( $n=5$ mice per group). ${ }^{* * P}<0.01$ compared to control and all other experimental groups. AMD, AMD3100; Fn, F. nucleatum.

\section{Host Response to treatment with AMD3100 in the subcutaneous chamber model}

We decided to look more closely at the cytokine response within the subcutaneous chamber model in response to $P$. gingivalis infection and AMD3100 treatment. We observed a slight increase in TNF- $\alpha$ production in response to $P$. gingivalis infection as compared to baseline controls. AMD3100 treatment alone did not elicit a TNF- $\alpha$ response, however, after repeated analysis of chamber exudates using the Luminex Bead 
Assay, we observed a reliably significant synergistic increase in TNF- $\alpha$ at two hours post injection in mice infected with $P$. gingivalis and injected with AMD3100, corresponding to an allowance of the TLR2 NF- $\mathrm{B}$ antimicrobial pathway activation. While AMD3100 treatment alone induced production of IL- 6 in the chamber nearly ten fold beyond the amount of IL- 6 found in the baseline samples, $P$. gingivalis infection caused an over ten fold decrease of IL-6 in the chamber and co-injection of AMD3100 with $P$. gingivalis into chambers did not cause a significant change in IL-6, an interesting reversal of our RT-PCR findings in the gingivae of orally infected mice. As opposed to our RT-PCR findings in the chronic oral infection model, these findings at two hours post infection in the subcutaneous chamber model indicate AMD3100 treatment doesn't change the effect of $P$. gingivalis on IL-6 levels, but does cause a productive increase in TNF- $\alpha$. Additionally we noted an approximately two fold increase of IL-10 in mice injected with both the pathogen and compound as compared to $P$. gingivalis infected mice (See Figure 15).

MIP-1 $\alpha$ and M-CSF were also increased in AMD3100 treated, P. gingivalis infected mice at two hours compared to mice infected alone. The increase in Mip-1 $\alpha$ indicates an increase in immediate inflammation in response to the pathogen and possibly an induction of superoxide production by neutrophils, one of the leukocyte's best weapons against $P$. gingivalis infection (235). Increases in M-CSF, though transient, could be an indicator of AMD3100's effect on CXCR4 signaling, as increased intracellular levels of cAMP inhibit the synthesis of M-CSF and CXCR4 blockade should inhibit cAMP-dependent PKA signaling (103) (292). M-CSF production indicates progression of the inflammatory process and the host direction of monocyte 
differentiation into macrophages and macrophage chemotaxis to the infected area. Our data show, compared to mice with subcutaneous chamber implants inoculated with $P$. gingivalis alone, that

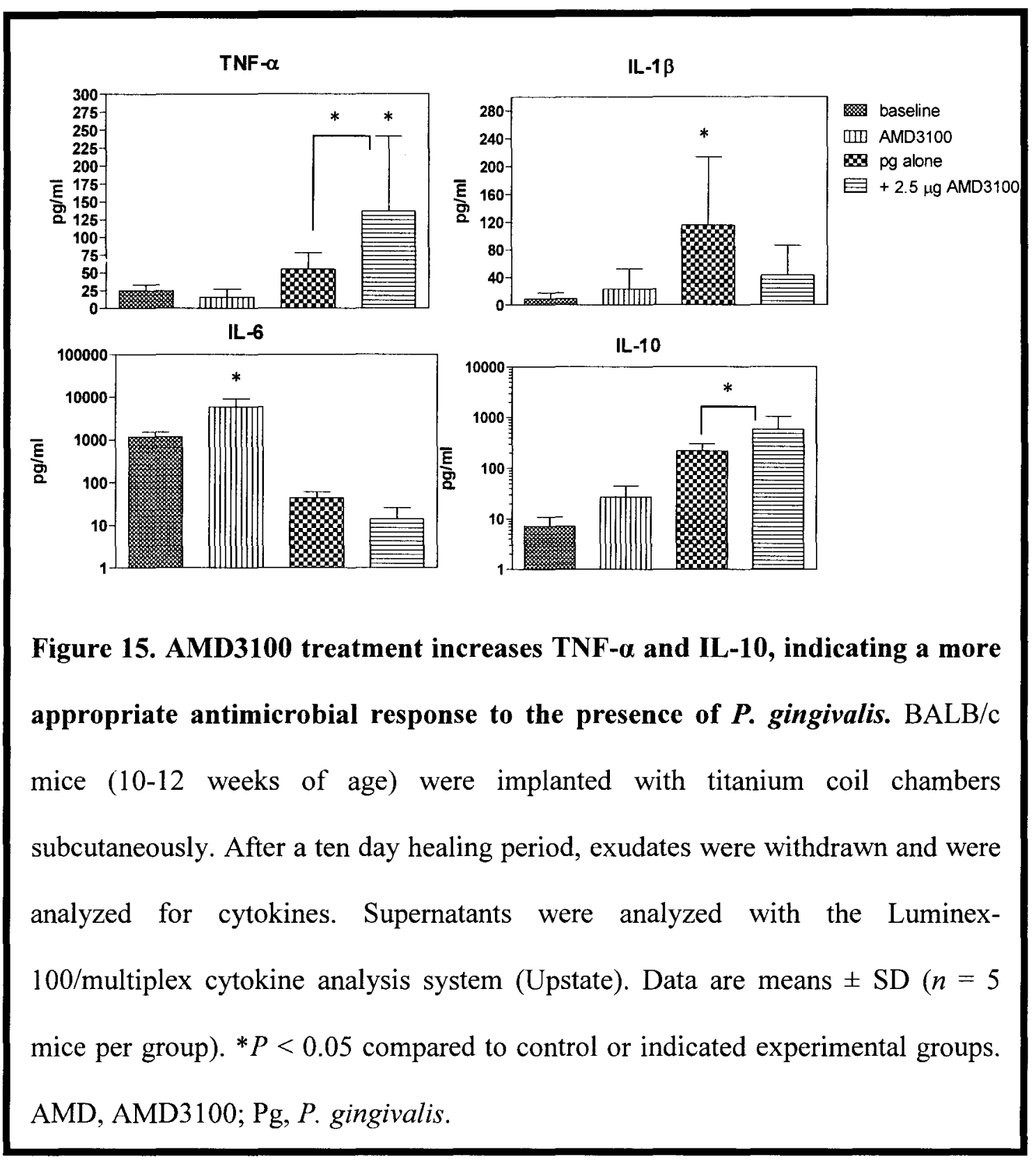



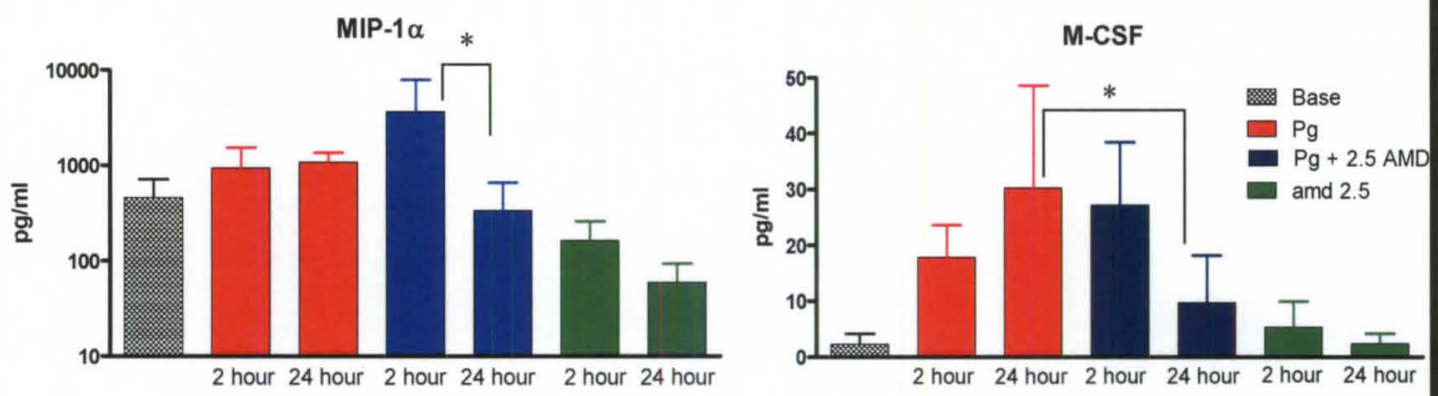

Figure 16. AMD3100 treatment leads to an ultimate suppression of MIP-1a, indicating a resolution of inflammation, decreased superoxide release by neutrophils. BALB/c mice (10-12 weeks of age) were implanted with titanium coil chambers subcutaneously. After a ten day healing period, exudates were withdrawn and were analyzed for cytokines. Supernatants were analyzed with the Luminex-100/multiplex cytokine analysis system (Upstate). Data are means \pm SD ( $n=5$ mice per group). ${ }^{*} P<0.01$ compared to indicated experimental groups. AMD, AMD3100; Pg, P. gingivalis.

co-injection of AMD3100, along with enhanced eradication of the bacteria, causes a decrease in Mip-1 $\alpha$ correspondent with clearance of the bacteria by 24 hours (See Figure 16). Thus the increases in these inflammatory markers are only transient in AMD3100 injected mice and demonstrate an initiation of productive inflammation resolution, as the viable bacteria numbers are being eradicated. Taken together, our observations gleaned from the subcutaneous chamber model indicate that the host response is enabled by the blockade of CXCR4 very early in $P$. gingivalis infection, allowing the host to proceed with a productive inflammatory response that works effectively to clear the pathogen. 


\section{Deficiency of CXCR4 or TLR2 differentially affects the inflammatory response to $P$. gingivalis infection in mice.}

P. gingivalis-fimbriae interact directly with CXCR4 to interfere with TLR2mediated NF- $\mathrm{kB}$ signaling. This in turn causes a down-regulation of inflammatory mediators such as TNF- $\alpha$, IL-6 and up-regulation of anti-inflammatory IL-10 (103) in mouse macrophages/human monocytes. AMD3100 treatment prevents this interaction and subsequently protects the host against $P$. gingivalis-mediated periodontal disease (Figures 10-13).

Deficiency of TLR2 was previously shown in both C57 B6 mice(30) and Balb/c mice (154) to be protective against $P$. gingivalis mediated bone loss. This, coupled with the knowledge that AMD3100 treatment halts bone loss, led us to question if deficiency of CXCR4 would likewise demonstrate protection against $P$. gingivalis.

We tested the ability of $P$. gingivalis to initiate bone destruction in CXCR4 conditional knockout mice compared to their wild-type counterparts. CXCR4-deficient mice die perinatally and so their use in in vivo periodontitis models is precluded. We verified successful deletion of CXCR4 in periodontal tissues via RT-PCR (See Figure 18). We infected each group with $P$. gingivalis or vehicle 5 times and euthanized mice on day 60 .

The effect of $P$. gingivalis infection upon alveolar bone in CXCR4 knockout mice compared to corresponding wild-types was inconclusive (See Figure 17A) perhaps due to the small size of each group. Both infected and sham-infected CXCR4 deficient mice did, however, demonstrated elevated transcriptional levels of several inflammatory molecules, albeit to various degrees. 
As in mice administered AMD3100 for several days, mRNA levels for inflammatory cytokines in the gingivae were elevated in CXCR4 deficient, sham-infected mice. This indicates the importance of CXCR4 signaling in regulation of proinflammatory cytokine expression, however given these mice did not suffer bone loss, high mRNA levels of inflammatory cytokines alone is not indicative of disease. TNF- $\alpha$ and RANK-L were most notably down regulated in CXCR4 deficient, $P$. gingivalisinfected mice as compared to their wildtype counterparts. These data agree fundamentally with our previous data showing $P$. gingivalis induces crosstalk between TLR2 and CXCR4 to inhibit TLR2-mediated inflammation (103).

CXCR4 deficient mice, while not suffering the extent of periodontal bone loss seen in their wild-type counterparts, did demonstrate a trend of inflammatory upregulation as compared to the downregulatory trend noted in TLR2 deficient mice. The enhanced ability of the host to quickly eliminate $P$. gingivalis when it cannot recognize CXCR4 is more important than the ability to modulate inflammation over a longer period of time. 

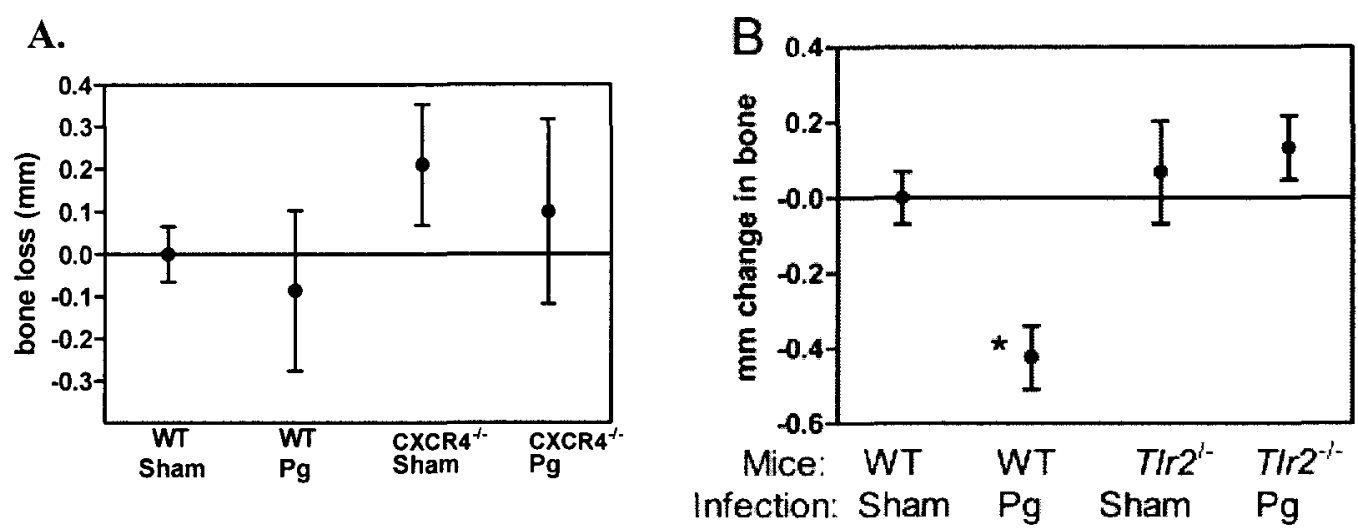

C.

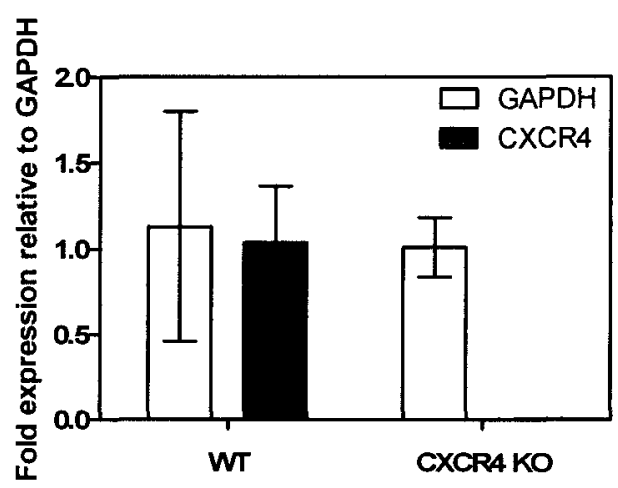

Figure 17. Deficiency of TLR2, but not necessarily CXCR4, protects orally infected mice against alveolar bone loss. A. C57/B6 CXCR4 conditional knockout mice were treated according to the Baker Model of Oral infection. Data are means $\pm \mathrm{SD}\left(\mathrm{n}=3\right.$ mice), ${ }^{*} \mathrm{p}<0.05$ compared to all other groups. B. Balb/c TLR2 deficient mice were treated according to the Baker model. Data are means $\pm \mathrm{SD}$ (n $=5$ mice), ${ }^{*} \mathrm{p}<0.05$ compared to all other groups. C. Confirmation of CXCR4 knockout in mice prior to use. 


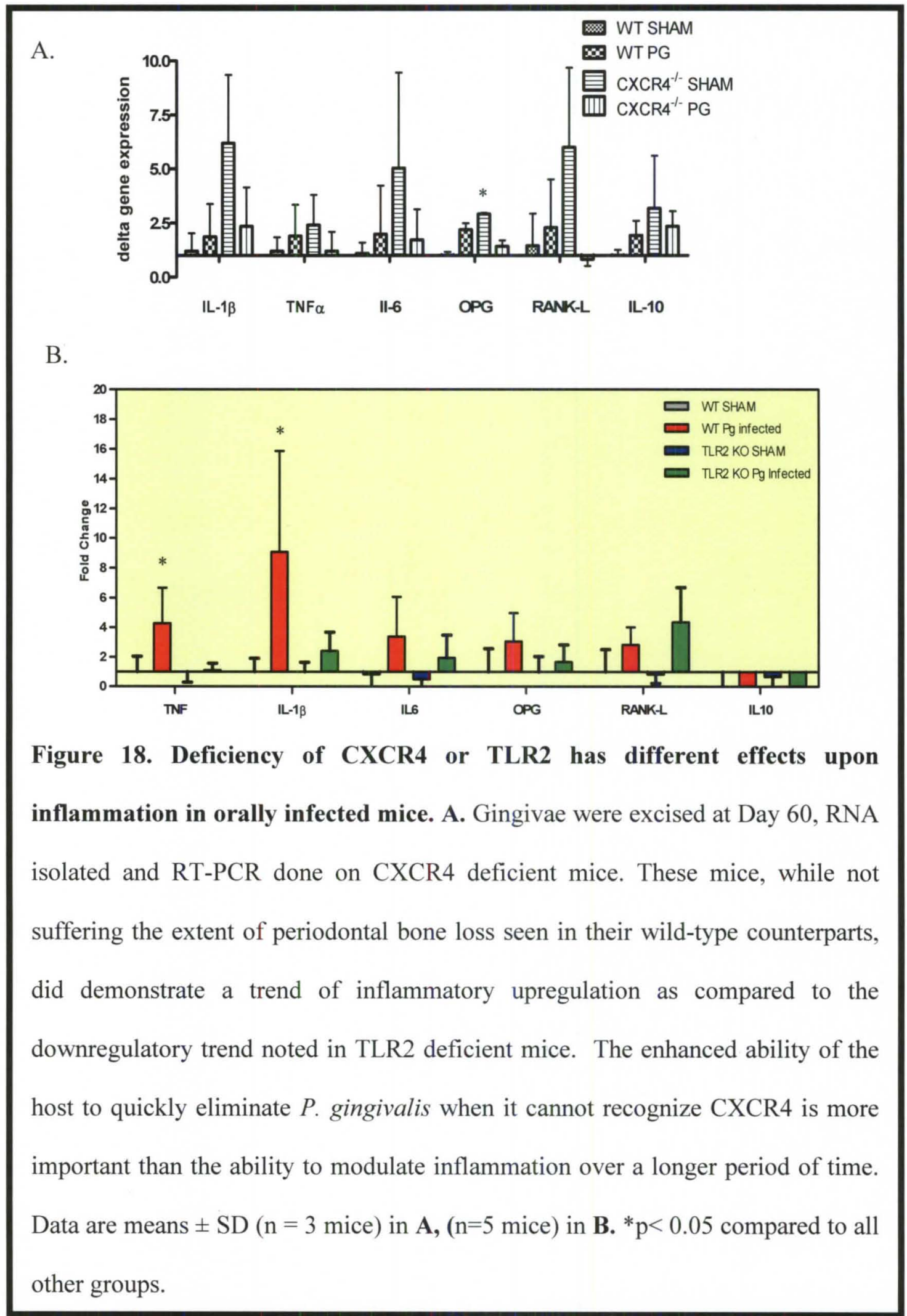




\section{Discussion}

In this study we addressed whether CXCR4 blockade has a direct benefit in controlling $P$. gingivalis infection in the chamber model. We found that recognition of CXCR4 by $P$. gingivalis indeed plays an integral part in ability of the pathogen to survive in the oral cavity. Blockade of this recognition led to clearance of the pathogen and consequent halt to bone resorption in both preventative and therapeutic context.

This effect was shown to be specific at least to a certain degree as AMD3100 treatment had no survival effect upon $F$. nucleatum, a gram negative member of the "orange complex" oral bacteria. Like our data at earlier time-points in the oral model of infection, in the subcutaneous chamber we saw higher protein levels of TNF- $\alpha$ in response to AMD3100 injection with $P$. gingivalis. These findings indicate strongly that TLR2 antimicrobial signaling is restored upon blockade of CXCR4.

In the absence of CXCR4 signaling in the chamber model we noted that, as opposed to the oral infection model, at two hours post injection AMD3100 treatment did not effect $P$. gingivalis repression of Il-6 levels below the baseline level. This suggests that effects of IL-6 in the oral infection model are either temporal in nature, perhaps driving later inflammatory damage, or is an outcome of chronically dysregulated $P$. gingivalis-induced inflammation, perhaps via dysregulation of SOCS3 feedback inhibition. It is worthy to note that Il-6 protein levels are elevated in chamber baseline exudates as compared to the gingivae tissues, such that the dynamics of IL- 6 feedback regulation are different in the chamber versus the oral cavity. 
Regarding our host response data from the chamber model, Nakajima and coworkers in their report "Periodontitis-associated up-regulation of systemic inflammatory mediator level may increase the risk of coronary heart disease" showed that patients with periodontal disease have increased levels of IL-6 but decreased levels of TNF- $\alpha$ and our chamber model results reflect these established observations in humans. TNF- $\alpha$ has been described as a more "protective" cytokine regarding early periodontal inflammation as opposed to IL-6, which, when upregulated, generally corresponds to uncoupled inflammatory periodontal destruction. It is important to remember, however, that without some appropriate inflammation, the host will fail to clear the bacteria and disease will manifest due simply to chronic infection. Therefore inflammation has to happen in order to clear the pathogen, but it must be appropriate and carefully regulated. Specific subversion by $P$. gingivalis of TLR 2 via crosstalk with other receptors plays a critical role in throwing the inflammatory response out of balance $(86)(9)(11,39)(115)$ $(53,76)$.

Since Mip- $1 \alpha$ is a strong chemoattractant of both monocytes and T cells, we interpreted the decrease of this cytokine by 24 hours in $P$. gingivalis infected, AMD3100 treated mice as an indicator of enhanced resolution of the infection. $P$. gingivalis-infected mice showed no reduction in Mip-1 $\alpha$ levels relative to infected mice co-injected with AMD3100 by 24 hours (254) (140). It is worthy to note that Mip-1 $\alpha$ is also a proosteoclastogenesis cytokine the induction of which helps in the maturity of osteoclastprecursors into functional osteoclasts (239). Along with the other key proinflammatory cytokines involved with the periodontal disease process, macrophage colony stimulating factor and MCP-1 are both involved with regulation of bone metabolism. M-CSF 
contributes to activation and differentiation of quiescent osteoclasts. The functions of these cytokines make them useful in determining how theoretically prone to bone destruction the subcutaneous chamber environment becomes in response to infection or treatment. Both these molecules are decreased significantly in response to AMD3100 treatment in infected mice from oral infection or chamber model experiments, suggesting that AMD3100 treatment, through enhancing host clearance of the bacteria, ameliorates conditions leading to uncoupling the resorption/regeneration balance within the alveolar bone (226).

To address the sometimes increased levels of TNF- $\alpha$ in both our gingivae RTPCR as well as the chamber exudates, it is useful to consider the philosophy reviewed by Graves and coworkers that induced TNF- $\alpha$ in gingivitis is actually protective as blocking the cytokine leads to increased bone loss $(39)(76,86)$. The overall message to take from these results which seemingly contradict common reason is that oral health is a sort of homeostasis in which the amount of microbe-induced inflammation is not too extensive, but also not too gentle. If the microflora is not kept in check, a pathogenic shift in the oral biofilm becomes increasingly likely, but if the inflammatory response is overly abundant, the host homeostasis is disrupted, notably the coupling of bone resorption and restructuring. In the situation of a chronic, non-productive, highly chemotactic inflammation, resorptive signals and processes outrun the restorative processes and periodontitis is the result (86).

The distinct and arguably proinflammatory profile caused by long term systemic AMD3100 administration was paralleled in conditional CXCR4 KO mice. We observed upregulation of several proinflammatory genes with no corresponding bone loss in sham 
infected mice. CXCR4 deficient mice have elevated amounts of inflammatory molecules in their gingivae as compared to TLR2 deficient mice. While the difference in background of these two knockout mice precludes a direct comparison of their respective immune responses, in the context of comparing differences in gene expression between uninfected mice and $P$. gingivalis infected mice, CXCR4 deficient mice seem more prone to inflammation, based on the RT-PCR data of inflammatory cytokines. While these mice do not demonstrate an accelerated loss of alveolar bone, inflammation in CXCR4 KO mice appears to be more easily triggered due to the receptors functional loss, showing that perhaps there are two opposing mechanisms at work. Primarily, the beneficial effect of blocking $P$. gingivalis- CXCR4 interaction through removal of the receptor should enhance killing of the pathogen as in AMD3100 treated mice. However, in mice which do not possess a functional CXCR4 at all, the pro-inflammatory NF-K $\beta$ mediated pathway is apparently non-specifically activated (See Figure 18A).These findings are also compatible with other findings regarding AMD3100, CXCR4 and inflammatory modulation, among them murine osteolytic tumor models wherein short term administration of AMD3100 causes increased neutrophil mobilization without effecting bone resorption (112).

CXCR4 deficient mice showed mixed results regarding protection from $P$. gingivalis induced bone loss, however, the inflammatory profile of CXCR4 deficient mice reflected nicely the differential expression observed in mice systemically administered AMD3100 for extended periods of time. As in the AMD3100 treated mice, transcript levels of several pro-inflammatory cytokines as well as bone resorptive molecule transcripts are upregulated. However, sham-infected CXCR4 deficient mice 
demonstrate absolutely no bone loss despite an apparent inflammatory state. RANK-L and TNF- $\alpha$ were downregulated in CXCR4 deficient mice infected with $P$. gingivalis as compared to infected wild-type mice. Even though the bone loss data were largely inconclusive, the differential expression of inflammatory markers indicate the importance of CXCR4 signaling in $P$. gingivalis- mediated periodontal disease.

Lee and coworkers showed direct activation of granulocytes by AMD3100 and consequent activation of C5 by these granulocytes in the peripheral blood (149). These observations has led us very recently to wonder whether the in vivo protective effects we observed in AMD3100 treated mice were in fact due to CXCR4 blockade or perhaps to enhanced peripheral C5 cleavage by granulocytes to counter other subversive strategies widely documented to be used by $P$. gingivalis. One question that remains is whether a local administration of AMD3100 into the oral cavity would have comparable therapeutic advantages while bypassing the transient HPSC mobilization seen with systemic treatment.

$P$. gingivalis selectively suppresses and induces periodontal inflammation to its own benefit. $P$.gingivalis recognizes TLR2, CXCR4, TLR4 as well as C5aR and CR3. TIR2 subversion, however, has been revealed as a recurrent theme amoung the tactics employed by $P$. gingivalis to avoid elimination by the host immune response. $P$. gingivalis induces co-association and crosstalk between receptors of its choosing to suppress anti-microbial signaling and also to upregulate destructive, untargeted collateral periodontal tissue damage. In these studies we demonstrated that $P$. gingivalis-induced CXCR4 modulation of TLR2 antimicrobial signaling is a crucial method to the pathogen. P. gingivalis induces co-association of CXCR4, TLR2 as well as CD14 into close 
physical proximity $(103,276)$ and as a result TLR2-mediated antimicrobial signaling is inhibited CXCR4 instigated cAMP mediated PKA signaling (See Figure 19).

In conclusion, we showed that when $P$. gingivalis is unable to incite subversive crosstalk between CXCR4 and TLR2 mice are protected from periodontal bone loss and furthermore that $P$. gingivalis is not detectable at day 7 of infection after AMD3100 treatment. The host response in these mice reflects a differential expression of inflammatory cytokines and markers. Mice solely infected with $P$. gingivalis demonstrate a broad uncontrolled inflammation that is a hallmark of chronic progressive periodontal destruction. In contrast, mice that are treated with the CXCR4 antagonist in addition to $P$. gingivalis infection display at earlier time-points a different inflammatory response, and at later time-points indicate resolution of inflammation.

However, $P$. gingivalis also relies upon its ability to subvert complementmediated killing as well as resistance of oxidative killing by neutrophils. AMD3100 has been shown to enhance both egress of neutrophils into the circulation as well as their noncanonical cleavage of C5 (149). This cleavage of C5 could in turn, prime neutrophils in the circulation prior to their influx into the periodontium. This priming, if it occurs, would give incoming neutrophils an advantage in taking up and clearing $P$. gingivalis. Both these outcomes could supplement the protective effect of CXCR4 blockade targeted with long term systemic AMD3100 treatment. Also, it has been recently discovered that AMD3100 is a partial agonist of CXCR7 (123). 


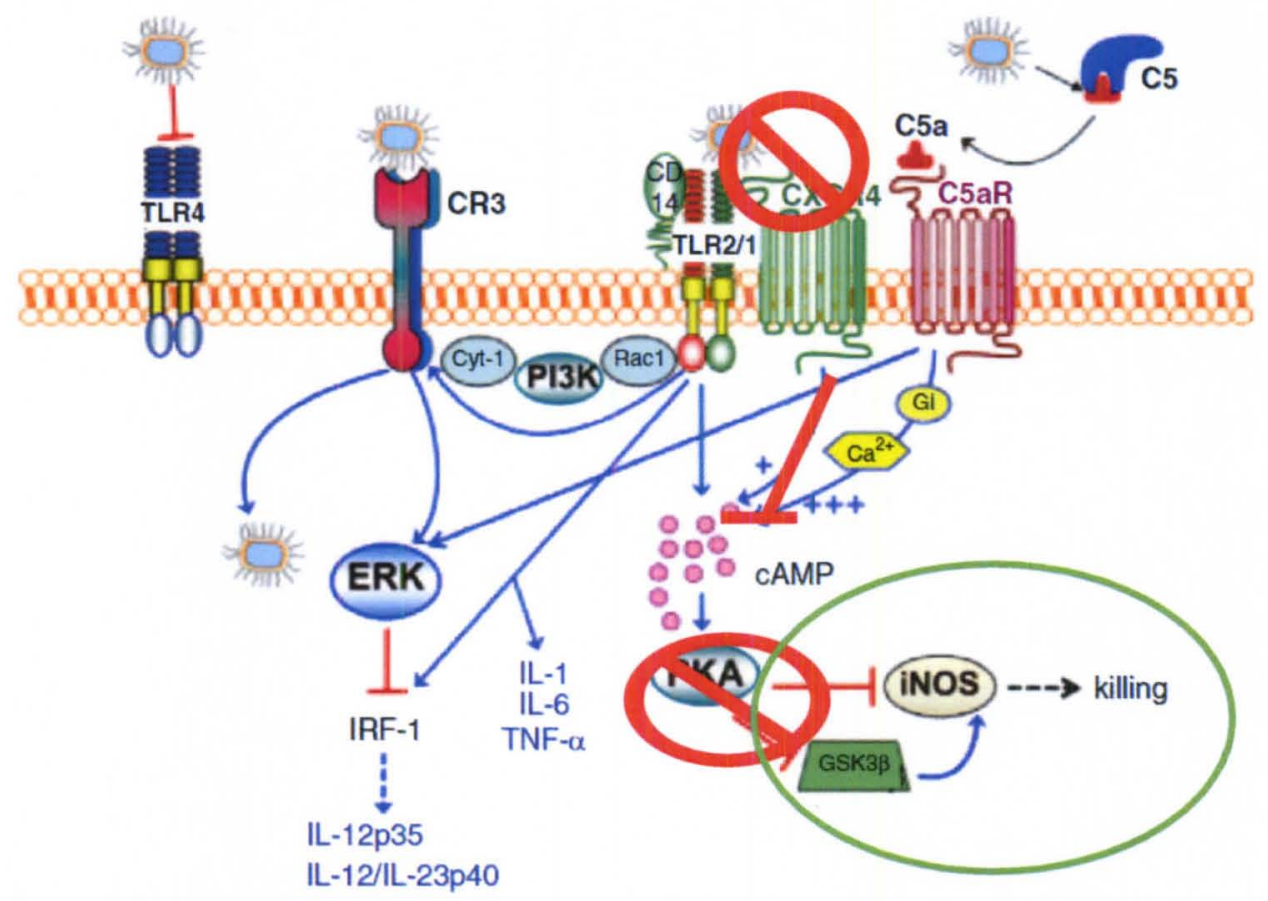

Figure 19. AMD3100 in the chronic $P$. gingivalis periodontitis model. In macrophages, $P$. gingivalis interacts with the CD14/TLR2/TLR1 receptor complex (99). Upon C5aR binding, C5a stimulates Gai-dependent intracellular $\mathrm{Ca} 2+$ signaling which synergistically enhances the otherwise weak cAMP responses induced by TLR2/TLR1 activation alone. Maximal cAMP induction is achieved by the participation of another G protein coupled receptor, the CXCR4, which interacts directly with $P$. gingivalis and co-associates with both TLR2 and C5aR in lipid rafts (103) (275). The ensuing activation of the cAMP-dependent protein kinase A (PKA) pathway inactivates glycogen synthase kinase-3 $\beta$ (GSK3 $\beta$ ) and impairs the inducible nitrogen synthase (iNOS)-dependent killing of the pathogen in macrophages in vitro and in vivo (275). AMD3100 prevents $P$. gingivalis from interacting with CXCR4 and ever initiating this cascade of events. 
While it is still uncertain whether there are other, collateral mechanisms by which AMD3100 protects against periodontal bone loss mediated by $P$. gingivalis, we have shown that CXCR4 blockade, and the subsequent abrogation of pathogen instigated CXCR4-TLR2 crosstalk, renders mice protected from periodontal bone destruction in both a prophylactic and therapeutic context. 


\section{CHAPTER FIVE: FUTURE DIRECTIONS}

There is persisting necessity for innovative therapeutic strategies regarding chronic periodontal disease, and an integral step to developing those strategies is identification of specific mechanisms used by periodontal pathogens to subvert the host immunity. Our studies have demonstrated a key role for CXCR4 in disease pathogenesis involving $P$. gingivalis in the oral cavity. $P$. gingivalis interacts directly with CXCR4 via its fimbriae to induce functional TLR2/CXCR4 co-association in lipid rafts. A cross-talk then ensues between the receptor pathways which results in a cAMP dependent PKA signaling that inhibits TLR2 induced NF- $\kappa B$ activation (See Figure 19). It was initially hypothesized that these events were solely responsible for CXCR4's benefit to $P$. gingivalis. During the ensuing in vivo experiments, however, other possibilities have come to light in addition to this evidence that $P$.gingivalis depends upon its fimbriae to mediate immune evasion.

\section{Therapeutic benefit of Local AMD3100 administration?}

We have demonstrated a therapeutic advantage to AMD3100 administration on a systemic scale, showing that when AMD3100 is administered via osmotic pump to the 
entire body for several days, $P$. gingivalis mediated bone loss is halted. We also showed that local injection of AMD3100 into the gingivae just prior to infection with $P$. gingivalis prevents inflammation of the periodontium. Taken with the other data presented above, the prevention of this inflammation and neutrophil chemotaxis is indicative of $P$. gingivalis being cleared from the infected site and bone loss should not happen. However, this remains to be proven in a therapeutic setting. It would be valuable to observe the effect of local administration of AMD3100 after induction of alveolar bone loss in mice. Since CXCR4 blockade has unrelated, unnecessary effects to the body systemically it would be vastly preferable to minimalize the physiological area of contact to the drug.

Should microinjection of AMD3100 halt development of alveolar bone loss in response to chronic $P$. gingivalis infection then other, less invasive methods of local administration could be considered. Perhaps AMD3100 application could accompany the scaling and root planing that is the current standard of care for patients with periodontitis.

\section{CXCR7 and AMD3100, relevance to our model?}

The recent discovery that AMD3100 acts as a partial agonist to CXCR7, and the relative uncertainty of the $\mathrm{CXCR} 7$ receptors activity or relevance to periodontal disease processes, has led us to wonder whether agonism of CXCR7 by AMD3100 has any effect on disease progress, especially considering the finding that $\mathrm{CXCR} 4$ and 7 form heterodimers and thus effect CXCL12 signaling (190). Considering the heterodimerization of the two chemokine receptors and the known agonism of CXCR7 by AMD3100, any effect of the chemokine receptor on periodontal infection would likely be 
in response to the compound. Whether such a theoretical effect runs counter to clearance of the pathogen or actually works to enhance the action of AMD3100 remains to be investigated.

\section{Role of granulocyte mobilizations, priming and C5 in response to AMD3100 treatment?}

We showed using CXCR4 conditional knockout mice that CXCR4 signaling is important to modulation of inflammation in these mice independent of periodontal disease. As stated above, subcutaneous injection of AMD3100 in normal human volunteers at a dose of $80 \mu \mathrm{g} / \mathrm{kg}$ causes granulocytosis immediately followed by mobilization of CD34+ HPSCs into the circulation. This is in turn followed by direct activation of complement $(147)(116,155)$ and the complement cascade contributes to regulation of HSPC egress from the bone marrow (212). C5 has been identified as arguably the most important component of the complement cascade to this process (149). The previously observed activation of $\mathrm{C} 5$ by these granulocytes in the peripheral blood (148) raises the possibility that the in vivo protective effects we observed in AMD3100 treated mice were in fact due to CXCR4 blockade or enhanced peripheral $\mathrm{C} 5$ activation by granulocytes before $P$. gingivalis has a chance to degrade the complement component. In response to AMD3100 treatment circulating neutrophils were reported to enhance $\mathrm{C} 5$ activation. It isn't unreasonable to think neutrophils could be primed in this way before they reach the periodontium, directly resulting in enhanced clearance of the bacteria. In principle, however, this could also lead to more inflammation and more bone loss if the neutrophils do not evacuate the periodontium once the bacteria are neutralized. The 
"coupling" theory of bone remodeling addresses this concern to an extent. Even if the host does suffer inflammation and tissue damage during the transient infection, there is also a greater possibility that the host will recover as the periodontal infection has now been changed from a chronic to acute process.

\section{AMD3100 treatment and osteoclastogenesis}

CXCR4 is an osteoclastogenic factor in addition to regulating chemotaxis, so it is possible that blocking CXCR4 with AMD3100 could reduce bone resorption independently of the inhibited Pg-CXCR4 interaction. Multiple myeloma plasma cells produce significantly increased amounts of SDF-1 $\alpha$ correlating with the presence of radiological bone lesions in patients. When SDF-1 $\alpha$ is added to an in vitro osteoclastpotentiating culture system the number and size of bone resorption lacunae are increased and there is an increase in osteoclast activation related genes like RANK-L, and these findings were reversed upon addition of a small-molecule CXCR4 inhibitor (289). A separate study of oral squamous cell carcinoma cells showed that SDF-1 $\alpha$ increased the secretion of IL-6 in an ERK-dependent way, enhancing the downstream binding of p65 and $\mathrm{p} 50$ to the NF- $\mathrm{kB}$ element on the IL-6 promoter. This indicates a potential second role of SDF-1 in alveolar bone loss. Inhibition of CXCR4 prevented this reaction as well (252).

However, our RT-PCR of gingivae infected with $P$. gingivalis does not confirm this hypothesis as IL-6 and its feedback regulators are not down or up regulated as consistently as we would expect were this true. Therefore, more studies would be needed to confirm or disprove this hypothesis. 
Conversely, CXCR4 has been shown in vivo to participate in osteoclast formation. CXCR4 -/-mice generated by lethal irradiation and fetal liver transplant displayed enhanced osteoclastogenesis and increased precursor proliferation and differentiation. Enhanced tumor growth in bone but not in lung or small cell cancers was noted in the CXCR4 -/- mice compared to equivalent wildtypes and the authors used the $\mathrm{OC}$ inhibitor, zoledronic acid to reverse these effects. They proposed that these observation indicate that inhibition of CXCR4 can actually enhance osteoclastogenesis at least in the in vivo context of tumor metastasis to bone (111). The ligature model could be used to discern which of the above statements is true regarding CXCR4 and periodontal bone resorption. In the ligature model, sterile silk ligatures are pretreated either with vehicle or the experimental compound, in this case AMD3100, and tied around the right maxillary first molar. The left maxillary first molar is left alone to serve as a control for each mouse. Placement of the ligature alone causes some inflammation and bone loss due to accumulation of bacteria, however if AMD3100 treatment protects against inflammation in and of itself, mice bearing the ligature and AMD3100 should show less bone loss than their untreated counterparts (130).

\section{CXCR4 blockade, SDF-1 and inflammation?}

We have shown that CXCR4 blockade with an antagonist prevents periodontal disease. The antagonist used for these studies, AMD3100, is an allosteric antagonist blocking SDF-1 also from binding CXCR4, therefore, not only is $P$. gingivalis unable to interact with CXCR4, neither is SDF-1. This means that, while we are inhibiting the TLR2 crosstalk pathway, we are also inhibiting any homing or chemoattraction signals $P$. 
gingivalis might attempt to induce host cells to produce via the CXCR4-SDF-1 signaling axis.

Since CXCR4 plays a role in $P$. gingivalis-mediated periodontal disease pathogenesis, and AMD3100 treatment ameliorates this effect, it is reasonable to wonder about any role the natural ligand of CXCR4, SDF-1, might play in disease pathogenesis, especially in light of the fact that CXCR7 is allosterically agonized by AMD3100 and does have a binding capacity for SDF-1 (13).

While it is possible that SDF-1 signaling has its own importance to periodontal bone loss, we think, rather, that the effect of blocking $P$. gingivalis-fimbriae signaling through CXCR4 is specifically the cause of AMD3100's amelioration of periodontal bone loss and that SDF-1 deficiency would not prove protective. $P$. gingivalis expressing fimbriae lacking the "minor" fimbrial components FimCDE fails to interact with CXCR4, precluding the ability of the bacteria to exploit the receptor. While strains such as JI-1 (nonfimbriated), OZ 5001C (DAP) or KO4 (DAP) which lack part or all of their fimbriae cannot manipulate CXCR4 to promote their survival, it's very likely that all subtypes of $P$. gingivalis possessing fimbriae that are the same or structurally similar have some ability to use CXCR4 to promote their survival (205).

Inhibition of the interaction between CXCR4 and $P$. gingivalis fimbriae allows the host immune response to eliminate the pathogen by appropriate regulation of inflammatory cytokines such as IL-6 and TNF- $\alpha$. Without downstream inhibitory crosstalk between CXCR4 and TLR2, the balance is tipped in favor of the host and P. gingivalis cannot create the permissive niche it requires to survive in the oral cavity, making CXCR4 a critical co-receptor for $P$. gingivalis mediated pathogenesis. These 
assertions don't invalidate the pursuit of the question whether SDF-1 is involved, however, due to the ligands close association with CXCR4. There is a possibility that SDF-1 deficiency would reveal unforeseen effects upon periodontal bone loss.

It is possible that $P$. gingivalis uses CXCR4 as a homing device without which leukocytes are not chemoattracted to the site of infection. It would be of interest to determine the role of SDF-1-CXCR4 signaling in AMD3100 treatment of periodontal disease. Perhaps constant stimulation of $\mathrm{CXCR} 4$ by $P$. gingivalis fimbriae contributes to the constant and non-productive influx of neutrophils which is a hallmark of chronic periodontal disease. Further experiments focusing on SDF-1 signaling could elucidate any anti-microbial effect seen as a result of CXCR4-SDF-1 signaling blockade as well as potentially contribute to our understand as to why, in the chamber model of infection, AMD3100 injection alone and $P$. gingivalis inoculation both induce leukocyte recruitment into the chamber but when the two are co-injected, leukocyte recruitment appears to be attenuated.

\section{The polymicrobial nature of periodontal disease}

We have shown that AMD3100 treatment has a relatively specific effect on disease progression when pathology is instigated solely by $P$. gingivalis, however, chronic periodontal disease is more and more being characterized as a polymicrobial disease of the host immunity. In other words, many oral pathogens or microbial opportunists are present in the patients oral cavity and contribute to disease progression. Knowing the inhibitory effect of AMD3100 on $P$. gingivalis survival, and that $F$. nucleatum is not affected by AMD3100 in the chamber model is a starting point for 
pressing on to ask what the effects of AMD3100 treatment are on the total oral microbe community. Are there lasting ecological effects of CXCR4 blockade? Is the population balance shifted, and if so, in what way? These questions lead to even more fundamental questions concerning the nature of our interaction with environmental microflora. Such as, does CXCR4 deficiency cause a shift in the population dynamics of the oral microbiota in mice, and with what consequence? We observed mice for sixty days, to an approximate age of 3 months, but what about longer term effects of CXCR4 blockade? It is difficult to believe that absence/blockade of the receptor would have no effect, especially concerning the knowledge that certain viruses and $P$. gingivalis use it for pathogenic gain.

\section{AMD3100 periodontal treatment and its (fortuitous?) effect on other systemic}

\section{diseases?}

We have demonstrated a therapeutic advantage to AMD3100 administration on a systemic scale, an exciting finding considering the current philosophy that periodontal and certain systemic diseases of inflammatory or autoimmune etiology share a relationship of bidirectional effects. As stated above, it has been shown that diabetic patients suffer an increased prevalence and severity of periodontal disease, and that chronic periodontitis can worsen or accelerate metabolic disease which leads to diabetes. Periodontitis also has been shown as both a risk factor for and disease of consequence for patients suffering rheumatoid arthritis. This, coupled with a finding regarding the benefit of systemic AMD3100 treatment via the same osmotic pumps used in this study on mice with CIA (168), raises the possibility that therapy for disorders such as rheumatoid 
arthritis, diabetes and atherosclerosis could overlap. Periodontal treatment might benefit patients by reducing risk of associated diseases not only through improved oral health but also through pharmacological targeting so that individual patients can enjoy a maximized benefit with minimized pharmaceutical burden.

In conclusion, systemic pharmacological blockade of CXCR4 signaling provides protection and therapy in a $P$. gingivalis mediated model of chronic periodontitis by enhancing specific clearance of the pathogen. These findings will hopefully aid in directing development of therapeutic strategies that will not only possess relevance in a preventative context but also provide strategies for halting periodontal disease such that a focus can be placed eventually upon healing damage already done in afflicted patients. 


\section{REFERENCES}

1. 2000. Oral health in America: A Report of the Surgeon General. Journal of the California Dental Association 28:685-695.

2. Abbink, J. J., A. M. Kamp, J. H. Nuijens, T. J. Swaak, and C. E. Hack. 1993. Proteolytic Inactivation of Alpha 1-antitrypsin and Alpha 1-antichymotrypsin by Neutrophils in Arthritic Joints. Arthritis and Rheumatism 36:168-180.

3. Aiuti, A., M. Tavian, A. Cipponi, F. Ficara, E. Zappone, J. Hoxie, B. Peault, and C. Bordignon. 1999. Expression of CXCR4, the Receptor for Stromal Cellderived Factor-1 on Fetal and Adult Human Lympho-hematopoietic Progenitors. European Journal of Immunology 29:1823-1831.

4. Aiuti, A., I. J. Webb, C. Bleul, T. Springer, and J. C. Gutierrez-Ramos. 1997. The Chemokine SDF-1 is a Chemoattractant for Human CD34+ Hematopoietic Progenitor Cells and Provides a New Mechanism to Explain the Mobilization of CD34+ Progenitors to Peripheral Blood. The Journal of Experimental Medicine 185:111-120.

5. Akira, S., and K. Takeda. 2004. Toll-like Receptor Signalling. Nature Reviews. Immunology 4:499-511.

6. Andersson, K. B., L. H. Winer, H. K. Mork, J. D. Molkentin, and F. Jaisser. 2010. Tamoxifen administration routes and dosage for inducible Cre-mediated gene disruption in mouse hearts. Transgenic research 19:715-725.

7. Apatzidou, D. A. 2012. Modern Approaches to Non-surgical Biofilm Management. Frontiers of Pral Biology 15:99-116.

8. Armitage, G. C., and P. B. Robertson. 2009. The Biology, Prevention, Diagnosis and Treatment of Periodontal Diseases: Scientific Advances in the United States. The Journal of the American Dental Association 140 Suppl 1:36S$43 \mathrm{~S}$.

9. Assuma, R., T. Oates, D. Cochran, S. Amar, and D. T. Graves. 1998. IL-1 and TNF Antagonists Inhibit the Inflammatory Response and Bone Loss in Experimental Periodontitis. The Journal of Immunology 160:403-409.

10. Bains, V. K., V. Gupta, G. P. Singh, and R. Bains. 2011. Mucogingival Surgery: Where we Stand Today. Journal of the California Dental Association 39:573-583.

11. Baker, P. J., M. Dixon, R. T. Evans, L. Dufour, E. Johnson, and D. C. Roopenian. 1999. CD4(+) T cells and the Proinflammatory Cytokines Gamma 
interferon and Interleukin-6 Contribute to Alveolar Bone Loss in Mice. Infection and Immunity 67:2804-2809.

12. Baker, P. J., R. T. Evans, and D. C. Roopenian. 1994. Oral Infection with Porphyromonas gingivalis and Induced Alveolar Bone Loss in Immunocompetent and Severe Combined Immunodeficient Mice. Archives of Oral Biology 39:10351040.

13. Balabanian, K., B. Lagane, S. Infantino, K. Y. Chow, J. Harriague, B. Moepps, F. Arenzana-Seisdedos, M. Thelen, and F. Bachelerie. 2005. The Chemokine SDF-1/CXCL12 Binds to and Signals Through the Orphan Receptor RDC1 in T lymphocytes. The Journal of Biological Chemistry 280:35760-35766.

14. Banks, W. A., S. A. Farr, and J. E. Morley. 2002. Entry of Blood-borne Cytokines into the Central Nervous System: Effects on Cognitive Processes. Neuroimmunomodulation 10:319-327.

15. Barbieri, F., A. Bajetto, R. Stumm, A. Pattarozzi, C. Porcile, G. Zona, A. Dorcaratto, J. L. Ravetti, F. Minuto, R. Spaziante, G. Schettini, D. Ferone, and T. Florio. 2008. Overexpression of Stromal Cell-derived Factor 1 and its Receptor CXCR4 Induces Autocrine/paracrine Cell Proliferation in Human Pituitary Adenomas. Clinical Cancer Research : An Official Journal of the American Association for Cancer Research 14:5022-5032.

16. Bartold, P. M., R. I. Marshall, and D. R. Haynes. 2005. Periodontitis and Rheumatoid Arthritis: A Review. The Journal of Periodontology 76:2066-2074.

17. Berger, E. A., P. M. Murphy, and J. M. Farber. 1999. Chemokine Receptors as HIV-1 Coreceptors: Roles in Viral Entry, Tropism, and Disease. Annual Review of Immunology 17:657-700.

18. Berthelot, J. M., and B. Le Goff. 2010. Rheumatoid Arthritis and Periodontal Disease. Joint, Bone, Spine : Revue du rhumatisme 77:537-541.

19. Beutler, B., Z. Jiang, P. Georgel, K. Crozat, B. Croker, S. Rutschmann, X. Du, and K. Hoebe. 2006. Genetic Analysis of Host Resistance: Toll-like Receptor Signaling and Immunity at Large. Annual Review of Immunology 24:353-389.

20. Blaizot, A., J. N. Vergnes, S. Nuwwareh, J. Amar, and M. Sixou. 2009. Periodontal Diseases and Cardiovascular Events: Meta-analysis of Observational Studies. International Dental Journal 59:197-209.

21. Blasko, I., and B. Grubeck-Loebenstein. 2003. Role of the Immune System in the Pathogenesis, Prevention and Treatment of Alzheimer's disease. Drugs \& Aging 20:101-113.

22. Bleul, C. C., R. C. Fuhlbrigge, J. M. Casasnovas, A. Aiuti, and T. A. Springer. 1996. A Highly Efficacious Lymphocyte Chemoattractant, Stromal cell-derived Factor 1 (SDF-1). The Journal of Experimental Medicine 184:11011109.

23. Boldajipour, B., H. Mahabaleshwar, E. Kardash, M. Reichman-Fried, H. Blaser, S. Minina, D. Wilson, Q. Xu, and E. Raz. 2008. Control of Chemokineguided Cell Migration by Ligand Sequestration. Cell 132:463-473.

24. Bonnet, D., and J. E. Dick. 1997. Human Acute Myeloid Leukemia is Organized as a Hierarchy that Originates from a Primitive Hematopoietic Cell. Nature Medicine 3:730-737. 
25. Brenner, S., S. Prosch, K. Schenke-Layland, U. Riese, U. Gausmann, and C. Platzer. 2003. cAMP-induced Interleukin-10 Promoter Activation Depends on CCAAT/enhancer-binding Protein Expression and Monocytic Differentiation. The Journal of Biological Chemistry 278:5597-5604.

26. Brentano, F., D. Kyburz, O. Schorr, R. Gay, and S. Gay. 2005. The Role of Toll-like Receptor Signalling in the Pathogenesis of Arthritis. Cellular Immunology 233:90-96.

27. Brikos, C., and L. A. O'Neill. 2008. Signalling of Toll-like Receptors. Handbook of Experimental Pharmacology:21-50.

28. Brinkmann, V., U. Reichard, C. Goosmann, B. Fauler, Y. Uhlemann, D. S. Weiss, Y. Weinrauch, and A. Zychlinsky. 2004. Neutrophil Extracellular Traps Kill Bacteria. Science 303:1532-1535.

29. Broxmeyer, H. E., L. Kohli, C. H. Kim, Y. Lee, C. Mantel, S. Cooper, G. Hangoc, M. Shaheen, X. Li, and D. W. Clapp. 2003. Stromal Cell-derived factor-1/CXCL12 Directly Enhances Survival/antiapoptosis of Myeloid Progenitor Cells through CXCR4 and G(alpha)i Proteins and Enhances Engraftment of Competitive, Repopulating Stem Cells. Journal of Leukocyte Biology 73:630-638.

30. Burns, E., G. Bachrach, L. Shapira, and G. Nussbaum. 2006. Cutting Edge: TLR2 is Required for the Innate Response to Porphyromonas gingivalis: Activation Leads to Bacterial Persistence and TLR2 Deficiency Attenuates Induced Alveolar Bone Resorption. The Journal of Immunology 177:8296-8300.

31. Burns, J. M., B. C. Summers, Y. Wang, A. Melikian, R. Berahovich, Z. Miao, M. E. Penfold, M. J. Sunshine, D. R. Littman, C. J. Kuo, K. Wei, B. E. McMaster, K. Wright, M. C. Howard, and T. J. Schall. 2006. A Novel Chemokine Receptor for SDF-1 and I-TAC Involved in Cell Survival, Cell Adhesion, and Tumor Development. The Journal of Experimental Medicine 203:2201-2213.

32. Cashen, A. F., H. M. Lazarus, and S. M. Devine. 2007. Mobilizing Stem Cells from Normal Donors: Is it Possible to Improve Upon G-CSF? Bone marrow Transplantation 39:577-588.

33. Cashen, A. F., B. Nervi, and J. DiPersio. 2007. AMD3100: CXCR4 Antagonist and Rapid Stem Cell-mobilizing agent. Future Oncology 3:19-27.

34. Cetin, I., P. Pileri, A. Villa, S. Calabrese, L. Ottolenghi, and S. Abati. 2012. Pathogenic Mechanisms Linking Periodontal Diseases With Adverse Pregnancy Outcomes. Reproductive Sciences.

35. Chambrone, L., C. M. Pannuti, M. R. Guglielmetti, and L. A. Chambrone. 2011. Evidence Grade Associating Periodontitis with Preterm Birth and/or Low Birth Weight: II: A Systematic Review of Randomized Trials Evaluating the Effects of Periodontal Treatment. The Journal of Clinical Periodontology 38:902914.

36. Chambrone, L. A., and L. Chambrone. 2011. Results of a 20-year Oral Hygiene and Prevention Programme on Caries and Periodontal Disease in Children Attended at a Private Periodontal Practice. International Journal of Dental Hygiene 9:155-158. 
37. Chapple, I. L., and J. B. Matthews. 2007. The Role of Reactive Oxygen and Antioxidant Species in Periodontal Tissue Destruction. The Journal of Periodontology. 2000 43:160-232.

38. Chaves, E. S., M. K. Jeffcoat, C. C. Ryerson, and B. Snyder. 2000. Persistent Bacterial Colonization of Porphyromonas gingivalis, Prevotella intermedia, and Actinobacillus actinomycetemcomitans in Periodontitis and its Association with Alveolar Bone Loss after 6 Months of Therapy. The Journal of Clinical Periodontology 27:897-903.

39. Chen, C. P., M. Hertzberg, Y. Jiang, and D. T. Graves. 1999. Interleukin-1 and Tumor Necrosis Factor Receptor Signaling is not Required for Bacteria-induced Osteoclastogenesis and Bone Loss but is Essential for Protecting the Host from a Mixed Anaerobic Infection. The American Journal of Pathology 155:2145-2152.

40. Chiu, B. 1999. Multiple infections in Carotid Atherosclerotic Plaques. American Heart Journal 138:S534-536.

41. Coats, S. R., J. W. Jones, C. T. Do, P. H. Braham, B. W. Bainbridge, T. T. To, D. R. Goodlett, R. K. Ernst, and R. P. Darveau. 2009. Human Toll-like Receptor 4 Responses to P. gingivalis are Regulated by Lipid A 1- and 4'phosphatase Activities. Cellular Microbiology 11:1587-1599.

42. Coats, S. R., T. T. Pham, B. W. Bainbridge, R. A. Reife, and R. P. Darveau. 2005. MD-2 Mediates the Ability of Tetra-acylated and Penta-acylated Lipopolysaccharides to Antagonize Escherichia coli Lipopolysaccharide at the TLR4 Signaling Complex. The Journal of Immunology 175:4490-4498.

43. Culshaw, S., I. B. McInnes, and F. Y. Liew. 2011. What Can the Periodontal Community Learn from the Pathophysiology of Rheumatoid Arthritis? The Journal of Clinical Periodontology 38 Suppl 11:106-113.

44. Curtis, M. A., C. Zenobia, and R. P. Darveau. 2011. The Relationship of the Oral Microbiotia to Periodontal Health and Disease. Cell Host \& Microbe 10:302306.

45. Darveau, R. P. 2009. The Oral Microbial Consortium's Interaction with the Periodontal Innate Defense System. DNA and Cell Biology 28:389-395.

46. Darveau, R. P. 2010. Periodontitis: a Polymicrobial Disruption of Host Homeostasis. Nature Reviews. Microbiology 8:481-490.

47. Datema, R., L. Rabin, M. Hincenbergs, M. B. Moreno, S. Warren, V. Linquist, B. Rosenwirth, J. Seifert, and J. M. McCune. 1996. Antiviral Efficacy in Vivo of the Anti-human Immunodeficiency Virus Bicyclam SDZ SID 791 (JM 3100), an Inhibitor of Infectious Cell Entry. Antimicrobial Agents and Chemotherapy 40:750-754.

48. De Clereq, E. 2009. The AMD3100 Story: The Path to the Discovery of a Stem Cell Mobilizer (Mozobil). Biochemical Pharmacology 77:1655-1664.

49. De Clercq, E. 2005. Potential Clinical Applications of the CXCR4 Antagonist Bicyclam AMD3100. Mini Reviews in Medicinal Chemistry 5:805-824.

50. De Clercq, E., N. Yamamoto, R. Pauwels, M. Baba, D. Schols, H. Nakashima, J. Balzarini, Z. Debyser, B. A. Murrer, D. Schwartz, and et al. 1992. Potent and Selective Inhibition of Human Immunodeficiency Virus (HIV)-1 and HIV-2 Replication by a Class of Bicyclams Interacting with a Viral Uncoating Event. 
Proceedings of the National Academy of Sciences of the United States of America 89:5286-5290.

51. De Clercq, E., N. Yamamoto, R. Pauwels, J. Balzarini, M. Witvrouw, K. De Vreese, Z. Debyser, B. Rosenwirth, P. Peichl, R. Datema, and et al. 1994. Highly Potent and Selective Inhibition of Human Immunodeficiency Virus by the Bicyclam Derivative JM3100. Antimicrobial Agents and Chemotherapy 38:668674.

52. De Falco, V., V. Guarino, E. Avilla, M. D. Castellone, P. Salerno, G. Salvatore, P. Faviana, F. Basolo, M. Santoro, and R. M. Melillo. 2007. Biological Role and Potential Therapeutic Targeting of the Chemokine Receptor CXCR4 in Undifferentiated Thyroid Cancer. Cancer Research 67:11821-11829.

53. De Rossi, A., L. B. Rocha, and M. A. Rossi. 2008. Interferon-gamma, Interleukin-10, Intercellular Adhesion Molecule-1, and Chemokine Receptor 5, but not Interleukin-4, Attenuate the Development of Periapical Lesions. The Journal of Endodontics 34:31-38.

54. De Vreese, K., I. Van Nerum, K. Vermeire, J. Anne, and E. De Clercq. 1997. Sensitivity of Human Immunodeficiency Virus to Bicyclam Derivatives is Influenced by the Three-dimensional Structure of gp120. Antimicrobial Agents and Chemotherapy 41:2616-2620.

55. Delima, A. J., and T. E. Van Dyke. 2003. Origin and Function of the Cellular Components in Gingival Crevice Fluid. The Journal of Periodontology 2000 31:55-76.

56. Dendorfer, U. 1996. Molecular Biology of Cytokines. Artificial Organs 20:437444.

57. Devine, S. M., N. Flomenberg, D. H. Vesole, J. Liesveld, D. Weisdorf, K. Badel, G. Calandra, and J. F. DiPersio. 2004. Rapid Mobilization of CD34+ cells Following Administration of the CXCR4 Antagonist AMD3100 to Patients with Multiple Myeloma and non-Hodgkin's Lymphoma. Journal of Clinical Oncology : Official Journal of the American Society of Clinical Oncology 22:1095-1102.

58. Dimopoulos, N., C. Piperi, A. Salonicioti, P. Mitropoulos, E. Kallai, I. Liappas, R. W. Lea, and A. Kalofoutis. 2006. Indices of Low-grade Chronic Inflammation Correlate with Early Cognitive Deterioration in an Elderly Greek Population. Neuroscience Letters 398:118-123.

59. Dixon, D. R., B. W. Bainbridge, and R. P. Darveau. 2004. Modulation of the Innate Immune Response within the Periodontium. The Journal of Periodontology 2000 35:53-74.

60. Donzella, G. A., D. Schols, S. W. Lin, J. A. Este, K. A. Nagashima, P. J. Maddon, G. P. Allaway, T. P. Sakmar, G. Henson, E. De Clercq, and J. P. Moore. 1998. AMD3100, a Small Molecule Inhibitor of HIV-1 Entry via the CXCR4 Co-receptor. Nature Medicine 4:72-77.

61. Dorn, B. R., W. A. Dunn, Jr., and A. Progulske-Fox. 1999. Invasion of Human Coronary Artery Cells by Periodontal Pathogens. Infection and Immunity 67:5792-5798. 
62. Dortbudak, O., R. Eberhardt, M. Ulm, and G. R. Persson. 2005. Periodontitis, a Marker of Risk in Pregnancy for Preterm Birth. The Journal of Clinical Periodontology 32:45-52.

63. Doungudomdacha, S., A. Rawlinson, and C. W. Douglas. 2000. Enumeration of Porphyromonas gingivalis, Prevotella intermedia and Actinobacillus actinomycetemcomitans in Subgingival Plaque Samples by a Quantitativecompetitive PCR method. Journal of Medical Microbiology 49:861-874.

64. Duda, D. G., S. V. Kozin, N. D. Kirkpatrick, L. Xu, D. Fukumura, and R. K. Jain. 2011. CXCL12 (SDF1alpha)-CXCR4/CXCR7 Pathway Inhibition: An Emerging Sensitizer for Anticancer Therapies? Clinical Cancer Research : An Official Journal of the American Association for Cancer Research 17:2074-2080.

65. Dunkelberger, J. R., and W. C. Song. 2010. Complement and its Role in Innate and Adaptive Immune Responses. Cell Research 20:34-50.

66. Engelhart, M. J., M. I. Geerlings, J. Meijer, A. Kiliaan, A. Ruitenberg, J. C. van Swieten, T. Stijnen, A. Hofman, J. C. Witteman, and M. M. Breteler. 2004. Inflammatory Proteins in Plasma and the Risk of Dementia: The Rotterdam Study. Archives of Neurology 61:668-672.

67. Esmon, C. T. 2004. The Impact of the Inflammatory Response on Coagulation. Thrombosis Reseasrch 114:321-327.

68. Este, J. A., and A. Telenti. 2007. HIV Entry Inhibitors. Lancet 370:81-88.

69. Farhat, K., S. Riekenberg, H. Heine, J. Debarry, R. Lang, J. Mages, U. Buwitt-Beckmann, K. Roschmann, G. Jung, K. H. Wiesmuller, and A. J. Ulmer. 2008. Heterodimerization of TLR2 with TLR1 or TLR6 Expands the Ligand Spectrum but does not Lead to Differential Signaling. Journal of Leukocyte Biology 83:692-701.

70. Finlay, B. B., and G. McFadden. 2006. Anti-immunology: Evasion of the Host Immune System by Bacterial and Viral Pathogens. Cell 124:767-782.

71. Flomenberg, N., J. DiPersio, and G. Calandra. 2005. Role of CXCR4 Chemokine Receptor Blockade using AMD3100 for Mobilization of Autologous Hematopoietic Progenitor Cells. Acta Haematologica 114:198-205.

72. Fransen, S., G. Bridger, J. M. Whitcomb, J. Toma, E. Stawiski, N. Parkin, C. J. Petropoulos, and W. Huang. 2008. Suppression of Dualtropic Human Immunodeficiency Virus Type 1 by the CXCR4 Antagonist AMD3100 is Associated with Efficiency of CXCR4 use and Baseline Virus Composition. Antimicrobial Agents and Chemotherapy 52:2608-2615.

73. Fredriksson, R., M. C. Lagerstrom, L. G. Lundin, and H. B. Schioth. 2003. The G-protein-coupled Receptors in the Human Genome form Five Main Families. Phylogenetic Analysis, Paralogon Groups, and Fingerprints. Molecular Pharmacology 63:1256-1272.

74. Fricker, S. P., V. Anastassov, J. Cox, M. C. Darkes, O. Grujic, S. R. Idzan, J. Labrecque, G. Lau, R. M. Mosi, K. L. Nelson, L. Qin, Z. Santucci, and R. S. Wong. 2006. Characterization of the Molecular Pharmacology of AMD3100: A Specific Antagonist of the G-protein Coupled Chemokine Receptor, CXCR4. Biochemical Pharmacology 72:588-596.

75. Gao, Y., F. Grassi, M. R. Ryan, M. Terauchi, K. Page, X. Yang, M. N. Weitzmann, and R. Pacifici. 2007. IFN-gamma Stimulates Osteoclast Formation 
and Bone Loss in vivo via Antigen-driven $\mathrm{T}$ cell Activation. The Journal of Clinical Investigation 117:122-132.

76. Garlet, G. P., C. R. Cardoso, A. P. Campanelli, B. R. Ferreira, M. J. AvilaCampos, F. Q. Cunha, and J. S. Silva. 2007. The Dual Role of p55 Tumour Necrosis Factor-alpha Receptor in Actinobacillus actinomycetemcomitansinduced Experimental Periodontitis: Host Protection and Tissue Destruction. Clinical and Experimental Immunology 147:128-138.

77. Garlet, G. P., C. R. Cardoso, A. P. Campanelli, T. P. Garlet, M. J. AvilaCampos, F. Q. Cunha, and J. S. Silva. 2008. The Essential Role of IFN-gamma in the Control of Lethal Aggregatibacter actinomycetemcomitans Infection in Mice. Microbes and Infection / Institut Pasteur 10:489-496.

78. Garlet, G. P., C. R. Cardoso, T. A. Silva, B. R. Ferreira, M. J. Avila-Campos, F. Q. Cunha, and J. S. Silva. 2006. Cytokine Pattern Determines the Progression of Experimental Periodontal Disease Induced by Actinobacillus actinomycetemcomitans through the Modulation of MMPs, RANKL, and their Physiological Inhibitors. Oral Microbiology and Immunology 21:12-20.

79. Genco, C. A., C. W. Cutler, D. Kapczynski, K. Maloney, and R. R. Arnold. 1991. A Novel Mouse Model to Study the Virulence of and Host Response to Porphyromonas (Bacteroides) gingivalis. Infection and Immunity 59:1255-1263.

80. Genco, R. J., and T. E. Van Dyke. 2010. Prevention: Reducing the Risk of CVD in Patients with Periodontitis. Nature Reviews. Cardiology 7:479-480.

81. Gibson, F. C., 3rd, T. Ukai, and C. A. Genco. 2008. Engagement of Specific Innate Immune Signaling Pathways during Porphyromonas gingivalis induced Chronic Inflammation and Atherosclerosis. Frontiers in Bioscience : A Journal and Virtual Library 13:2041-2059.

82. Graves, D. 2008. Cytokines that Promote Periodontal Tissue Destruction. The Journal of Periodontology 79:1585-1591.

83. Graves, D. T., and D. Cochran. 2003. The Contribution of Interleukin-1 and Tumor Necrosis Factor to Periodontal Tissue Destruction. The Journal of Periodontology 74:391-401.

84. Graves, D. T., A. J. Delima, R. Assuma, S. Amar, T. Oates, and D. Cochran. 1998. Interleukin-1 and Tumor Necrosis Factor Antagonists Inhibit the Progression of Inflammatory Cell Infiltration toward Alveolar Bone in Experimental Periodontitis. The Journal of Periodontology 69:1419-1425.

85. Graves, D. T., D. Fine, Y. T. Teng, T. E. Van Dyke, and G. Hajishengallis. 2008. The Use of Rodent Models to Investigate Host-bacteria Interactions related to Periodontal Diseases. The Journal of Clinical Periodontology 35:89-105.

86. Graves, D. T., J. Li, and D. L. Cochran. 2011. Inflammation and Uncoupling as Mechanisms of Periodontal Bone Loss. The Journal of Dental Research 90:143153.

87. Grootveld, M., E. B. Henderson, A. Farrell, D. R. Blake, H. G. Parkes, and P. Haycock. 1991. Oxidative Damage to Hyaluronate and Glucose in Synovial Fluid during Exercise of the Inflamed Rheumatoid Joint. Detection of Abnormal Lowmolecular-mass Metabolites by Proton-n.m.r. Spectroscopy. The Biochemical Journal 273(Pt 2):459-467. 
88. Haffajee, A. D., S. S. Socransky, M. R. Patel, and X. Song. 2008. Microbial Complexes in Supragingival Plaque. Oral Microbiology and Immunology 23:196205.

89. Haffajee, A. D., S. S. Socransky, C. Smith, and S. Dibart. 1991. Relation of Baseline Microbial Parameters to Future Periodontal Attachment Loss. The Journal of Clinical Periodontology 18:744-750.

90. Hajishengallis, G. 2010. Complement and Periodontitis. Biochemical Pharmacology. 15:1992-2001.

91. Hajishengallis, G. 2009. Porphyromonas gingivalis-host Interactions: Open War or Intelligent Guerilla Tactics? Microbes and Infection / Institut Pasteur 11:637645.

92. Hajishengallis, G. 2009. Toll Gates to Periodontal Host Modulation and Vaccine Therapy. The Journal of Periodontology 2000 51:181-207.

93. Hajishengallis, G. 2010. Too Old to Fight? Aging and its Toll on Innate Immunity. Molecular Oral Microbiology 25:25-37.

94. Hajishengallis, G., and E. Harokopakis. 2007. Porphyromonas gingivalis Interactions with Complement Receptor 3 (CR3): Innate Immunity or Immune Evasion? Frontiers in Bioscience : A Journal and Virtual Library 12:4547-4557.

95. Hajishengallis, G., and J. D. Lambris. 2010. Crosstalk Pathways Between Tolllike Receptors and the Complement System. Trends in Immunology 31:154-163.

96. Hajishengallis, G., and J. D. Lambris. 2011. Microbial Manipulation of Receptor Crosstalk in Innate Immunity. Nature Reviews. Immunology 11:187200.

97. Hajishengallis, G., S. Liang, M. A. Payne, A. Hashim, R. Jotwani, M. A. Eskan, M. L. McIntosh, A. Alsam, K. L. Kirkwood, J. D. Lambris, R. P. Darveau, and M. A. Curtis. 2011. Low-abundance Biofilm Species Orchestrates Inflammatory Periodontal Disease through the Commensal Microbiota and Complement. Cell Host \& Microbe 10:497-506.

98. Hajishengallis, G., M. A. Shakhatreh, M. Wang, and S. Liang. 2007. Complement Receptor 3 Blockade Promotes IL-12-mediated Clearance of Porphyromonas gingivalis and Negates its Virulence in vivo. The Journal of Immunology 179:2359-2367.

99. Hajishengallis, G., R. I. Tapping, E. Harokopakis, S. Nishiyama, P. Ratti, R. E. Schifferle, E. A. Lyle, M. Triantafilou, K. Triantafilou, and F. Yoshimura. 2006. Differential Interactions of Fimbriae and Lipopolysaccharide from Porphyromonas gingivalis with the Toll-like Receptor 2-centred Pattern Recognition Apparatus. Cellular Microbiology 8:1557-1570.

100. Hajishengallis, G., M. Wang, G. J. Bagby, and S. Nelson. 2008. Importance of TLR2 in Early Innate Immune Response to Acute Pulmonary Infection with Porphyromonas gingivalis in Mice. The Journal of Immunology 181:4141-4149.

101. Hajishengallis, G., M. Wang, E. Harokopakis, M. Triantafilou, and K. Triantafilou. 2006. Porphyromonas gingivalis Fimbriae Proactively Modulate Beta2 Integrin Adhesive Activity and Promote Binding to and Internalization by Macrophages. Infection and Immunity 74:5658-5666. 
102. Hajishengallis, G., M. Wang, and S. Liang. 2009. Induction of Distinct TLR2mediated Proinflammatory and Proadhesive Signaling Pathways in Response to Porphyromonas gingivalis Fimbriae. The Journal of Immunology 182:6690-6696.

103. Hajishengallis, G., M. Wang, S. Liang, M. Triantafilou, and K. Triantafilou. 2008. Pathogen Induction of CXCR4/TLR2 Cross-talk Impairs Host Defense Function. Proceedings of the National Academy of Sciences of the United States of America 105:13532-13537.

104. Haraszthy, V. I., J. J. Zambon, M. Trevisan, M. Zeid, and R. J. Genco. 2000. Identification of Periodontal Pathogens in Atheromatous Plaques. The Journal of Periodontology 71:1554-1560.

105. Harokopakis, E., M. H. Albzreh, M. H. Martin, and G. Hajishengallis. 2006. TLR2 Transmodulates Monocyte Adhesion and Transmigration via Rac1- and PI3K-mediated Inside-out Signaling in Response to Porphyromonas gingivalis Fimbriae. The Journal of Immunology 176:7645-7656.

106. Hatse, S., K. Princen, G. Bridger, E. De Clercq, and D. Schols. 2002. Chemokine Receptor Inhibition by AMD3100 is Strictly Confined to CXCR4. Federation of European Biochemical Societies Letters 527:255-262.

107. Hattermann, K., J. Held-Feindt, R. Lucius, S. S. Muerkoster, M. E. Penfold, T. J. Schall, and R. Mentlein. 2010. The Chemokine Receptor CXCR7 is Highly Expressed in Human Glioma Cells and Mediates Antiapoptotic Effects. Cancer Research 70:3299-3308.

108. Hawlisch, H., Y. Belkaid, R. Baelder, D. Hildeman, C. Gerard, and J. KohI. 2005. C5a Negatively Regulates Toll-like Receptor 4-induced Immune Responses. Immunity 22:415-426.

109. Hendrix, C. W., A. C. Collier, M. M. Lederman, D. Schols, R. B. Pollard, S. Brown, J. B. Jackson, R. W. Coombs, M. J. Glesby, C. W. Flexner, G. J. Bridger, K. Badel, R. T. MacFarland, G. W. Henson, and G. Calandra. 2004. Safety, Pharmacokinetics, and Antiviral Activity of AMD3100, a Selective CXCR4 Receptor Inhibitor, in HIV-1 Infection. The Journal of Acquired Immune Deficiency Syndrome 37:1253-1262.

110. Hendrix, C. W., C. Flexner, R. T. MacFarland, C. Giandomenico, E. J. Fuchs, E. Redpath, G. Bridger, and G. W. Henson. 2000. Pharmacokinetics and Safety of AMD-3100, a Novel Antagonist of the CXCR-4 Chemokine Receptor, in Human Volunteers. Antimicrobial Agents and Chemotherapy 44:1667-1673.

111. Hirbe, A. C., J. Rubin, O. Uluckan, E. A. Morgan, M. C. Eagleton, J. L. Prior, D. Piwnica-Worms, and K. N. Weilbaecher. 2007. Disruption of CXCR4 Enhances Osteoclastogenesis and Tumor Growth in Bone. Proceedings of the National Academy of Sciences of the United States of America 104:14062-14067.

112. Hirbe, A. C., O. Uluckan, E. A. Morgan, M. C. Eagleton, J. L. Prior, D. Piwnica-Worms, K. Trinkaus, A. Apicelli, and K. Weilbaecher. 2007. Granulocyte Colony-stimulating Factor Enhances Bone Tumor Growth in mice in an Osteoclast-dependent Manner. Blood 109:3424-3431.

113. Hogaboam, C. M., K. J. Carpenter, J. M. Schuh, A. A. Proudfoot, G. Bridger, and K. F. Buckland. 2005. The Therapeutic Potential in Targeting 
CCR5 and CXCR4 Receptors in Infectious and Allergic Pulmonary Disease. Pharmacology \& Therapeutics 107:314-328.

114. Holt, S. C., and J. L. Ebersole. 2005. Porphyromonas gingivalis, Treponema denticola, and Tannerella forsythia: The "Red Complex", a Prototype Polybacterial Pathogenic Consortium in Periodontitis. The Journal of Periodontology 2000 38:72-122.

115. Huang, G. T., M. Do, M. Wingard, J. S. Park, and N. Chugal. 2001. Effect of Interleukin-6 Deficiency on the Formation of Periapical Lesions after Pulp Exposure in Mice. Oral Surgery, Oral Medicine, Oral Pathology, Oral Radiology, Endodontics 92:83-88.

116. Hubel, K., W. C. Liles, H. E. Broxmeyer, E. Rodger, B. Wood, S. Cooper, G. Hangoc, R. Macfarland, G. J. Bridger, G. W. Henson, G. Calandra, and D. C. Dale. 2004. Leukocytosis and Mobilization of CD34+ Hematopoietic Progenitor Cells by AMD3100, a CXCR4 Antagonist. Supportive Cancer Therapy 1:165-172.

117. Infantino, S., B. Moepps, and M. Thelen. 2006. Expression and Regulation of the Orphan Receptor RDC1 and its Putative Ligand in Human Dendritic and B Cells. The Journal of Immunology 176:2197-2207.

118. Iwasaki, A., and R. Medzhitov. 2004. Toll-like Receptor Control of the Adaptive Immune Responses. Nature Immunology 5:987-995.

119. Jalili, A., N. Shirvaikar, L. Marquez-Curtis, Y. Qiu, C. Korol, H. Lee, A. R. Turner, M. Z. Ratajczak, and A. Janowska-Wieczorek. 2010. Fifth Complement Cascade Protein (C5) Cleavage Fragments Disrupt the SDF1/CXCR4 Axis: Further Evidence that Innate Immunity Orchestrates the Mobilization of Hematopoietic Stem/progenitor Cells. Experimental Hematology 38:321-332.

120. Jeffcoat, M. K., J. C. Hauth, N. C. Geurs, M. S. Reddy, S. P. Cliver, P. M. Hodgkins, and R. L. Goldenberg. 2003. Periodontal Disease and Preterm Birth: Results of a Pilot Intervention Study. The Journal of Periodontology 74:12141218.

121. Jiao, C., S. Fricker, and G. C. Schatteman. 2006. The Chemokine (C-X-C motif) Receptor 4 Inhibitor AMD3100 Accelerates Blood Flow Restoration in Diabetic Mice. Diabetologia 49:2786-2789.

122. Jotwani, R., M. Muthukuru, and C. W. Cutler. 2004. Increase in HIV Receptors/co-receptors/alpha-defensins in Inflamed Human Gingiva. The Journal of Dental Research 83:371-377.

123. Kalatskaya, I., Y. A. Berchiche, S. Gravel, B. J. Limberg, J. S. Rosenbaum, and N. Heveker. 2009. AMD3100 is a CXCR7 Ligand with Allosteric Agonist Properties. Molecular Pharmacology 75:1240-1247.

124. Karin, M., T. Lawrence, and V. Nizet. 2006. Innate Immunity Gone Awry: Linking Microbial Infections to Chronic Inflammation and Cancer. Cell 124:823835.

125. Keating, G. M. 2011. Plerixafor: A Review of its Use in Stem-cell Mobilization in Patients with Lymphoma or Multiple Myeloma. Drugs 71:1623-1647.

126. Kebschull, M., R. Demmer, J. H. Behle, A. Pollreisz, J. Heidemann, P. B. Belusko, R. Celenti, P. Pavlidis, and P. N. Papapanou. 2009. Granulocyte 
Chemotactic Protein 2 (gcp-2/cxcl6) Complements Interleukin-8 in Periodontal Disease. The Journal of Periodontal Research 44:465-471.

127. Kebschull, M., R. T. Demmer, and P. N. Papapanou. "Gum Bug, Leave My Heart Alone!"--Epidemiologic and Mechanistic Evidence Linking Periodontal Infections and Atherosclerosis. The Journal of Dental Research 89:879-902.

128. Khader, Y. S., Z. S. Albashaireh, and M. A. Alomari. 2004. Periodontal Diseases and the Risk of Coronary Heart and Cerebrovascular Diseases: A Metaanalysis. The Journal of Periodontology 75:1046-1053.

129. Kim, H. M., B. S. Park, J. I. Kim, S. E. Kim, J. Lee, S. C. Oh, P. Enkhbayar, N. Matsushima, H. Lee, O. J. Yoo, and J. O. Lee. 2007. Crystal Structure of the TLR4-MD-2 Complex with Bound Endotoxin Antagonist Eritoran. Cell 130:906917.

130. Kimura, S., A. Nagai, T. Onitsuka, T. Koga, T. Fujiwara, H. Kaya, and S. Hamada. 2000. Induction of Experimental Periodontitis in Mice with Porphyromonas gingivalis-adhered ligatures. The Journal of Periodontology 71:1167-1173.

131. Kinane, D. F., M. Peterson, and P. G. Stathopoulou. 2006. Environmental and other Modifying Factors of the Periodontal Diseases. The Journal of Periodontology 2000 40:107-119.

132. Kishore, S. P., M. K. Bungum, J. L. Platt, and G. J. Brunn. 2005. Selective Suppression of Toll-like Receptor 4 Activation by Chemokine Receptor 4. Federation of European Biochemical Societies Letters 579:699-704.

133. Kolenbrander, P. E., R. J. Palmer, Jr., S. Periasamy, and N. S. Jakubovics. 2010. Oral Multispecies Biofilm Development and the Key Role of Cell-cell Distance. Nature Reviews. Microbiology 8:471-480.

134. Kornman, K. S. 2006. Interleukin 1 Genetics, Inflammatory Mechanisms, and Nutrigenetic Opportunities to Modulate Diseases of Aging. The American Journal of Clinical Nutrition 83:475S-483S.

135. Kozarov, E. V., B. R. Dorn, C. E. Shelburne, W. A. Dunn, Jr., and A. Progulske-Fox. 2005. Human Atherosclerotic Plaque Contains Viable Invasive Actinobacillus actinomycetemcomitans and Porphyromonas gingivalis. Arteriosclerosis, Thrombosis and Vascular Biology 25:e17-18.

136. Krauss, J. L., J. Potempa, J. D. Lambris, and G. Hajishengallis. 2010. Complementary Tolls in the Periodontium: How Periodontal Bacteria Modify Complement and Toll-like Receptor Responses to Prevail in the Host. The Journal of Periodontology 2000 52:141-162.

137. Kuboniwa, M., A. Amano, K. R. Kimura, S. Sekine, S. Kato, Y. Yamamoto, N. Okahashi, T. Iida, and S. Shizukuishi. 2004. Quantitative Detection of Periodontal Pathogens using Real-time Polymerase Chain Reaction with TaqMan Probes. Oral Microbiology and Immunology 19:168-176.

138. Kumar, M. S., G. Vamsi, R. Sripriya, and P. K. Sehgal. 2006. Expression of Matrix Metalloproteinases (MMP-8 and -9) in Chronic Periodontitis Patients with and without Diabetes Mellitus. The Journal of Periodontology 77:1803-1808.

139. Kumpf, O., and R. R. Schumann. 2008. Genetic Influence on Bloodstream Infections and Sepsis. International Journal of Antimicrobial Agents 32 Suppl $1:$ S44-50. 
140. Kunstfeld, R., S. Lechleitner, K. Wolff, and P. Petzelbauer. 1998. MCP-1 and MIP-1alpha are most Efficient in Recruiting $T$ cells into the Skin in vivo. The Journal of Investigative Dermatology 111:1040-1044.

141. Kurihara, N., Y. Inoue, T. Iwai, M. Umeda, Y. Huang, and I. Ishikawa. 2004. Detection and Localization of Periodontopathic Bacteria in Abdominal Aortic Aneurysms. European Journal of Vascular and Endovascular Surgery 28:553-558.

142. Kushner, I., S. L. Jiang, D. Zhang, G. Lozanski, and D. Samols. 1995. Do Post-transcriptional Mechanisms Participate in Induction of C-reactive Protein and Serum Amyloid A by IL-6 and IL-1? Annals of the New York Academy of Sciences 762:102-107.

143. Lalla, E., and P. N. Papapanou. Diabetes Mellitus and Periodontitis: A Tale of Two Common Interrelated Diseases. Nature Reviews. Endocrinology 7:738-748.

144. Lamont, R. J., and H. F. Jenkinson. 1998. Life Below the Gum Line: Pathogenic Mechanisms of Porphyromonas gingivalis. Microbiology and Molecular Biology Reviews : MMBR 62:1244-1263.

145. Lange, D., and H. E. Schroeder. 1971. Cytochemistry and Ultrastructure of Gingival Sulcus Cells. Helvetica odontologica acta 15:Suppl 15:65+.

146. Lataillade, J. J., D. Clay, C. Dupuy, S. Rigal, C. Jasmin, P. Bourin, and M. C. Le Bousse-Kerdiles. 2000. Chemokine SDF-1 Enhances Circulating CD34(+) Cell Proliferation in Synergy with Cytokines: Possible Role in Progenitor Survival. Blood 95:756-768.

147. Lee, H., and M. Z. Ratajczak. 2009. Innate Immunity: A Key Player in the Mobilization of Hematopoietic stem/progenitor cells. Archivum immunologiae et therapiae experimentalis 57:269-278.

148. Lee, H. M., W. Wu, M. Wysoczynski, R. Liu, E. K. Zuba-Surma, M. Kucia, J. Ratajczak, and M. Z. Ratajczak. 2009. Impaired Mobilization of Hematopoietic Stem/progenitor Cells in C5-deficient Mice Supports the Pivotal Involvement of Innate Immunity in this Process and Reveals Novel Promobilization Effects of Granulocytes. Leukemia : Official Journal of the Leukemia Society of America, Leukemia Research Fund, U.K 23:2052-2062.

149. Lee, H. M., M. Wysoczynski, R. Liu, D. M. Shin, M. Kucia, M. Botto, J. Ratajczak, and M. Z. Ratajczak. 2010. Mobilization Studies in Complementdeficient Mice Reveal that Optimal AMD3100 Mobilization of Hematopoietic Stem Cells Depends on Complement Cascade Activation by AMD3100Stimulated Granulocytes. Leukemia : Official Journal of the Leukemia Society of America, Leukemia Research Fund, U.K 24:573-582.

150. Levoye, A., K. Balabanian, F. Baleux, F. Bachelerie, and B. Lagane. 2009. CXCR7 Heterodimerizes with CXCR4 and Regulates CXCL12-mediated G protein Signaling. Blood 113:6085-6093.

151. Li, J. K., L. Yu, Y. Shen, L. S. Zhou, Y. C. Wang, and J. H. Zhang. 2008. Inhibition of CXCR4 Activity with AMD3100 Decreases Invasion of Human Colorectal Cancer Cells in vitro. World Journal of Gastroenterology : WJG 14:2308-2313.

152. Li, X., T. Iwai, H. Nakamura, Y. Inoue, Y. Chen, M. Umeda, and H. Suzuki. 2008. An Ultrastructural Study of Porphyromonas gingivalis-induced Platelet Aggregation. Thrombosis Research 122:810-819. 
153. Li, X., Q. Ma, Q. Xu, H. Liu, J. Lei, W. Duan, K. Bhat, F. Wang, E. Wu, and Z. Wang. 2012. SDF-1/CXCR4 Signaling Induces Pancreatic Cancer Cell Invasion and Epithelial-mesenchymal Transition in vitro Through Non-canonical Activation of Hedgehog Pathway. Cancer letters.

154. Liang, S., J. L. Krauss, H. Domon, M. L. McIntosh, K. B. Hosur, H. Qu, F. Li, A. Tzekou, J. D. Lambris, and G. Hajishengallis. 2011. The C5a Receptor Impairs IL-12-dependent Clearance of Porphyromonas gingivalis and is Required for Induction of Periodontal Bone Loss. The Journal of Immunology 186:869877.

155. Liles, W. C., H. E. Broxmeyer, E. Rodger, B. Wood, K. Hubel, S. Cooper, G. Hangoc, G. J. Bridger, G. W. Henson, G. Calandra, and D. C. Dale. 2003. Mobilization of Hematopoietic Progenitor Cells in Healthy Volunteers by AMD3100, a CXCR4 Antagonist. Blood 102:2728-2730.

156. Loe, H. 2000. Oral Hygiene in the Prevention of Caries and Periodontal Disease. International Dental Journal 50:129-139.

157. Loesche, W. J., and D. E. Lopatin. 1998. Interactions Between Periodontal Disease, Medical Diseases and Immunity in the Older Individual. The Journal of Periodontology 2000 16:80-105.

158. Lukacs, N. W., A. Berlin, D. Schols, R. T. Skerlj, and G. J. Bridger. 2002. AMD3100, a CXCR4 Antagonist, Attenuates Allergic Lung Inflammation and Airway Hyperreactivity. The American Journal of Pathology 160:1353-1360.

159. Lundberg, K., N. Wegner, T. Yucel-Lindberg, and P. J. Venables. 2010. Periodontitis in RA-the Citrullinated Enolase Connection. Nature Reviews. Rheumatology 6:727-730.

160. Ma, Q., D. Jones, and T. A. Springer. 1999. The Chemokine Receptor CXCR4 is Required for the Retention of B Lineage and Granulocytic Precursors within the Bone Marrow Microenvironment. Immunity 10:463-471.

161. Markiewski, M. M., and J. D. Lambris. 2007. The Role of Complement in Inflammatory Diseases from Behind the Scenes into the Spotlight. The American Journal of Pathology 171:715-727.

162. Markiewski, M. M., B. Nilsson, K. N. Ekdahl, T. E. Mollnes, and J. D. Lambris. 2007. Complement and Coagulation: Strangers or Partners in Crime? Trends in Immunology 28:184-192.

163. Martin, F. E., M. A. Nadkarni, N. A. Jacques, and N. Hunter. 2002. Quantitative Microbiological Study of Human Carious Dentine by Culture and Real-time PCR: Association of Anaerobes with Histopathological Changes in Chronic Pulpitis. The Journal of Clinical Microbiology 40:1698-1704.

164. Martinez-Martinez, R. E., C. Abud-Mendoza, N. Patino-Marin, J. C. RizoRodriguez, J. W. Little, and J. P. Loyola-Rodriguez. 2009. Detection of Periodontal Bacterial DNA in Serum and Synovial Fluid in Refractory Rheumatoid Arthritis Patients. The Journal of Clinical Periodontology 36:10041010.

165. Masada, M. P., R. Persson, J. S. Kenney, S. W. Lee, R. C. Page, and A. C. Allison. 1990. Measurement of Interleukin-1 alpha and -1 beta in Gingival Crevicular Fluid: Implications for the Pathogenesis of Periodontal Disease. The Journal of Periodontal Research 25:156-163. 
166. Massberg, S., P. Schaerli, I. Knezevic-Maramica, M. Kollnberger, N. Tubo, E. A. Moseman, I. V. Huff, T. Junt, A. J. Wagers, I. B. Mazo, and U. H. von Andrian. 2007. Immunosurveillance by Hematopoietic Progenitor Cells Trafficking through Blood, Lymph, and Peripheral Tissues. Cell 131:994-1008.

167. Mastragelopulos, N., V. I. Haraszthy, J. J. Zambon, and G. G. Zafiropoulos. 2002. [Detection of periodontal pathogenic microorganisms in atheromatous plaque. Preliminary results]. Chirurg 73:585-591.

168. Matthys, P., S. Hatse, K. Vermeire, A. Wuyts, G. Bridger, G. W. Henson, E. De Clercq, A. Billiau, and D. Schols. 2001. AMD3100, a Potent and Specific Antagonist of the Stromal Cell-derived Factor-1 Chemokine Receptor CXCR4, Inhibits Autoimmune Joint Inflammation in IFN-gamma Receptor-deficient Mice. The Journal of Immunology 167:4686-4692.

169. May, L. T., K. Leach, P. M. Sexton, and A. Christopoulos. 2007. Allosteric Modulation of $\mathrm{G}$ protein-coupled Receptors. Annual Review of Pharmacology and Toxicology 47:1-51.

170. McCandless, E. E., B. Zhang, M. S. Diamond, and R. S. Klein. 2008. CXCR4 Antagonism Increases $T$ cell Trafficking in the Central Nervous System and Improves Survival from West Nile Virus Encephalitis. Proceedings of the National Academy of Sciences of the United States of America 105:11270-11275.

171. Mealey, B. L., and T. W. Oates. 2006. Diabetes Mellitus and Periodontal Diseases. The Journal of Periodontology 77:1289-1303.

172. Mealey, B. L., and L. F. Rose. 2008. Diabetes Mellitus and Inflammatory Periodontal Diseases. Current Opinion in Endocrinology, Diabetes and Obesity 15:135-141.

173. Medzhitov, R. 2001. Toll-like Receptors and Innate Immunity. Nature Reviews. Immunology 1:135-145.

174. Mercado, F. B., R. I. Marshall, A. C. Klestov, and P. M. Bartold. 2001. Relationship between Rheumatoid Arthritis and Periodontitis. The Journal of Periodontology 72:779-787.

175. Metzger, Z., Y. Y. Lin, F. Dimeo, W. W. Ambrose, M. Trope, and R. R. Arnold. 2009. Synergistic Pathogenicity of Porphyromonas gingivalis and Fusobacterium nucleatum in the Mouse Subcutaneous Chamber Model. The Journal of Endodontics 35:86-94.

176. Miao, Z., K. E. Luker, B. C. Summers, R. Berahovich, M. S. Bhojani, A. Rehemtulla, C. G. Kleer, J. J. Essner, A. Nasevicius, G. D. Luker, M. C. Howard, and T. J. Schall. 2007. CXCR7 (RDC1) Promotes Breast and Lung Tumor Growth in vivo and is Expressed on Tumor-associated Vasculature. Proceedings of the National Academy of Sciences of the United States of America 104:15735-15740.

177. Moen, K., J. G. Brun, M. Valen, L. Skartveit, E. K. Eribe, I. Olsen, and R. Jonsson. 2006. Synovial Inflammation in Active Rheumatoid Arthritis and Psoriatic Arthritis Facilitates Trapping of a Variety of Oral Bacterial DNAs. Clinical and Experimental Rheumatology 24:656-663.

178. Mohle, R., F. Bautz, S. Rafii, M. A. Moore, W. Brugger, and L. Kanz. 1998. The Chemokine Receptor CXCR-4 is Expressed on CD34+ Hematopoietic 
Progenitors and Leukemic Cells and Mediates Transendothelial Migration Induced by Stromal Cell-derived factor-1. Blood 91:4523-4530.

179. Mohr, W. 2003. [Polymorphonuclear Granulocytes in Rheumatic Tissue Destruction VIII. Considerations on the Inflammatory Cartilage Destruction in Chronic Arthritides in Comparison with Liver Injuries by PMN's]. Zeitschrift fur Rheumatologie 62:539-546; discussion 547.

180. Mohr, W., G. Kohler, and D. Wessinghage. 1981. Polymorphonuclear Granulocytes in Rheumatic Tissue Destruction. II. Demonstration of PMNs in Rheumatoid Nodules by Electron Microscopy. Rheumatology International 1:2128.

181. Molendijk, W. J., A. van Oudenaren, H. van Dijk, M. R. Daha, and R. Benner. 1986. Complement Split Product C5a Mediates the Lipopolysaccharideinduced Mobilization of CFU-s and Haemopoietic Progenitor Cells, but not the Mobilization Induced by Proteolytic Enzymes. Cell and Tissue Kinetics 19:407417.

182. Mombelli, A. 2012. Antimicrobial Advances in Treating Periodontal Diseases. Frontiers of Oral Biology 15:133-148.

183. Montebugnoli, L., D. Servidio, R. A. Miaton, C. Prati, P. Tricoci, C. Melloni, and G. Melandri. 2005. Periodontal Health Improves Systemic Inflammatory and Haemostatic Status in Subjects with Coronary Heart Disease. The Journal of Clinical Periodontology 32:188-192.

184. Moore, W. E., L. V. Holdeman, R. M. Smibert, D. E. Hash, J. A. Burmeister, and R. R. Ranney. 1982. Bacteriology of Severe Periodontitis in Young Adult Humans. Infection and Immunity 38:1137-1148.

185. Muller, A., B. Homey, H. Soto, N. Ge, D. Catron, M. E. Buchanan, T. McClanahan, E. Murphy, W. Yuan, S. N. Wagner, J. L. Barrera, A. Mohar, E. Verastegui, and A. Zlotnik. 2001. Involvement of Chemokine Receptors in Breast Cancer Metastasis. Nature 410:50-56.

186. Nagai, Y., K. P. Garrett, S. Ohta, U. Bahrun, T. Kouro, S. Akira, K. Takatsu, and P. W. Kincade. 2006. Toll-like Receptors on Hematopoietic Progenitor Cells Stimulate Innate Immune System Replenishment. Immunity 24:801-812.

187. Nagasawa, T. 2000. A Chemokine, SDF-1/PBSF, and its Receptor, CXC chemokine Receptor 4, as Mediators of Hematopoiesis. International Journal of Hematology 72:408-411.

188. Nagasawa, T., S. Hirota, K. Tachibana, N. Takakura, S. Nishikawa, Y. Kitamura, N. Yoshida, H. Kikutani, and T. Kishimoto. 1996. Defects of B-cell Lymphopoiesis and Bone-marrow Myelopoiesis in Mice Lacking the CXC chemokine PBSF/SDF-1. Nature 382:635-638.

189. Nakajima, T., and K. Yamazaki. 2009. Periodontal Disease and Risk of Atherosclerotic Coronary Heart Disease. Odontology / the Society of the Nippon Dental University 97:84-91.

190. Naumann, U., E. Cameroni, M. Pruenster, H. Mahabaleshwar, E. Raz, H. G. Zerwes, A. Rot, and M. Thelen. 2010. CXCR7 Functions as a Scavenger for CXCL12 and CXCL11. Public Library of Science One 5:e9175.

191. Newman, H. N. 1980. Neutrophils and IgG at the Host-plaque Interface on Children's Teeth. The Journal of Periodontology 51:642-651. 
192. Ngo, H. T., X. Leleu, J. Lee, X. Jia, M. Melhem, J. Runnels, A. S. Moreau, N. Burwick, A. K. Azab, A. Roccaro, F. Azab, A. Sacco, M. Farag, R. Sackstein, and I. M. Ghobrial. 2008. SDF-1/CXCR4 and VLA-4 Interaction Regulates Homing in Waldenstrom Macroglobulinemia. Blood 112:150-158.

193. O'Neill, L. A. 2008. When Signaling Pathways Collide: Positive and Negative Regulation of Toll-like Receptor Signal Transduction. Immunity 29:12-20.

194. O'Neill, L. A., and A. G. Bowie. 2007. The Family of Five: TIR-domainContaining Adaptors in Toll-like Receptor Signalling. Nature Reviews. Immunology 7:353-364.

195. Oberlin, E., A. Amara, F. Bachelerie, C. Bessia, J. L. Virelizier, F. ArenzanaSeisdedos, O. Schwartz, J. M. Heard, I. Clark-Lewis, D. F. Legler, M. Loetscher, M. Baggiolini, and B. Moser. 1996. The CXC Chemokine SDF-1 is the Ligand for LESTR/fusin and Prevents Infection by T-cell-line-adapted HIV-1. Nature 382:833-835.

196. Offenbacher, S. 1996. Periodontal Diseases: Pathogenesis. Annals of Periodontology 1:821-878.

197. Ohlrich, E. J., M. P. Cullinan, and G. J. Seymour. 2009. The Immunopathogenesis of Periodontal Disease. Australian Dental Journal 54 Suppl 1:S2-10.

198. Page, R. C., and H. E. Schroeder. 1981. Current Status of the Host Response in Chronic Marginal Periodontitis. The Journal of Periodontology 52:477-491.

199. Pan, W., and A. J. Kastin. 1999. Penetration of Neurotrophins and Cytokines across the Blood-brain/blood-spinal cord Barrier. Advanced Drug Delivery Reviews 36:291-298.

200. Parfitt, A. M. 1982. The Coupling of Bone Formation to Bone Resorption: A Critical Analysis of the Concept and of its Relevance to the Pathogenesis of Osteoporosis. Metabolic Bone Disease \& Related Research 4:1-6.

201. Pasare, C., and R. Medzhitov. 2005. Toll-like Receptors: Linking Innate and Adaptive Immunity. Advances in Experimental Medicine and Biology 560:11-18.

202. Paster, B. J., I. Olsen, J. A. Aas, and F. E. Dewhirst. 2006. The Breadth of Bacterial Diversity in the Human Periodontal Pocket and Other Oral Sites. The Journal of Periodontology 2000 42:80-87.

203. Perry, V. H. 2004. The Influence of Systemic Inflammation on Inflammation in the Brain: Implications for Chronic Neurodegenerative Disease. Brain, Behavior, and Immunity 18:407-413.

204. Petersen, P. E. 2003. The World Oral Health Report 2003: Continuous Improvement of Oral Health in the 21st century--The Approach of the WHO Global Oral Health Programme. Community Dental Oral Epidemiology 31 Suppl 1:3-23.

205. Pierce, D. L., S. Nishiyama, S. Liang, M. Wang, M. Triantafilou, K. Triantafilou, F. Yoshimura, D. R. Demuth, and G. Hajishengallis. 2009. Host Adhesive Activities and Virulence of Novel Fimbrial Proteins of Porphyromonas gingivalis. Infection and Immunity 77:3294-3301.

206. Pihlstrom, B. L., B. S. Michalowicz, and N. W. Johnson. 2005. Periodontal Diseases. Lancet 366: 1809-1820. 
207. Potempa, J., and R. N. Pike. 2009. Corruption of Innate Immunity by Bacterial Proteases. Journal of Innate Immunity 1:70-87.

208. Potempa, M., J. Potempa, M. Okroj, K. Popadiak, S. Eick, K. A. Nguyen, K. Riesbeck, and A. M. Blom. 2008. Binding of Complement Inhibitor C4b-binding Protein Contributes to Serum Resistance of Porphyromonas gingivalis. The Journal of Immunology 181:5537-5544.

209. Prevention, C. f. D. C. a. 2011. Oral Health: Preventing Cavities, Gum Disease, Tooth Loss, and Oral Cancers at a Glance 2011. Author, Washington, DC.

210. Pruijt, J. F., P. Verzaal, R. van Os, E. J. de Kruijf, M. L. van Schie, A. Mantovani, A. Vecchi, I. J. Lindley, R. Willemze, S. Starckx, G. Opdenakker, and W. E. Fibbe. 2002. Neutrophils are Indispensable for Hematopoietic Stem Cell Mobilization Induced by Interleukin-8 in Mice. Proceedings of the National Academy of Sciences of the United States of America 99:6228-6233.

211. Ramirez, J. H., R. M. Arce, and A. Contreras. 2011. Periodontal Treatment Effects on Endothelial Function and Cardiovascular Disease Biomarkers in Subjects with Chronic Periodontitis: Protocol for a Randomized Clinical Trial. Trials 12:46.

212. Ratajczak, J., R. Reca, M. Kucia, M. Majka, D. J. Allendorf, J. T. Baran, A. Janowska-Wieczorek, R. A. Wetsel, G. D. Ross, and M. Z. Ratajczak. 2004. Mobilization Studies in Mice Deficient in Either C3 or C3a Receptor (C3aR) Reveal a Novel Role for Complement in Retention of Hematopoietic stem/progenitor Cells in Bone Marrow. Blood 103:2071-2078.

213. Ratajczak, M. Z., R. Reca, M. Wysoczynski, J. Yan, and J. Ratajczak. 2006. Modulation of the SDF-1-CXCR4 Axis by the Third Complement Component (C3)--Implications for Trafficking of CXCR4+ Stem Cells. Experimental Hematology 34:986-995.

214. Ridker, P. M., N. Rifai, M. Clearfield, J. R. Downs, S. E. Weis, J. S. Miles, and A. M. Gotto, Jr. 2001. Measurement of C-reactive Protein for the Targeting of Statin Therapy in the Primary Prevention of Acute Coronary Events. The New England Journal of Medicine 344:1959-1965.

215. Roberts, G. J., H. S. Holzel, M. R. Sury, N. A. Simmons, P. Gardner, and P. Longhurst. 1997. Dental Bacteremia in Children. Pediatric Cardiology 18:24-27.

216. Roger, V. L., A. S. Go, D. M. Lloyd-Jones, E. J. Benjamin, J. D. Berry, W. B. Borden, D. M. Bravata, S. Dai, E. S. Ford, C. S. Fox, H. J. Fullerton, C. Gillespie, S. M. Hailpern, J. A. Heit, V. J. Howard, B. M. Kissela, S. J. Kittner, D. T. Lackland, J. H. Lichtman, L. D. Lisabeth, D. M. Makuc, G. M. Marcus, A. Marelli, D. B. Matchar, C. S. Moy, D. Mozaffarian, M. E. Mussolino, G. Nichol, N. P. Paynter, E. Z. Soliman, P. D. Sorlie, N. Sotoodehnia, T. N. Turan, S. S. Virani, N. D. Wong, D. Woo, and M. B. Turner. 2012. Heart Disease and Stroke Statistics--2012 update: A Report from the American Heart Association. Circulation 125:e2-e220.

217. Rogers, J., R. Strohmeyer, C. J. Kovelowski, and R. Li. 2002. Microglia and Inflammatory Mechanisms in the Clearance of Amyloid Beta Peptide. Glia 40:260-269. 
218. Rombouts, E. J., B. Pavic, B. Lowenberg, and R. E. Ploemacher. 2004. Relation between CXCR-4 Expression, Flt3 Mutations, and Unfavorable Prognosis of Adult Acute Myeloid Leukemia. Blood 104:550-557.

219. Rosenkilde, M. M., L. O. Gerlach, J. S. Jakobsen, R. T. Skerlj, G. J. Bridger, and T. W. Schwartz. 2004. Molecular Mechanism of AMD3100 Antagonism in the CXCR4 Receptor: Transfer of Binding Site to the CXCR3 Receptor. The Journal of Biological Chemistry 279:3033-3041.

220. Rosenstein, E. D., R. A. Greenwald, L. J. Kushner, and G. Weissmann. 2004. Hypothesis: The Humoral Immune Response to Oral Bacteria Provides a Stimulus for the Development of Rheumatoid Arthritis. Inflammation 28:311-318.

221. Rowe, D. J., and L. S. Bradley. 1981. Quantitative Analyses of Osteoclasts, Bone Loss and Inflammation in Human Periodontal Disease. The Journal of Periodontal Research 16:13-19.

222. Rubin, J. B., A. L. Kung, R. S. Klein, J. A. Chan, Y. Sun, K. Schmidt, M. W. Kieran, A. D. Luster, and R. A. Segal. 2003. A Small-molecule Antagonist of CXCR4 Inhibits Intracranial Growth of Primary Brain Tumors. Proceedings of the National Academy of Sciences of the United States of America 100:1351313518.

223. Saini, V., A. Marchese, and M. Majetschak. 2010. CXC Chemokine Receptor 4 is a Cell Surface Receptor for Extracellular Ubiquitin. The Journal of Biological Chemistry 285:15566-15576.

224. Saur, D., B. Seidler, G. Schneider, H. Algul, R. Beck, R. SenekowitschSchmidtke, M. Schwaiger, and R. M. Schmid. 2005. CXCR4 Expression Increases Liver and Lung Metastasis in a Mouse Model of Pancreatic Cancer. Gastroenterology 129:1237-1250.

225. Schatzle, M., M. J. Faddy, M. P. Cullinan, G. J. Seymour, N. P. Lang, W. Burgin, A. Anerud, H. Boysen, and H. Loe. 2009. The Clinical Course of Chronic Periodontitis: V. Predictive Factors in Periodontal Disease. The Journal of Clinical Periodontology 36:365-371.

226. Scheres, N., M. L. Laine, T. J. de Vries, V. Everts, and A. J. van Winkelhoff. 2010. Gingival and Periodontal Ligament Fibroblasts Differ in their Inflammatory Response to Viable Porphyromonas gingivalis. The Journal of Periodontal Research 45:262-270.

227. Schols, D. 2004. HIV Co-receptors as Targets for Antiviral Therapy. Current Topics in Medicinal Chemistry 4:883-893.

228. Schols, D., S. Struyf, J. Van Damme, J. A. Este, G. Henson, and E. De Clercq. 1997. Inhibition of T-tropic HIV Strains by Selective antagonization of the Chemokine Receptor CXCR4. The Journal of Experimental Medicine 186:13831388.

229. Schroeder, H. E., and J. Lindhe. 1980. Conditions and Pathological Features of Rapidly Destructive, Experimental Periodontitis in Dogs. The Journal of Periodontology 51:6-19.

230. Schroeder, H. E., and M. A. Listgarten. 1997. The Gingival Tissues: The Architecture of Periodontal Protection. The Journal of Periodontology 2000 13:91-120. 
231. Schroeder, M. A., and J. F. DiPersio. 2012. Mobilization of Hematopoietic Stem and Leukemia Cells. Journal of Leukocyte Biology 91:47-57.

232. Scott, D. A., and J. Krauss. 2012. Neutrophils in Periodontal Inflammation. Frontiers of Oral Biology 15:56-83.

233. Seibl, R., T. Birchler, S. Loeliger, J. P. Hossle, R. E. Gay, T. Saurenmann, B. A. Michel, R. A. Seger, S. Gay, and R. P. Lauener. 2003. Expression and Regulation of Toll-like Receptor 2 in Rheumatoid Arthritis Synovium. The American Journal of Pathology 162:1221-1227.

234. Seymour, G. J., P. J. Ford, M. P. Cullinan, S. Leishman, and K. Yamazaki. 2007. Relationship between Periodontal Infections and Systemic Disease. Clinical Microbiology and Infection : The Official Publication of the European Society of Clinical Microbiology and Infectious Diseases 13 Suppl 4:3-10.

235. Sherry, B., P. Tekamp-Olson, C. Gallegos, D. Bauer, G. Davatelis, S. D. Wolpe, F. Masiarz, D. Coit, and A. Cerami. 1988. Resolution of the Two Components of Macrophage Inflammatory Protein 1, and Cloning and Characterization of One of those Components, Macrophage Inflammatory Protein 1 beta. The Journal of Experimental Medicine 168:2251-2259.

236. Shi, Z., Z. Cai, A. Sanchez, T. Zhang, S. Wen, J. Wang, J. Yang, S. Fu, and D. Zhang. 2011. A Novel Toll-like Receptor that Recognizes Vesicular Stomatitis Virus. The Journal of Biological Chemistry 286:4517-4524.

237. Shi, Z., Z. Cai, S. Wen, C. Chen, C. Gendron, A. Sanchez, K. Patterson, S. Fu, J. Yang, D. Wildman, R. H. Finnell, and D. Zhang. 2009. Transcriptional Regulation of the Novel Toll-like Receptor Tlr13. The Journal of Biological Chemistry 284:20540-20547.

238. Sierro, F., C. Biben, L. Martinez-Munoz, M. Mellado, R. M. Ransohoff, M. Li, B. Woehl, H. Leung, J. Groom, M. Batten, R. P. Harvey, A. C. Martinez, C. R. Mackay, and F. Mackay. 2007. Disrupted Cardiac Development but Normal Hematopoiesis in Mice Deficient in the Second CXCL12/SDF-1 Receptor, CXCR7. Proceedings of the National Academy of Sciences of the United States of America 104:14759-14764.

239. Silva, T. A., G. P. Garlet, S. Y. Fukada, J. S. Silva, and F. Q. Cunha. 2007. Chemokines in Oral Inflammatory Diseases: Apical Periodontitis and Periodontal Disease. The Journal of Dental Research 86:306-319.

240. Silverstein, A. M. 2002. The Collected Papers of Paul Ehrlich : Why was volume 4 never published? Bulletin of the History of Medicine 76:335-339.

241. Slots, J. 1977. The Predominant Cultivable Microflora of Advanced Periodontitis. Scandinavian Journal of Dental Research 85:114-121.

242. Smith, P. C., V. C. Munoz, L. Collados, and A. D. Oyarzun. 2004. In situ Detection of Matrix Metalloproteinase-9 (MMP-9) in Gingival Epithelium in Human Periodontal Disease. The Journal of Periodontal Research 39:87-92.

243. Socransky, S. S., A. D. Haffajee, M. A. Cugini, C. Smith, and R. L. Kent, Jr. 1998. Microbial Complexes in Subgingival Plaque. The Journal of Clinical Periodontology 25:134-144.

244. Soder, B. 2009. Periodontitis and Premature Death: A Longitudinal, Prospective Clinical Trial. Journal of Dental Hygiene : JDH / American Dental Hygienists' Association 83:184-185. 
245. Soder, B., L. J. Jin, B. Klinge, and P. O. Soder. 2007. Periodontitis and Premature Death: A 16-year Longitudinal Study in a Swedish Urban Population. The Journal of Periodontal Research 42:361-366.

246. Spiegel, C. A., S. E. Hayduk, G. E. Minah, and G. N. Krywolap. 1979. Blackpigmented Bacteroides from Clinically Characterized Periodontal Sites. The Journal of Periodontal Research 14:376-382.

247. Spoo, A. C., M. Lubbert, W. G. Wierda, and J. A. Burger. 2007. CXCR4 is a Prognostic Marker in Acute Myelogenous Leukemia. Blood 109:786-791.

248. Stelzel, M., G. Conrads, S. Pankuweit, B. Maisch, S. Vogt, R. Moosdorf, and L. Flores-de-Jacoby. 2002. Detection of Porphyromonas gingivalis DNA in Aortic Tissue by PCR. The Journal of Periodontology 73:868-870.

249. Stoll, L. L., G. M. Denning, and N. L. Weintraub. 2004. Potential Role of Endotoxin as a Proinflammatory Mediator of Atherosclerosis. Arteriosclerosis, Thrombosis and Vascular Biology 24:2227-2236.

250. Suomi, J. D., J. D. West, J. J. Chang, and B. J. McClendon. 1971. The Effect of Controlled Oral Hygiene Procedures on the Progression of Periodontal Disease in Adults: Radiographic Findings. The Journal of Periodontology 42:562-564.

251. Tan, Z. S., A. S. Beiser, R. S. Vasan, R. Roubenoff, C. A. Dinarello, T. B. Harris, E. J. Benjamin, R. Au, D. P. Kiel, P. A. Wolf, and S. Seshadri. 2007. Inflammatory Markers and the Risk of Alzheimer Disease: The Framingham Study. Neurology 68:1902-1908.

252. Tang, C. H., J. Y. Chuang, Y. C. Fong, M. C. Maa, T. D. Way, and C. H. Hung. 2008. Bone-derived SDF-1 Stimulates IL-6 Release via CXCR4, ERK and NF-kappaB Pathways and Promotes Osteoclastogenesis in Human Oral Cancer Cells. Carcinogenesis 29:1483-1492.

253. Tanner, A. C., C. Haffer, G. T. Bratthall, R. A. Visconti, and S. S. Socransky. 1979. A Study of the Bacteria Associated with Advancing Periodontitis in Man. The Journal of Clinical Periodontology 6:278-307.

254. Taub, D. D., K. Conlon, A. R. Lloyd, J. J. Oppenheim, and D. J. Kelvin. 1993. Preferential Migration of Activated CD4+ and CD8+ T Cells in Response to MIP1 alpha and MIP-1 beta. Science 260:355-358.

255. Taubman, M. A., T. Kawai, and X. Han. 2007. The New Concept of Periodontal Disease Pathogenesis Requires New and Novel Therapeutic Strategies. The Journal of Clinical Periodontology 34:367-369.

256. Taylor, G. W., and W. S. Borgnakke. 2008. Periodontal Disease: Associations with Diabetes, Glycemic Control and Complications. Oral Diseases 14:191-203.

257. Teng, Y. T. 2006. Protective and Destructive Immunity in the Periodontium: Part 1--Innate and Humoral Immunity and the Periodontium. The Journal of Dental Research 85:198-208.

258. Terpenning, M. 2005. Geriatric Oral Health and Pneumonia Risk. Clinical Infectious Diseases 40:1807-1810.

259. Thelen, M., and S. Thelen. 2008. CXCR7, CXCR4 and CXCL12: An Eccentric Trio? Journal of Neuroimmunology 198:9-13.

260. Thorstensson, H., J. Kuylenstierna, and A. Hugoson. 1996. Medical Status and Complications in Relation to Periodontal Disease Experience in Insulin-dependent Diabetics. The Journal of Clinical Periodontology 23:194-202. 
261. Tonetti, M. S., F. D'Aiuto, L. Nibali, A. Donald, C. Storry, M. Parkar, J. Suvan, A. D. Hingorani, P. Vallance, and J. Deanfield. 2007. Treatment of Periodontitis and Endothelial Function. The New England Journal of Medicine 356:911-920.

262. Toyofuku, T., Y. Inoue, N. Kurihara, T. Kudo, M. Jibiki, N. Sugano, M. Umeda, and Y. Izumi. Differential Detection Rate of Periodontopathic Bacteria in Atherosclerosis. Surgery Today 41:1395-1400.

263. Triantafilou, K., M. Triantafilou, and R. L. Dedrick. 2001. A CD14Independent LPS Receptor Cluster. Nature Immunology 2:338-345.

264. Triantafilou, M., F. G. Gamper, P. M. Lepper, M. A. Mouratis, C. Schumann, E. Harokopakis, R. E. Schifferle, G. Hajishengallis, and K. Triantafilou. 2007. Lipopolysaccharides from Atherosclerosis-associated Bacteria Antagonize TLR4, Induce Formation of TLR2/1/CD36 Complexes in Lipid Rafts and Trigger TLR2-induced Inflammatory Responses in Human Vascular Endothelial Cells. Cellular Microbiology 9:2030-2039.

265. Triantafilou, M., P. M. Lepper, C. D. Briault, M. A. Ahmed, J. M. Dmochowski, C. Schumann, and K. Triantafilou. 2008. Chemokine Receptor 4 (CXCR4) is Part of the Lipopolysaccharide "Sensing Apparatus". European Journal of Immunology 38:192-203.

266. Trinchieri, G. 2003. Interleukin-12 and the Regulation of Innate Resistance and Adaptive Immunity. Nature Reviews. Immunology 3:133-146.

267. Tsesis, I., E. Rosen, A. Tamse, S. Taschieri, and M. Del Fabbro. 2011. Effect of Guided Tissue Regeneration on the Outcome of Surgical Endodontic Treatment: A Systematic Review and Meta-analysis. The Journal of Endodontics 37:1039-1045.

268. Urban, C. F., U. Reichard, V. Brinkmann, and A. Zychlinsky. 2006. Neutrophil Extracellular Traps Capture and Kill Candida albicans Yeast and Hyphal forms. Cellular Microbiology 8:668-676.

269. Valentin, G., P. Haas, and D. Gilmour. 2007. The Chemokine SDF1a Coordinates Tissue Migration Through the Spatially Restricted Activation of CXCR7 and CXCR4b. Current Biology : CB 17:1026-1031.

270. Valtonen, V. V. 1991. Infection as a Risk Factor for Infarction and Atherosclerosis. Annals of Medicine 23:539-543.

271. Van Gelder, J., M. Witvrouw, C. Pannecouque, G. Henson, G. Bridger, L. Naesens, E. De Clercq, P. Annaert, M. Shafiee, G. Van den Mooter, R. Kinget, and P. Augustijns. 1999. Evaluation of the Potential of Ion Pair Formation to Improve the Oral Absorption of Two Potent Antiviral Compounds, AMD3100 and PMPA. International Journal of Pharmaceutics 186:127-136.

272. Vose, J. M., A. D. Ho, B. Coiffier, P. Corradini, I. Khouri, A. Sureda, K. Van Besien, and J. Dipersio. 2009. Advances in Mobilization for the Optimization of Autologous Stem Cell Transplantation. Leukemia \& Lymphoma 50:1412-1421.

273. Wada, K., and Y. Kamisaki. 2010. Roles of Oral Bacteria in Cardiovascular Diseases--From Molecular Mechanisms to Clinical Cases: Involvement of Porphyromonas gingivalis in the Development of Human Aortic Aneurysm. Journal of Pharmacological Sciences 113:115-119. 
274. Wang, J., Y. Shiozawa, Y. Wang, Y. Jung, K. J. Pienta, R. Mehra, R. Loberg, and R. S. Taichman. 2008. The Role of CXCR7/RDC1 as a Chemokine Receptor for CXCL12/SDF-1 in Prostate Cancer. The Journal of Biological Chemistry 283:4283-4294.

275. Wang, M., J. L. Krauss, H. Domon, K. B. Hosur, S. Liang, P. Magotti, M. Triantafilou, K. Triantafilou, J. D. Lambris, and G. Hajishengallis. 2010. Microbial Hijacking of Complement-toll-like Receptor Crosstalk. Science Signaling 3:ral 1.

276. Wang, M., M. A. Shakhatreh, D. James, S. Liang, S. Nishiyama, F. Yoshimura, D. R. Demuth, and G. Hajishengallis. 2007. Fimbrial Proteins of Porphyromonas gingivalis Mediate in vivo Virulence and Exploit TLR2 and Complement Receptor 3 to Persist in Macrophages. The Journal of Immunology 179:2349-2358.

277. Watts, A., E. M. Crimmins, and M. Gatz. 2008. Inflammation as a Potential Mediator for the Association between Periodontal Disease and Alzheimer's Disease. Neuropsychiatric Disease and Treatment 4:865-876.

278. Weaver, J. D., M. H. Huang, M. Albert, T. Harris, J. W. Rowe, and T. E. Seeman. 2002. Interleukin-6 and Risk of Cognitive Decline: MacArthur Studies of Successful Aging. Neurology 59:371-378.

279. Wingrove, J. A., R. G. DiScipio, Z. Chen, J. Potempa, J. Travis, and T. E. Hugli. 1992. Activation of Complement Components C3 and C5 by a Cysteine Proteinase (Gingipain-1) from Porphyromonas (Bacteroides) gingivalis. The Journal of Biological Chemistry 267:18902-18907.

280. Wojta, J., K. Huber, and P. Valent. 2003. New Aspects in Thrombotic Research: Complement Induced Switch in Mast Cells from a Profibrinolytic to a Prothrombotic Phenotype. Pathophysiology of Haemostasis and Thrombosis 33:438-441.

281. Wojta, J., C. Kaun, G. Zorn, M. Ghannadan, A. W. Hauswirth, W. R. Sperr, G. Fritsch, D. Printz, B. R. Binder, G. Schatzl, J. Zwirner, G. Maurer, K. Huber, and P. Valent. 2002. C5a Stimulates Production of Plasminogen Activator Inhibitor-1 in Human Mast Cells and Basophils. Blood 100:517-523.

282. Wong, R. S., V. Bodart, M. Metz, J. Labrecque, G. Bridger, and S. P. Fricker. 2008. Comparison of the Potential Multiple Binding Modes of Bicyclam, Monocylam, and Noncyclam Small-molecule CXC Chemokine Receptor 4 Inhibitors. Molecular Pharmacology 74:1485-1495.

283. Xie, Q. W., Y. Kashiwabara, and C. Nathan. 1994. Role of Transcription Factor NF-kappa B/Rel in Induction of Nitric Oxide Synthase. The Journal of Biological Chemistry 269:4705-4708.

284. Ximenez-Fyvie, L. A., A. D. Haffajee, and S. S. Socransky. 2000. Comparison of the Microbiota of Supra- and Subgingival Plaque in Health and Periodontitis. The Journal of Clinical Periodontology 27:648-657.

285. Ximenez-Fyvie, L. A., A. D. Haffajee, and S. S. Socransky. 2000. Microbial Composition of Supra- and Subgingival Plaque in Subjects with Adult Periodontitis. The Journal of Clinical Periodontology 27:722-732.

286. Yaffe, K., K. Lindquist, B. W. Penninx, E. M. Simonsick, M. Pahor, S. Kritchevsky, L. Launer, L. Kuller, S. Rubin, and T. Harris. 2003. 
Inflammatory Markers and Cognition in Well-functioning African-American and White Elders. Neurology 61:76-80.

287. Yang, S., P. Madyastha, W. Ries, and L. L. Key. 2002. Characterization of Interferon Gamma Receptors on Osteoclasts: Effect of Interferon Gamma on Osteoclastic Superoxide Generation. Journal of Cellular Biochemistry 84:645654.

288. Zabel, B. A., Y. Wang, S. Lewen, R. D. Berahovich, M. E. Penfold, P. Zhang, J. Powers, B. C. Summers, Z. Miao, B. Zhao, A. Jalili, A. JanowskaWieczorek, J. C. Jaen, and T. J. Schall. 2009. Elucidation of CXCR7-mediated Signaling Events and Inhibition of CXCR4-mediated Tumor Cell Transendothelial Migration by CXCR7 Ligands. The Journal of Immunology 183:3204-3211.

289. Zannettino, A. C., A. N. Farrugia, A. Kortesidis, J. Manavis, L. B. To, S. K. Martin, P. Diamond, H. Tamamura, T. Lapidot, N. Fujii, and S. Gronthos. 2005. Elevated Serum Levels of Stromal-derived Factor-1alpha are Associated with Increased Osteoclast Activity and Osteolytic Bone Disease in Multiple Myeloma Patients. Cancer Research 65:1700-1709.

290. Zhang, X., Y. Kimura, C. Fang, L. Zhou, G. Sfyroera, J. D. Lambris, R. A. Wetsel, T. Miwa, and W. C. Song. 2007. Regulation of Toll-like Receptormediated Inflammatory Response by Complement in vivo. Blood 110:228-236.

291. Zhou, Q., T. Desta, M. Fenton, D. T. Graves, and S. Amar. 2005. Cytokine Profiling of Macrophages Exposed to Porphyromonas gingivalis, its Lipopolysaccharide, or its FimA Protein. Infection and Immunity 73:935-943.

292. Zhu, N., J. Cui, C. Qiao, Y. Li, Y. Ma, J. Zhang, and B. Shen. 2008. cAMP Modulates Macrophage Development by Suppressing M-CSF-induced MAPKs Activation. Cellular \& Molecular Immunology 5:153-157. 


\title{
CURRICULUM VITAE
}

\author{
Megan L. Mc Intosh \\ Department of Microbiology \& Immunology \\ University of Louisville School of Medicine \\ 501 S. Preston Street, Room 261 \\ Louisville, KY 40202
}

Cell: (502)-303-0912; FAX: (502)-859-4052

Email:mlmcin05@louisville.edu

\section{Education \& Training:}

Ph.D., Microbiology \& Immunology, University of Louisville

2008-Present

Louisville, KY (expected graduation date is May 11, 2012)

Field of Research:

M.S., Immunology \& Microbiology, University of Louisville

2008-2011

Louisville, KY

B.A., Cellular and Molecular Biology, Cornell University, Ithaca, NY $\quad$ 2002-2006

B.A. English (20th Century Literature), Cornell University, Ithaca, NY 2002-2006

Educational/Teaching Experience:

Student Microbiology \& Immunology Student (MISO) Mentor

2010-Present

University of Louisville, Department of Microbiology \& Immunology

Moderator for Small Group Discussions, Medical Microbiology POPs

Fall 2009, 2010

Student teacher of Basic Dance,

2012-Present

Ruric-Amari School of Ethnic and Experimental Dance, Louisville, KY 
Mentorship:

Abe, Toshiaru, D.M.D.

Project: Detection and quantification of bacterial copy number and relative host gene expression changes in a variety of experimental mouse models

Ciero, Paul, M.S. (Oral Biology Masters Student)

Project: Age-associated periodontal bone loss in normal and TLR2- or MyD88-deficient mice.

Eskan, Akif, D.M.D. Ph.D. 2011

Project: Low-abundance biofilm species orchestrates inflammatory periodontal disease through the commensal microbiota and complement

Krauss, Jennifer, Ph.D.

Project: RT-PCR of bacterial and host genes, applications and variations of the Baker model of chronic periodontitis

Rob, B.S. (DMD/Oral Biology Masters Student)

Project: RT-PCR of bacterial and host genes, applications and variations of the Baker model of chronic periodontitis

$\underline{\text { Service: }}$

University of Louisville Graduate Student Council

2008-Present

University of Louisville, MISO

2008-Present

MISO President

2010-2011

MISO Student Representative on Admissions Committee

2009-2010

Festival of Trees and Lights Volunteer

2006

Medical Housing Information Volunteer

2007

Medical School Charity Auction Donations Committee

Medical School Informatics Volunteer 
Membership in Professional and Scientific Societies:

American Medical Students Association 2006-2008

$\begin{array}{ll}\text { Phi Delta Epsilon 2006-2010 } & \text { 200 }\end{array}$

$\begin{array}{ll}\text { Women in Medicine 2006-2008 } & \end{array}$

Awards \& Honors:

$2^{\text {nd }}$ place in Doctoral Basic Science Research at Gordon Conference Periodontics

June 2011

Arnold Ravin-Muriel Rogers Fellowship, Travel Award

June 2010

Wind River Conference on Prokaryotic Biology

\section{Grants:}

Funding Source: NIH/NIDCR

Grant Number: 1F31DE021304-01A1 (Ruth L. Kirschstein NRSA-F31)

Title of Research: Counteracting microbial immune evasion for the treatment of periodontitis

Principal Investigator: Megan L. Mc Intosh

Sponsor: George N. Hajishengallis Co-Sponsor: R. Demuth

Support per year (maximum of 3 years): $\$ 29,969.00$

\section{Publications:}

Hajishengallis, G., Liang, S., Payne, M.A., Hashim, A., Jotwani,R., Eskan, M.A., McIntosh, M.L., Alsam, A., Kirkwood, K.L., Lambris, J.D., Darveau, R.P., Curtis, M.A. 2011. Low-Abundance Biofilm Species Orchestrates Inflammatory Periodontal Disease through the Commensal Microbiota and Complement. Cell Host Microbe. 10(5):497-506. PMID: 22036469.

Liang, S., Krauss, J.L., Domon, H., McIntosh, M.L., Hosur, K.B., Qu, H., Li, F., Tzekou, A., Lambris, J.D., Hajishengallis, G. 2011. The C5a receptor impairs IL-12-dependent clearance of Porphyromonas gingivalis and is required for induction of periodontal bone loss. The Journal of Immunology. 186(2):869-77. PMID: 21149611.

Book Chapters: 
Hajishengallis, G., Krauss, J.L., Liang, S., McIntosh, M.L., Lambris, J.D. 2012. Pathogenic microbes and community service through manipulation of innate immunity. In Current Topics in Innate Immunity II: Advances in Experimental Medicine and Biology. Lambris, J.D, Hajishengallis, G., Ed. Springer New York USA. Volume 946, 69-85, DOI: 10.1007/978-1-4614-0106-3_5.

\section{Abstracts:}

Initiation Factor Overexpression and Progression to MDS or AML in patients with Shwachman Diamond Syndrome. Presented at Research!Louisville, Louisville, KY. October 2007.

A CXCR4 antagonist blocks immune evasion and inflammatory bone loss by Porphyromonas gingivalis. Presented at the Wind River Conference on Prokaryotic Biology, Estes Park, CO June 2010.

A CXCR4 antagonist blocks immune evasion and inflammatory bone loss by Porphyromonas gingivalis. Presented at the Gordon Research Conference: Periodontal Diseases Poster Session, Davidson, NC. 07/19/11. $2^{\text {nd }}$ Place, I.S.M.E. Award for Outstanding Student Poster Presentation.

A CXCR4 antagonist blocks immune evasion and inflammatory bone loss by Porphyromonas gingivalis. Presented at Research!Louisville, Louisville, KY. 10/08/2011. 